KEYWORDS:

Vadose Flow

Vadose Transport

Aquifer Transport

RETENTION

Permanent

\title{
PORFLOW Modeling for a Preliminary Assessment of the Performance of New Saltstone Disposal Unit Designs
}

F. G. Smith, III

AUGUST 6, 2012

Savannah River National Laboratory

Savannah River Nuclear Solutions

Savannah River Site

Aiken, SC 29808

Prepared for the U.S. Department of Energy Under

Contract Number DE-AC09-08SR22470

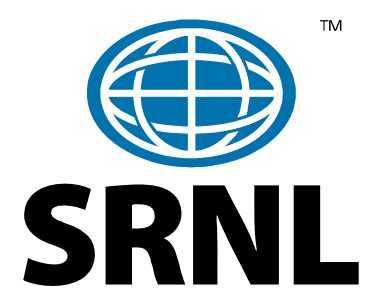




\section{DISCLAIMER}

This document was prepared in conjunction with work accomplished under Contract No. DE-AC09-08SR22470 with the U.S. Department of Energy.

This work was prepared under an agreement with and funded by the U.S. Government. Neither the U. S. Government or its employees, nor any of its contractors, subcontractors or their employees, makes any express or implied: 1 . warranty or assumes any legal liability for the accuracy, completeness, or for the use or results of such use of any information, product, or process disclosed; or 2 . representation that such use or results of such use would not infringe privately owned rights; or 3 . endorsement or recommendation of any specifically identified commercial product, process, or service. Any views and opinions of authors expressed in this work do not necessarily state or reflect those of the United States Government, or its contractors, or subcontractors.

Printed in the United States of America

Prepared For

U.S. Department of Energy 
KEYWORDS:

Vadose Flow

Vadose Transport

Aquifer Transport

RETENTION

Permanent

\title{
PORFLOW Modeling for a Preliminary Assessment of the Performance of New Saltstone Disposal Unit Designs
}

\author{
F. G. Smith, III
}

AUGUST 6, 2012

Savannah River National Laboratory

Savannah River Nuclear Solutions

Savannah River Site

Aiken, SC 29808

Prepared for the U.S. Department of Energy Under

Contract Number DE-AC09-08SR22470

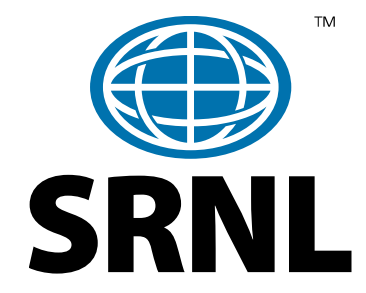




\section{REVIEWS AND APPROVALS}

Date:

F. G. Smith, III, Author

SRNL-CSS-PMCC

Date:

R. A. Hiergesell, Technical Reviewer

SRNL-ERT-RPA

Date:

H. H. Burns, Program Manager

SRNL-ERT-RPA

Date:

S. J. Hensel, Manager Computational Engineering \& Sciences

SRNL-CSS-PMCC

Date:

D. A. Crowley, Manager Performance Assessment

SRNL-ERT-RPA

Date:

R. S. Aylward, Manager Environmental Restoration Technology

SRNL-EM-ERT

Date:

K. H. Rosenberger, C\&W Design Authority SRR

Date:

G. B. Clendenen, SDU 6 Design Authority SRR 


\section{TABLE OF CONTENTS}

1.0 EXECUTIVE SUMMARY ............................................................................................... 1

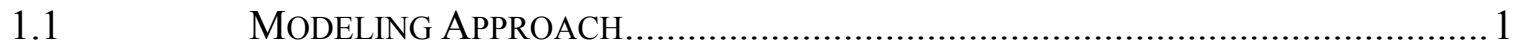

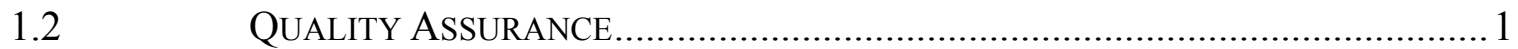

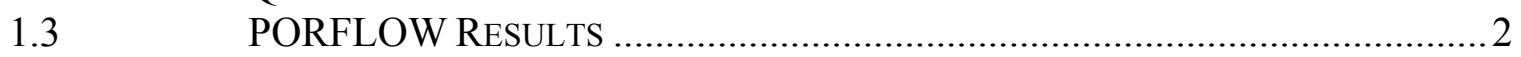

2.0 INTRODUCTION.................................................................................................... 3

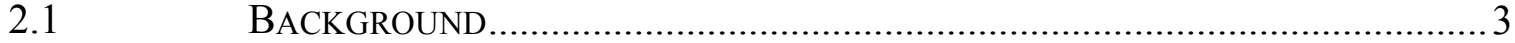

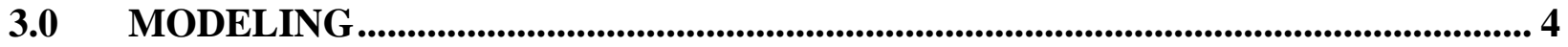

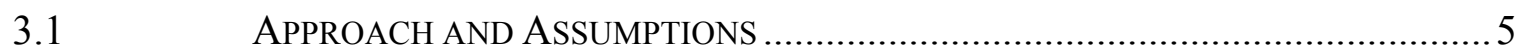

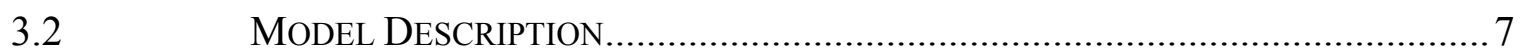

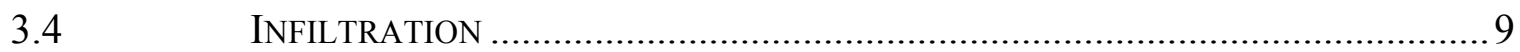

4.0 MODEL RESULTS ................................................................................................... 10

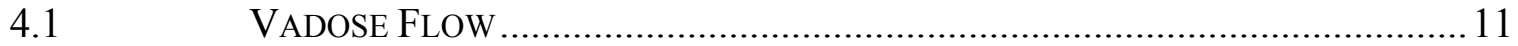

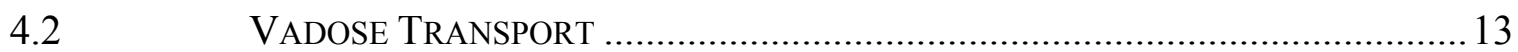

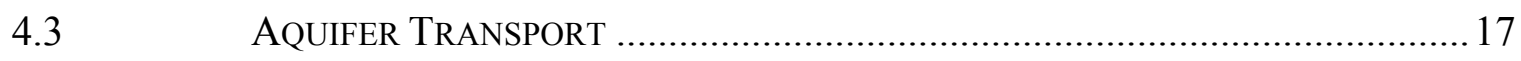

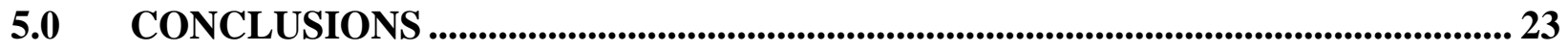

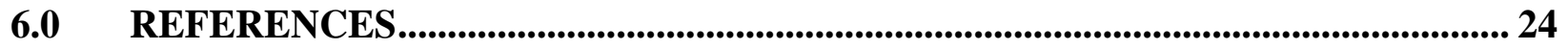

APPENDIX A RADIONUCLIDES AND DAUGHTERS INCLUDED IN ANALYSIS ..... 25

APPENDIX B ESTIMATION OF INITIAL WALL DEGRADATION ............................... 26

APPENDIX C EQUIVALENT GRAVEL FLOW PATH FOR ROOF AND FLOOR JOINTS ......................................................................................................... 27

APPENDIX D CONTOUR PLOTS OF RADIONUCLIDE CONCENTRATIONS............ 28

D. 1 CONCENTRATION PROFILES For SDU FinAl DESIGN CASE A AT 20,000 YEARS .........28

D. 1 CONCENTRATION PROFILES FOR SDU FinAl Design CASE A AT 20,000 YeARS

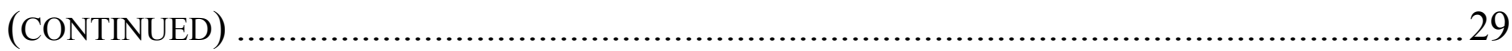

D. 2 CONCENTRATION PROFILES For SDU Final DeSign CASE K AT 20,000 YEARS .......... 30

D. 2 CONCENTRATION PROFILES FOR SDU Final DESIGN CASE K AT 20,000 YeARS

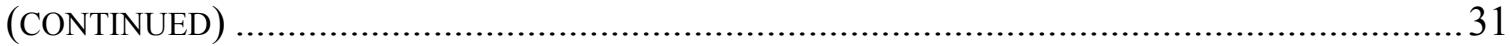

D. 3 Concentration Profiles for SDU Final Design Case K With SDU 9 Relocated

TO SOUTHWEST CORNER OF SDF AT 10,000 YEARS............................................................ 32

D. 3 Concentration Profiles for SDU Final Design CASE K WITH SDU 9 ReLocated

TO SOUTHWEST CORNER OF SDF AT 10,000 YEARS (CONTINUED) .......................................33

D. 4 CONCENTRATION PROFILES For SDU FINAL DeSIGN CASE K WITH SDU 9 RELOCATED

MIDWAY BETWEEN SDU 9 AND SDU 11 AT 10,000 YEARS................................................ 34

D. 4 Concentration Profiles For SDU Final Design CaSe K WITH SDU 9 ReLocated

MIDWAY BETWEEN SDU 9 AND SDU 11 AT 10,000 YEARS (CONTINUED) ............................35

D. 5 Concentration Profiles for SDU Final Design Case A with New $K_{D}$ Values at

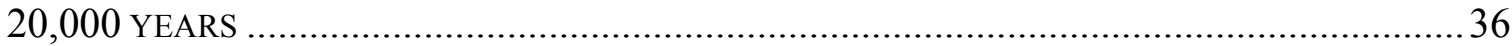

D. 5 Concentration Profiles for SDU Final Design Case A With New $K_{\mathrm{D}}$ Values at

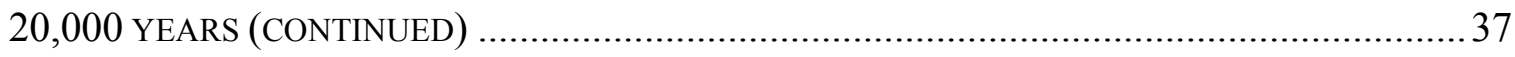

D.6 Concentration Profiles for SDU Final Design CaSe A with Worst CaSe

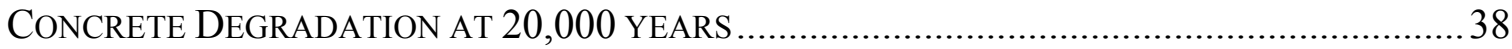


D.6 Concentration Profiles for SDU Final Design Case A with Worst Case CONCRETE DEGRADATION AT 20,000 YEARS (CONTINUED) .................................................39 D.7 Concentration Profiles for SDU Final Design With Margin CaSe A at 20,000 YEARS 40

D.7 ConCENTRATION PROfiles For SDU Final DESIGN With MARgin CASE A AT 20,000 YEARS (CONTINUED) 41

D.8 CONCENTRATION PROFILES FOR SDU FINAL DESIGN WITH MARGIN CASE K AT 20,000 YEARS 42

D. 8 Concentration Profiles for SDU Final Design With Margin CASE K AT 20,000 YEARS (CONTINUED) 43 D.9 Concentration ProfiLes for SDU Final Design With Margin Case A With NeW $\mathrm{K}_{\mathrm{D}}$ VALUES AT 20,000 YEARS .44 D. 9 Concentration Profiles for SDU Final Design with Margin Case A with New $\mathrm{K}_{\mathrm{D}}$ VALUES AT 20,000 YEARS (CONTINUED) 45 


\section{LIST OF TABLES}

Table 1. Listing of Folders Where PORFLOW Results are Stored ...................................... 2

Table 2. SDU Modeling Design Parameters....................................................................... 3

Table 3. Initial Concrete Degradation during Filling and Predicted Times for Complete

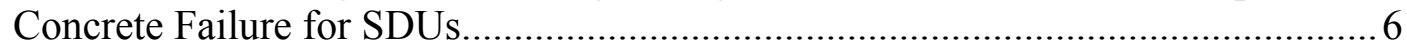

Table 4. Materials used in SDU 6 Model. ..................................................................... 7

Table 5. Radionuclide Inventories in Curies used in Case K Modeling............................. 10

\section{LIST OF FIGURES}

Figure 1. Diagram of SDF layout for SDU performance analysis.................................. 4

Figure 2. Computational model of SDU Final Design showing material zones.................. 8

Figure 3. Computational model of SDU Final Design with Margin showing material zones.

Figure 4. Case A infiltration and hydraulic conductivity with SDU Final Design................ 9

Figure 5. Case K infiltration and hydraulic conductivity with SDU Final Design............... 9

Figure 6. Flow streamlines and water saturation contours for SDU Final Design Case A in the time period $1000-1200$ years. ............................................................... 12

Figure 7. Flow streamlines and water saturation contours for SDU Final Design Case K in the time period $1000-1200$ years. ............................................................... 12

Figure 8. Flow streamlines and water saturation contours for SDU Final Design with Margin Case $\mathrm{K}$ in the time period 1000 - 1200 years........................................ 13

Figure 9. Fluxes to water table for six radionuclides for SDU Final Design case studies and FDC Case A and Case K............................................................................. 15

Figure 10. Fluxes to water table for six radionuclides for SDU Final Design with Margin case studies, SDU Final Design Case K, and FDC Case A and Case K.............. 16

Figure 11. PORFLOW groundwater aquifer model for the GSA and the SDF submodel. .. 17

Figure 12. PORFLOW model for SDF showing initial proposed layout of SDUs, existing disposal units, the $100 \mathrm{~m}$ boundary and boundary sectors................................ 18

Figure 13. PORFLOW model for SDF showing aquifer flow streamlines........................ 18

Figure 14. Source locations and $100 \mathrm{~m}$ boundary with SDU 9 relocated to southwest corner of SDF.

Figure 15. Source locations and $100 \mathrm{~m}$ boundary with SDU 9 relocated midway between original location and SDU 11. 


\section{LIST OF ACRONYMS}

CFD Computational Fluid Dynamics

DOE Department of Energy

FDC Future Disposal Cell (also referred to as Vault 2)

GSA General Separations Area

GCL Greater Confinement Liner

HDPE High Density Polyethylene

HPC High Performance Computing

NRC Nuclear Regulatory Commission

PA Performance Assessment

QA Quality Assurance

RAI Request for Additional Information

SDF Saltstone Disposal Facility

SDU Saltstone Disposal Unit

SRNL Savannah River National Laboratory

SRR Savannah River Remediation

TTQAP Task Technical and Quality Assurance Plan

TTR Task Technical Request 


\subsection{Executive Summary}

\section{$1.1 \quad$ Modeling Approach}

At the request of Savannah River Remediation (SRR), SRNL has analyzed the expected performance obtained from using seven 32 million gallon Saltstone Disposal Units (SDUs) in the Z-Area Saltstone Disposal Facility (SDF) to store future saltstone grout. The analysis was based on preliminary SDU final design specifications. The analysis used PORFLOW modeling to calculate the release of 20 radionuclides from an SDU and transport of the radionuclides and daughters through the vadose zone. Results from this vadose zone analysis were combined with previously calculated releases from existing saltstone vaults and FDCs and a second PORFLOW model run to calculate aquifer transport to assessment points located along a boundary $100 \mathrm{~m}$ from the nearest edge of the SDF sources. Peak concentrations within 12 sectors spaced along the $100 \mathrm{~m}$ boundary were determined over a period of evaluation extending 20,000 years after SDF closure cap placement. These peak concentrations were provided to SRR to use as input for dose calculations.

The assessment of SDU performance evaluated the nine cases listed below.

SDU Final Design with:

1. Parameter values used in the 2009 Saltstone PA Case A which was the PA base case.

2. Parameter values used in the Case $\mathrm{K}$ response to the NRC Request for Additional Information (RAI) Reference (9).

3. PA Case A parameters but using Case $\mathrm{K} \mathrm{K}_{\mathrm{d}}$ values.

4. PA Case A parameters but assuming worst case concrete degradation in the SDU walls, roof and floor prior to closure.

5. RAI Case K parameters with relocation of SDU 9 to the southwest corner of the SDF.

6. RAI Case K parameters with relocation of SDU 9 to a position midway between the initial proposed SDU 9 location in the northern section of the SDF and SDU 11.

SDU Final Design with Margin (reduced SDU roof and floor thickness also having more joints in the roof and floor concrete slabs) with:

7. PA Case A parameters.

8. RAI Case K parameters.

9. PA Case A parameters but with Case $\mathrm{K} \mathrm{K}_{\mathrm{d}}$ values.

\subsection{Quality Assurance}

This work was performed in response to Technical Task Request (TTR) HLW-SSF-TTR2012-0018. In compliance with SRNL QA procedures, a TTQAP "Task Technical and Quality Assurance Plan for SDU Preliminary Design PORFLOW Modeling," SRNL-RP2012-00190, Rev. 0, April 23, 2012 was issued. The modeling calculations used the commercial Computational Fluid Dynamics (CFD) code PORFLOW Version 6.30.2. PORFLOW has been used in previous PA and Special Analysis calculations performed by SRNL. The calculations reported here relied in large part on the previous saltstone 
calculations made in the 2009 PA for material properties, estimation of concrete degradation, and the general modeling approach. Fluxes of radionuclides to the water table from previous analyses of saltstone disposal Vaults 1 and 4 and Future Disposal Cells (FDCs) 2A, 2B, 3A, 3B, 5A, and 5B performed as part of the 2009 PA and subsequent response to the NRC RAI were used in this analysis. An independent design check of the PORFLOW models and supporting calculations was performed and is documented in Appendix E.

\subsection{PORFLOW Results}

The PORFLOW analysis was conducted in three parts:

1. Calculation of a series of steady-state solutions for infiltration flow through an SDU and the associated vadose zone over the time period 20,000 years following placement of the SDF closure cap.

2. Using the flow solutions from part 1 to calculate the transport of 20 parent radionuclides through an SDU and the associated vadose zone. These calculations gave fluxes to the water table for each radionuclide and daughters having half-lives greater than five years.

3. Using fluxes to the water table calculated for the SDUs together with fluxes to the water table calculated in previous work for Vault 1, Vault 4, and FDCs 2A, 2B, 3A, $3 \mathrm{~B}, 5 \mathrm{~A}$ and $5 \mathrm{~B}$ and inventories for each source, a PORFLOW model of aquifer flow below the SDF was run to calculate groundwater transport of the radionuclides. This calculation determined maximum concentrations within 12 sectors along the $100 \mathrm{~m}$ boundary. The peak concentrations were provided to SRR for dose calculations.

Results are stored on the High Performance Computing (HPC) file system maintained by SRNL in base directory:

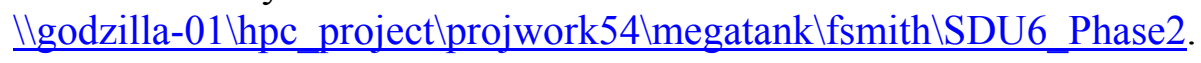

The subdirectory names listed below in Table 1 identify where peak radionuclide concentrations in each sector of the $100 \mathrm{~m}$ boundary and for each of the nine case studies listed in Section 1.1 are stored.

Table 1. Listing of Folders Where PORFLOW Results are Stored

\begin{tabular}{|c||c|}
\hline $\begin{array}{c}\text { Case } \\
\text { Number }\end{array}$ & Subdirectory \\
\hline \hline 1 & AquiferSDU_FD $\backslash$ Transport $\backslash$ CaseA \\
\hline 2 & AquiferSDU_FD $\backslash$ Transport $\backslash$ CaseK \\
\hline 3 & AquiferSDU_FD $\backslash$ Transport $\backslash$ CaseA_NewKd \\
\hline 4 & $\backslash$ AquiferSDU_FD $\backslash$ Transport $\backslash$ CaseA_Sensitivity \\
\hline 5 & $\backslash$ AquiferSDU_FDRev $\backslash$ Transport $\backslash C a s e K$ \\
\hline 6 & AquiferSDU_FDRev1 $\backslash$ Transport $\backslash$ CaseK \\
\hline 7 & AquiferSDU_FDM $\backslash$ Transport $\backslash$ CaseA \\
\hline 8 & AquiferSDU_FDM $\backslash$ Transport $\backslash$ CaseK \\
\hline 9 & AquiferSDU_FDM $\backslash$ Transport $\backslash$ CaseA_NewKd \\
\hline
\end{tabular}




\subsection{Introduction}

\subsection{Background}

In response to Technical Task Request HLW-SSF-TTR-2012-0018 (1), SRNL performed modeling studies to evaluate the performance of proposed 32 million gallon Saltstone Disposal Units in the Z-Area Saltstone Disposal Facility. This preliminary modeling study was intended to provide a calculation of release of radionuclides from SDUs for subsequent assessment of these estimated releases for potential impact on the 2009 PA. Key inputs and assumptions for the modeling were provided to SRNL in "SDU-6 Modeling Inputs for Preliminary PA Modeling”, SRR-SDU-2012-00021 (2). The table below list parameters for the two SDU designs modeled. The Final Design with Margin specified reduced concrete thickness in the roof, floor and walls and an increase in the total length of joints between concrete slabs used in the roof and floor.

As noted in Table 2, the 270 feet base elevation is assumed to apply at the bottom of the floor slab. The 2009 PA used an average elevation of 270 feet at the bottom of the lower mud mat for the 64 FDCs modeled in that work. While there will be upper and lower mud mats below the SDU floor to provide a base for the floor, no credit was taken for the mats in the PORFLOW modeling. The mat regions are assumed to have the properties of native soil with soil $\mathrm{K}_{\mathrm{d}}$ values. However, the high density polyethylene (HDPE) liner that would be placed between the mud mats was included in the model.

Table 2. SDU Modeling Design Parameters

\begin{tabular}{|l|c|c|}
\hline & Final Design & $\begin{array}{c}\text { Final Design with } \\
\text { Margin }\end{array}$ \\
\hline Tank Diameter & $375 \mathrm{ft}$. & $375 \mathrm{ft}$. \\
\hline Tank Height & $43 \mathrm{ft}$. & $43 \mathrm{ft}$. \\
\hline Support Columns & $\begin{array}{c}208-24 \text { in. OD } \\
(23 \mathrm{ft} \text { centers })\end{array}$ & $\begin{array}{c}208-24 \text { in. OD } \\
(23 \mathrm{ft} . \text { centers })\end{array}$ \\
\hline Roof Thickness & $12 \mathrm{in.}$ & $\mathbf{9}$ in. \\
\hline $\begin{array}{l}\text { Roof Joints } \\
\text { (total linear feet) }\end{array}$ & $750 \mathrm{ft}$. & $\mathbf{1 , 0 0 0} \mathbf{f t .}$ \\
\hline Roof Slope & $1.5 \%$ & $1.5 \%$ \\
\hline Floor Thickness & $12 \mathrm{in.}$ & $\mathbf{9}$ in. \\
\hline $\begin{array}{l}\text { Floor Joints } \\
\text { (total linear feet) }\end{array}$ & $750 \mathrm{ft}$. & $\mathbf{1 , 0 0 0} \mathbf{f t .}$ \\
\hline Wall/Floor Joint & $1,200 \mathrm{ft}$. & $1,200 \mathrm{ft}$. \\
\hline $\begin{array}{l}\text { Wall Thickness } \\
\text { to } 10 \mathrm{in} .\end{array}$ & $\begin{array}{c}\text { Tapered 20 in. } \\
\text { to 8 in. }\end{array}$ \\
\hline $\begin{array}{l}\text { Base Elevation } \\
\text { (bottom floor slab) }\end{array}$ & $270 \mathrm{ft}$. & $270 \mathrm{ft}$. \\
\hline
\end{tabular}

Reference 2 also provided a layout of saltstone disposal units within the SDF. This layout included Vault 1, Vault 4, the six FDCs 2A, 2B, 3A, 3B, 5A, and 5B, and included seven SDUs (SDU 6 through SDU 12). The SDF layout used for this preliminary assessment of SDU performance is shown in Figure 1. 
SRNL-STI-2012-00445, Rev. 0

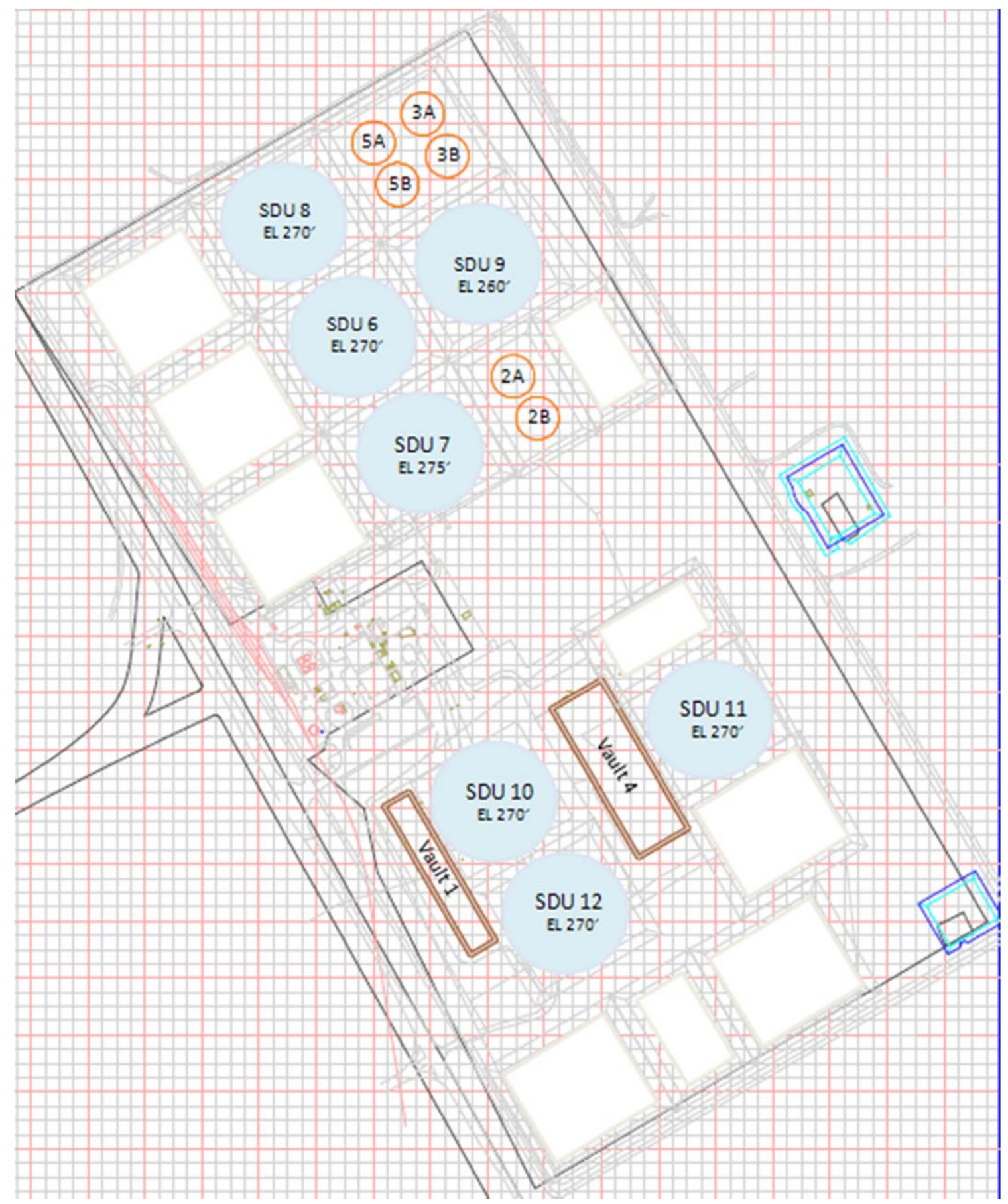

Figure 1. Diagram of SDF layout for SDU performance analysis. 


\subsection{Modeling}

\subsection{Approach and Assumptions}

To satisfy the requirements of the TTR (1), SRNL conducted PORFLOW modeling for the SDUs, that was similar to the modeling performed in the 2009 Saltstone PA and modeling performed in response to the NRC RAI. In particular, the modeling was based on the FDC Case A analysis performed in the PA and the revised Case $\mathrm{K}$ analysis performed as part of the RAI response. The assessment of SDU performance evaluated the nine cases listed below.

SDU Final Design with:

1. Parameter values used in the 2009 Saltstone PA Case A which was the PA base case.

2. Parameter values used in the Case $\mathrm{K}$ response to the NRC RAI.

3. PA Case A parameters but with Case $\mathrm{K} \mathrm{K}_{\mathrm{d}}$ values.

4. PA Case A parameters but assuming worst case concrete degradation in the SDU walls, roof and floor prior to closure.

5. RAI Case K parameters with relocation of SDU 9 to the southwest corner of the SDF.

6. RAI Case K parameters with relocation of SDU 9 to a position midway between the initial proposed SDU 9 location in the northern section of the SDF and SDU 11.

SDU Final Design with Margin (reduced SDU roof, wall and floor thickness with more joints in the roof and floor concrete slabs) with:

7. PA Case A parameters.

8. RAI Case K parameters.

9. PA Case A parameters but with Case $\mathrm{K} \mathrm{K}_{\mathrm{d}}$ values.

The modeling evaluated the expected groundwater contamination at a $100 \mathrm{~m}$ boundary from all SDF sources over a 20,000 year period following closure cap placement.

Key assumptions and a summary of the approach used in the modeling are provided below.

- As specified in Reference (2), the 20 radionuclides listed in Appendix A were included in the analysis. These 20 radionuclides have 48 daughters with half-lives greater than five years. As shown in Appendix A, there are a total of 27 unique radionuclides that were tracked in the analysis.

- The TTR calls for modeling SDUs without the presence of a coating on the inner wall to hinder sulfate attack on the concrete. Property degradation curves used in the analysis were modified to model the larger SDU configuration and the absence of a wall coating. It was assumed that the wall degraded to some depth prior to closure from sulfate attack by exposure to saltstone drain water. To simplify the analysis, the lower 41 feet of wall was divided into four equal segments of 10.25 feet each and the upper two feet of wall was modeled as a separate segment. It was assumed that the upper section of wall and the roof would not degrade during filling. 
The estimate of concrete degradation assumed a uniform $1.0 \mathrm{~cm}$ of surface cracking and a variable depth of sulfate attack during SDU filling. Shrinkage cracks during drying are typically shallow and typically around $1.0 \mathrm{~cm}$ in depth (Levitt 2003, page 5) (4). The depth of sulfate attack was calculated, as outlined in Appendix B, by taking the geometric mean of the minimum (fast reaction) and maximum (slow reaction) penetration depths assuming an initial concrete water saturation of $75 \%$ which is typical of field exposure conditions (5). The sensitivity case (Case 4) assumed the maximum penetration depth. Table 3 gives the calculated initial degradation depth and predicted time for full degradation to occur in the concrete components of the model.

Table 3. Initial Concrete Degradation during Filling and Predicted Times for Complete Concrete Failure for SDUs.

\begin{tabular}{|l||r|r|r|r|r|r|}
\hline \multirow{2}{*}{$\begin{array}{c}\text { Concrete } \\
\text { Section }\end{array}$} & \multicolumn{2}{c|}{ Final Design } & \multicolumn{2}{c|}{$\begin{array}{c}\text { Final Design with } \\
\text { Margin }\end{array}$} & \multicolumn{2}{c|}{ Sensitivity Case } \\
\cline { 2 - 8 } & $\begin{array}{c}\text { Initial } \\
\text { Degradation } \\
\text { (inches) }\end{array}$ & $\begin{array}{l}\text { Years to } \\
\text { Failure }\end{array}$ & $\begin{array}{c}\text { Initial } \\
\text { Degradation } \\
\text { (inches) }\end{array}$ & $\begin{array}{l}\text { Years to } \\
\text { Failure }\end{array}$ & $\begin{array}{c}\text { Initial } \\
\text { Degradation } \\
\text { (inches) }\end{array}$ & $\begin{array}{l}\text { Years to } \\
\text { Failure }\end{array}$ \\
\hline \hline Wall Section 1 & 0.933 & 100000 & 0.842 & 70000 & 5.977 & 45000 \\
\hline Wall Section 2 & 0.852 & 70000 & 0.773 & 50000 & 5.142 & 35000 \\
\hline Wall Section 3 & 0.772 & 50000 & 0.704 & 35000 & 4.308 & 25000 \\
\hline Wall Section 4 & 0.691 & 30000 & 0.635 & 20000 & 3.474 & 14000 \\
\hline Wall Section 5 & 0 & 25000 & 0 & 18000 & 0 & 25000 \\
\hline Floor & 0.683 & 30000 & 0.611 & 16000 & 3.394 & 14000 \\
\hline Roof & 0 & 35000 & 0 & 20000 & 0 & 35000 \\
\hline
\end{tabular}

- Based on the FDC PA analysis, the SDU concrete was assumed to be exposed to a sulfate concentration of $0.15 \mathrm{~mol} / \mathrm{L}$ which was used to estimate concrete degradation as a function of time following closure. Degradation was modeled as an increase in hydraulic conductivity and an increase in effective radionuclide diffusivity which progressed until values equivalent to those in vadose zone soil were reached.

- Three material regions below the SDU floor were included in the model to represent a four inch lower mud mat, a six inch upper mud mat, and an HDPE liner between the mats. However, the mud mat regions were given the properties of native vadose zone soil so no credit was taken for the presence of mud mats below the SDU floor acting as barriers to radionuclide transport.

- Model features not explicitly defined in Reference (2) were taken from the FDC PA model. For example, it was assumed that there would be a 2.0 foot thick sand drain over the roof extending 25 feet past the SDU outer wall.

- Joints between concrete slabs in the SDU roof and floor were assumed to be approximately $0.5 \mathrm{~mm}$ air gaps. As a point of reference, cracks are typically limited to $0.2 \mathrm{~mm}$ in watertight structures by design. Because a dimension on the order of $0.5 \mathrm{~mm}$ is too small to be included in the model, the joints were modeled as an equivalent 2.0 inch wide annular region containing gravel. The calculation of the 
equivalent gravel segment is provided in Appendix C. The joints were modeled as two annular regions equivalent to 750 linear feet (119.4 ft radius) and 250 linear feet (39.8 $\mathrm{ft}$ radius). The SDU final design was modeled by replacing the gravel properties in the smaller annular region in the roof and floor with roof and floor concrete properties, respectively. Joints are assumed to have $\mathrm{K}_{\mathrm{d}}$ values equal to zero.

\subsection{Model Description}

Model calculations simulating the flow of water infiltration around and through an SDU and radionuclide transport from the disposal unit through the vadose zone were made to simulate 20,000 years of operation following placement of a closure cap. Tc-99 transport calculations for Case A simulations ran very slowly requiring several days to complete because of the shrinking core oxidation sub-model. Other than the Tc-99 transport calculations, PORFLOW runs typically took on the order of several hours to complete. All of the fluid flow and contaminant transport calculations were made using Version 6.30 .2 of the PORFLOW code. PORFLOW is a commercial Computational Fluid Dynamics (CFD) code developed by Analytic \& Computational Research, Inc.

The computational model for the SDU final design is shown in Figure 2 where areas with different material properties are color coded. The model for the SDU Final Design with Margin is shown in Figure 3. At the scale of these figures, differences between the two models are difficult to see but the reduced roof, floor and wall thickness for the design with margin can be discerned. Materials corresponding to the figure legends are listed in Table 4. For the final design, the vadose zone is $42 \mathrm{ft}$ deep and the top surface of the model region extends $58.2 \mathrm{ft}$ above ground. This height gives a minimum backfill soil depth of $7.0 \mathrm{ft}$ at the center of the unit. The outer radius of the disposal unit is $188.9 \mathrm{ft}$ and the model domain extends $75 \mathrm{ft}$ further to include the $25 \mathrm{ft}$ sand drain overhang and an additional $50 \mathrm{ft}$ of backfill soil. Some narrow features such as the HDPE-GCL liners above the roof and between the mud mats are not visible at the scale of Figures 2 and 3. It is just possible to see the gaps in the roof and floor used to represent concrete joints.

Table 4. Materials used in SDU 6 Model.

\begin{tabular}{|c|l|r|l|}
\hline mtyp & \multicolumn{1}{|c|}{ Material } & mtyp & \multicolumn{1}{|c|}{ Material } \\
\hline 1 & Native soil in vadose zone & 9 & Wall section 2 \\
\hline 2 & Compacted backfill & 10 & Wall section 3 \\
\hline 3 & $\begin{array}{l}\text { Lower mud mat } \\
\text { (given native soil properties) }\end{array}$ & 11 & Wall section 4 \\
\hline 4 & $\begin{array}{l}\text { Upper mud mat } \\
\text { (given native soil properties) }\end{array}$ & 12 & Wall section 5 \\
\hline 5 & Concrete floor & 13 & Concrete roof \\
\hline 6 & Saltstone & 14 & HDPE GCL \\
\hline 7 & Clean grout & 15 & Sand drain \\
\hline 8 & Wall section 1 & 16 & $\begin{array}{l}\text { Joint (given properties of } \\
\text { gravel with } \mathrm{K}_{\mathrm{d}}=0 \text { ) }\end{array}$ \\
\hline & & 17 & Concrete support column \\
\hline
\end{tabular}




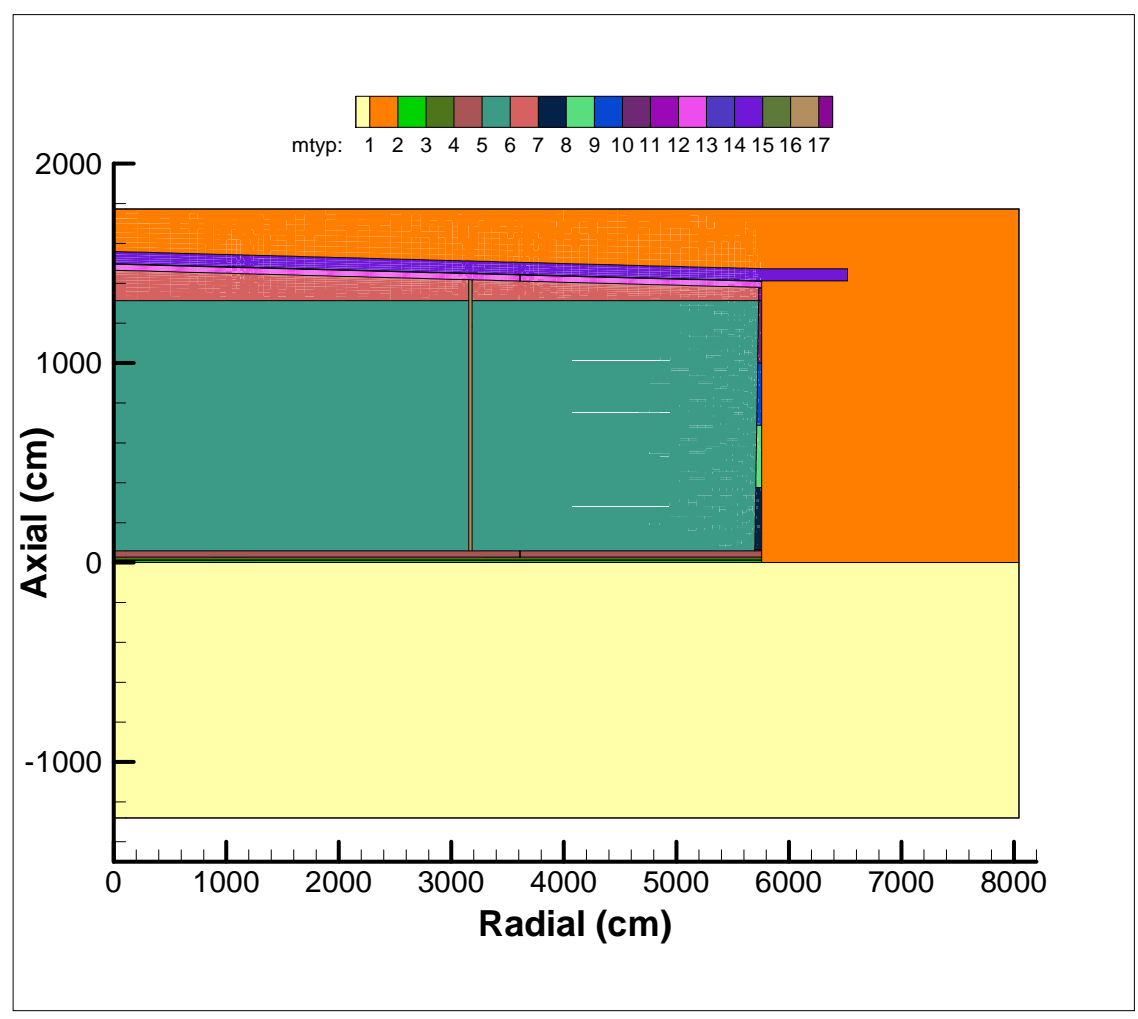

Figure 2. Computational model of SDU Final Design showing material zones.

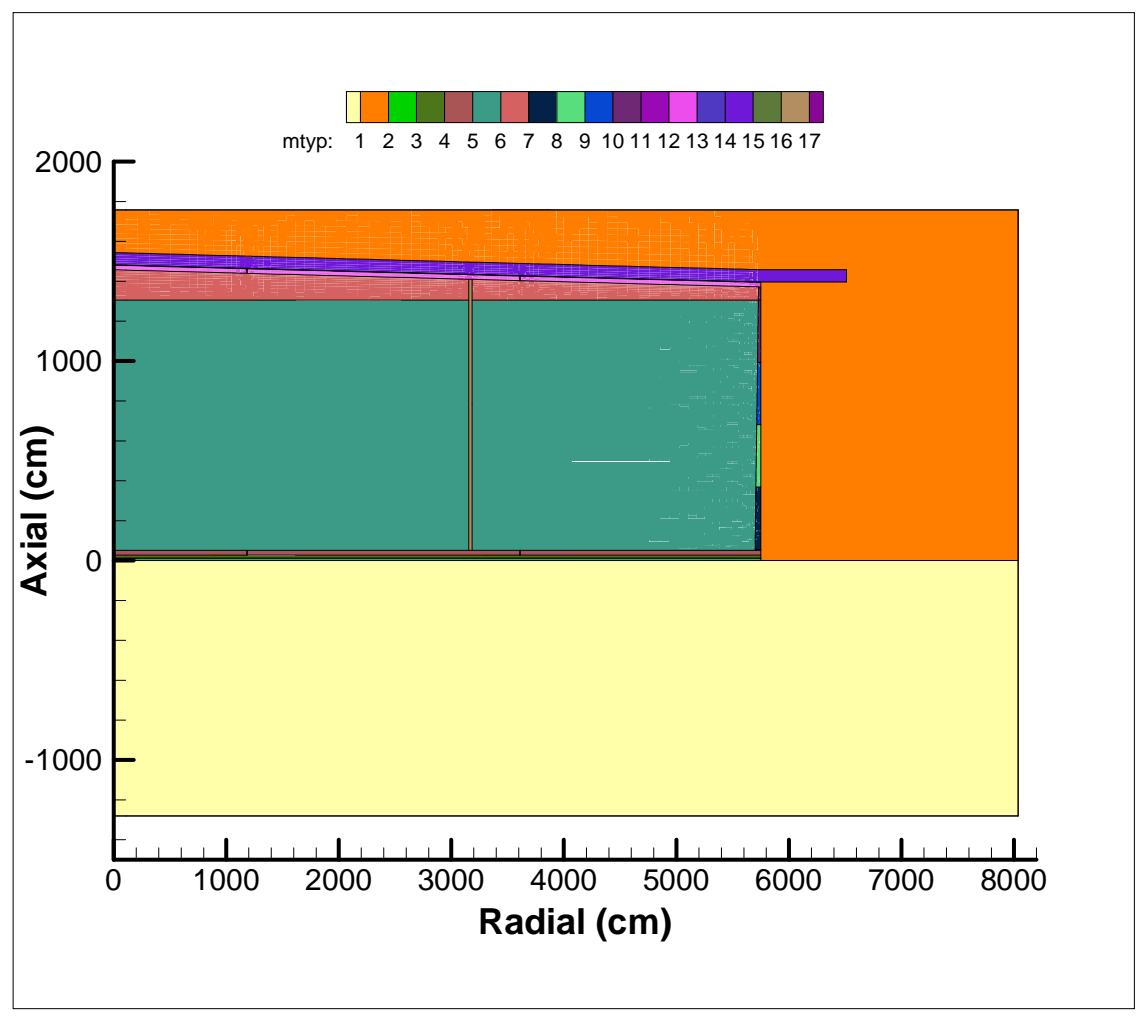

Figure 3. Computational model of SDU Final Design with Margin showing material zones. 


\subsection{Infiltration}

Infiltration rates imposed on the upper surface of the model domain were the same as those used in the 2009 Saltstone PA and are based on having the final SDF closure cover in place. The infiltration and saturated hydraulic conductivity of selected sections of an SDU are plotted in Figure 4 for Case A and in Figure 5 for Case K with the SDU Final Design. Infiltration rates for the SDU Final Design with Margin are not significantly different.

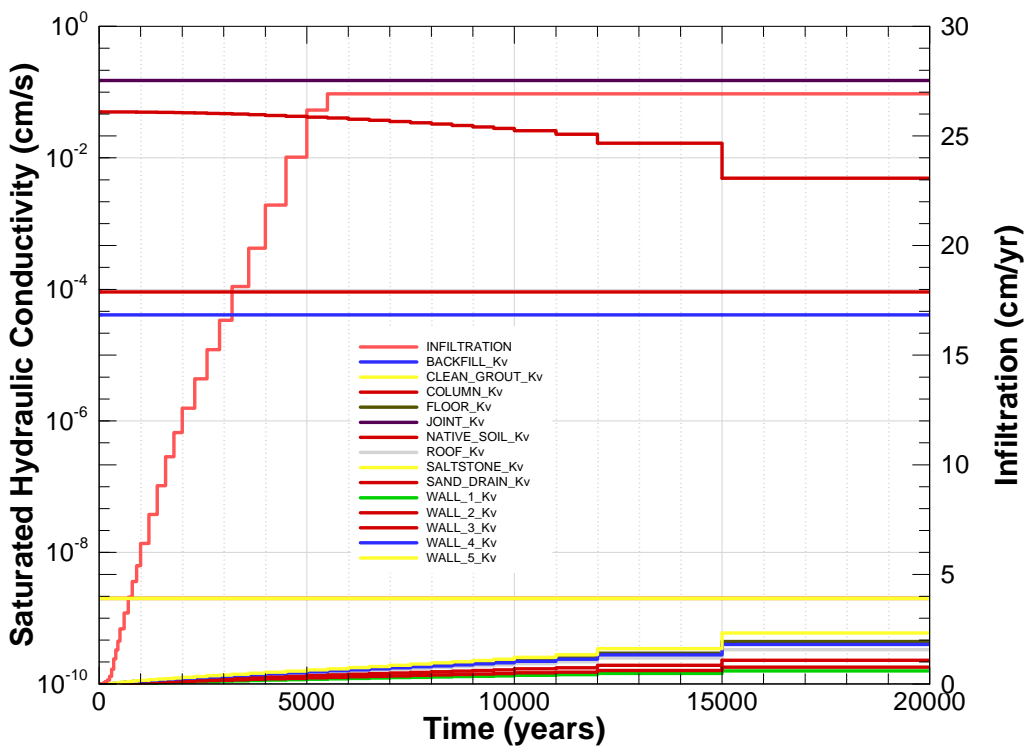

Figure 4. Case A infiltration and hydraulic conductivity with SDU Final Design.

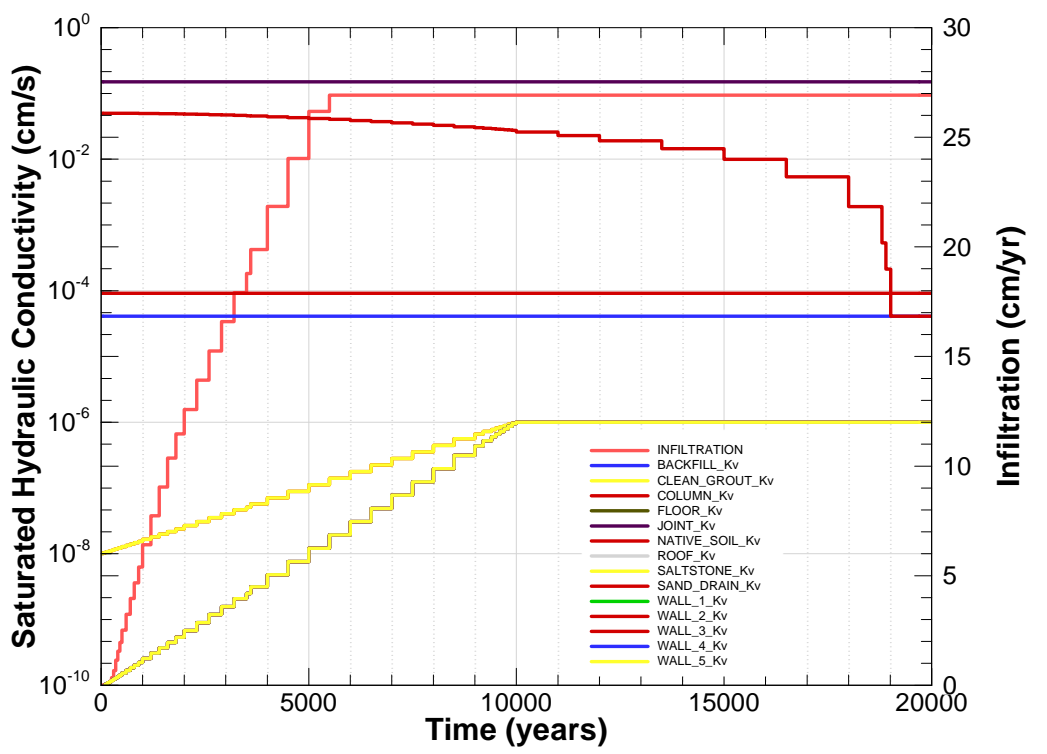

Figure 5. Case K infiltration and hydraulic conductivity with SDU Final Design. 


\subsection{Inventories}

Radionuclide inventories for the 20 parent radionuclides used in this analysis were extracted from spreadsheets used for previous saltstone calculations. Total inventories in Curies for each type of saltstone disposal unit used for the Case $\mathrm{K}$ analysis are listed in Table 5. In the original spreadsheet, the FDC inventory represented the total inventory for the 64 proposed FDCs. For the present analysis, the FDC inventory was reduced to $6 / 64$ of the original to account for the inventory in the six existing FDCs and 58/64 of the inventory was assigned to the seven SDUs.

Table 5. Radionuclide Inventories in Curies used in Case K Modeling.

\begin{tabular}{|l||l|l|l|l||l|}
\hline Nuclide & Vault 1 & Vault 4 & $\begin{array}{c}\text { Total } \\
\text { FDC }\end{array}$ & $\begin{array}{c}\text { Total } \\
\text { Total } \\
\text { SDU }\end{array}$ & $\begin{array}{c}\text { Saltstone } \\
\text { Inventory }\end{array}$ \\
\hline Am-241 & $4.71 \mathrm{E}-04$ & $1.33 \mathrm{E}+02$ & $8.27 \mathrm{E}+00$ & $7.99 \mathrm{E}+01$ & $2.21 \mathrm{E}+02$ \\
\hline $\mathrm{Am}-243$ & $0.00 \mathrm{E}+00$ & $1.76 \mathrm{E}+00$ & $2.23 \mathrm{E}-01$ & $2.16 \mathrm{E}+00$ & $4.14 \mathrm{E}+00$ \\
\hline $\mathrm{Cm}-244$ & $0.00 \mathrm{E}+00$ & $1.29 \mathrm{E}+02$ & $5.68 \mathrm{E}+00$ & $5.49 \mathrm{E}+01$ & $1.89 \mathrm{E}+02$ \\
\hline $\mathrm{Cm}-245$ & $0.00 \mathrm{E}+00$ & $9.17 \mathrm{E}-01$ & $1.45 \mathrm{E}-03$ & $1.40 \mathrm{E}-02$ & $9.32 \mathrm{E}-01$ \\
\hline $\mathrm{Cs}-135$ & $0.00 \mathrm{E}+00$ & $5.41 \mathrm{E}+00$ & $7.84 \mathrm{E}-04$ & $7.58 \mathrm{E}-03$ & $5.42 \mathrm{E}+00$ \\
\hline I-129 & $1.12 \mathrm{E}-01$ & $2.83 \mathrm{E}-01$ & $2.29 \mathrm{E}+00$ & $2.22 \mathrm{E}+01$ & $2.48 \mathrm{E}+01$ \\
\hline $\mathrm{Nb}-93 \mathrm{~m}$ & $4.92 \mathrm{E}-01$ & $8.42 \mathrm{E}+00$ & $2.22 \mathrm{E}+00$ & $2.15 \mathrm{E}+01$ & $3.26 \mathrm{E}+01$ \\
\hline $\mathrm{Np}-237$ & $8.98 \mathrm{E}-03$ & $6.09 \mathrm{E}-01$ & $2.99 \mathrm{E}-01$ & $2.89 \mathrm{E}+00$ & $3.81 \mathrm{E}+00$ \\
\hline $\mathrm{Pu}-238$ & $1.56 \mathrm{E}-02$ & $1.00 \mathrm{E}+03$ & $1.01 \mathrm{E}+03$ & $9.72 \mathrm{E}+03$ & $1.17 \mathrm{E}+04$ \\
\hline $\mathrm{Pu}-239$ & $2.46 \mathrm{E}-02$ & $3.83 \mathrm{E}+02$ & $9.06 \mathrm{E}+01$ & $8.76 \mathrm{E}+02$ & $1.35 \mathrm{E}+03$ \\
\hline $\mathrm{Pu}-240$ & $2.45 \mathrm{E}-02$ & $1.20 \mathrm{E}+02$ & $2.45 \mathrm{E}+01$ & $2.37 \mathrm{E}+02$ & $3.82 \mathrm{E}+02$ \\
\hline $\mathrm{Pu}-241$ & $1.96 \mathrm{E}-02$ & $2.41 \mathrm{E}+03$ & $2.54 \mathrm{E}+02$ & $2.45 \mathrm{E}+03$ & $5.12 \mathrm{E}+03$ \\
\hline $\mathrm{Pu}-244$ & $0.00 \mathrm{E}+00$ & $1.65 \mathrm{E}-02$ & $9.76 \mathrm{E}-05$ & $9.43 \mathrm{E}-04$ & $1.75 \mathrm{E}-02$ \\
\hline Tc-99 & $2.16 \mathrm{E}+02$ & $5.81 \mathrm{E}+02$ & $3.23 \mathrm{E}+03$ & $3.12 \mathrm{E}+04$ & $3.53 \mathrm{E}+04$ \\
\hline Th-229 & $5.97 \mathrm{E}-01$ & $2.49 \mathrm{E}+01$ & $2.36 \mathrm{E}-01$ & $2.28 \mathrm{E}+00$ & $2.80 \mathrm{E}+01$ \\
\hline Th-230 & $8.22 \mathrm{E}-01$ & $1.00 \mathrm{E}-02$ & $7.80 \mathrm{E}-04$ & $7.54 \mathrm{E}-03$ & $8.40 \mathrm{E}-01$ \\
\hline U-233 & $5.70 \mathrm{E}-01$ & $2.38 \mathrm{E}+01$ & $2.25 \mathrm{E}-01$ & $2.17 \mathrm{E}+00$ & $2.68 \mathrm{E}+01$ \\
\hline $\mathrm{U}-234$ & $5.70 \mathrm{E}-01$ & $1.00 \mathrm{E}+01$ & $7.78 \mathrm{E}-01$ & $7.52 \mathrm{E}+00$ & $1.89 \mathrm{E}+01$ \\
\hline $\mathrm{U}-235$ & $6.34 \mathrm{E}-03$ & $4.75 \mathrm{E}-01$ & $1.78 \mathrm{E}-02$ & $1.72 \mathrm{E}-01$ & $6.71 \mathrm{E}-01$ \\
\hline U-238 & $1.47 \mathrm{E}-02$ & $5.85 \mathrm{E}-01$ & $6.07 \mathrm{E}-01$ & $5.87 \mathrm{E}+00$ & $7.08 \mathrm{E}+00$ \\
\hline
\end{tabular}

For Case A, the following inventory values were different:

Vault $4-\mathrm{Pu}-238=9100 \mathrm{Ci}, \mathrm{U}-234=26 \mathrm{Ci}$, and $\mathrm{Th}-230=7.5 \mathrm{Ci}$,

6 FDCs $-\mathrm{Th}-230=1.14 \mathrm{Ci}$,

7 SDUs - Th-230 $=11.04 \mathrm{Ci}$. 


\subsection{Model Results}

\subsection{Vadose Flow}

PORFLOW calculations were made to determine the flow of infiltration water through the SDU and vadose zone. Vadose zone flow calculations were made for the following five cases that had either different SDU geometry or different concrete and saltstone hydraulic properties:

1. SDU Final Design Case A

2. SDU Final Design Case $K$

3. SDU Final Design with worst case concrete degradation Case A

4. SDU Final Design with Margin Case A

5. SDU Final Design with Margin Case K

The two other case studies that varied $\mathrm{K}_{\mathrm{d}}$ values required making vadose and aquifer transport calculations but used the existing Case A vadose zone flows while the two other case studies that varied SDU placement only required making additional aquifer transport calculations.

Figure 6 shows the flow pattern calculated for the SDU Final Design geometry and Case A over the time step from 1000 years to 1200 years. Figure 7 shows the flow pattern for the SDU Final Design and Case K over the same time period. Both figures show flow streamlines and contours of water saturation. In general, most of the water entering the computational domain was conducted across the disposal unit roof by the sand drain. At the roof edge, the water flows down the wall and at the bottom of the floor flows horizontally back under the SDU. The flow patterns through the saltstone are clearly different for Case A and Case K. For Case A flow through the SDU is essentially vertical for Case K, which modeled increased concrete and saltstone degradation, flow through the SDU is increased and the stream lines are curved. Figure 7 shows flow streamlines converging on the floor joint located to the right of the support column. Figure 8 shows the corresponding flow pattern through the SDU Final Design with Margin for Case K. For the Final Design with Margin a second floor joint is modeled and flow streamlines in Figure 8 converge on both joints. Flow patterns for the SDU Final Design with Margin and for the SDU Final Design with worst case concrete degradation for Case A looked very similar to the results shown in Figure 6. Note that these figures do not show the magnitude of the flow only the flow paths. The actual flow through the concrete roof, saltstone, and concrete floor is small compared to the total infiltration flow. 
s: $\quad 0.20 .30 .40 .50 .60 .70 .80 .9$

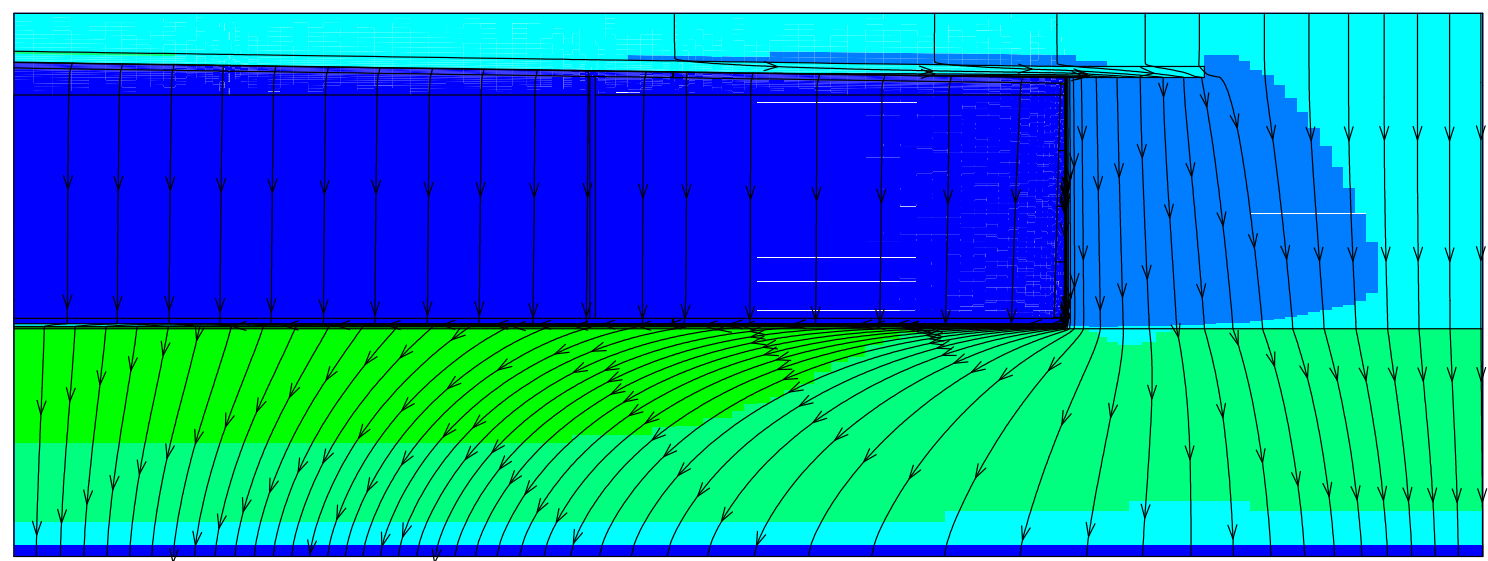

Figure 6. Flow streamlines and water saturation contours for SDU Final Design Case A in the time period $1000-1200$ years.
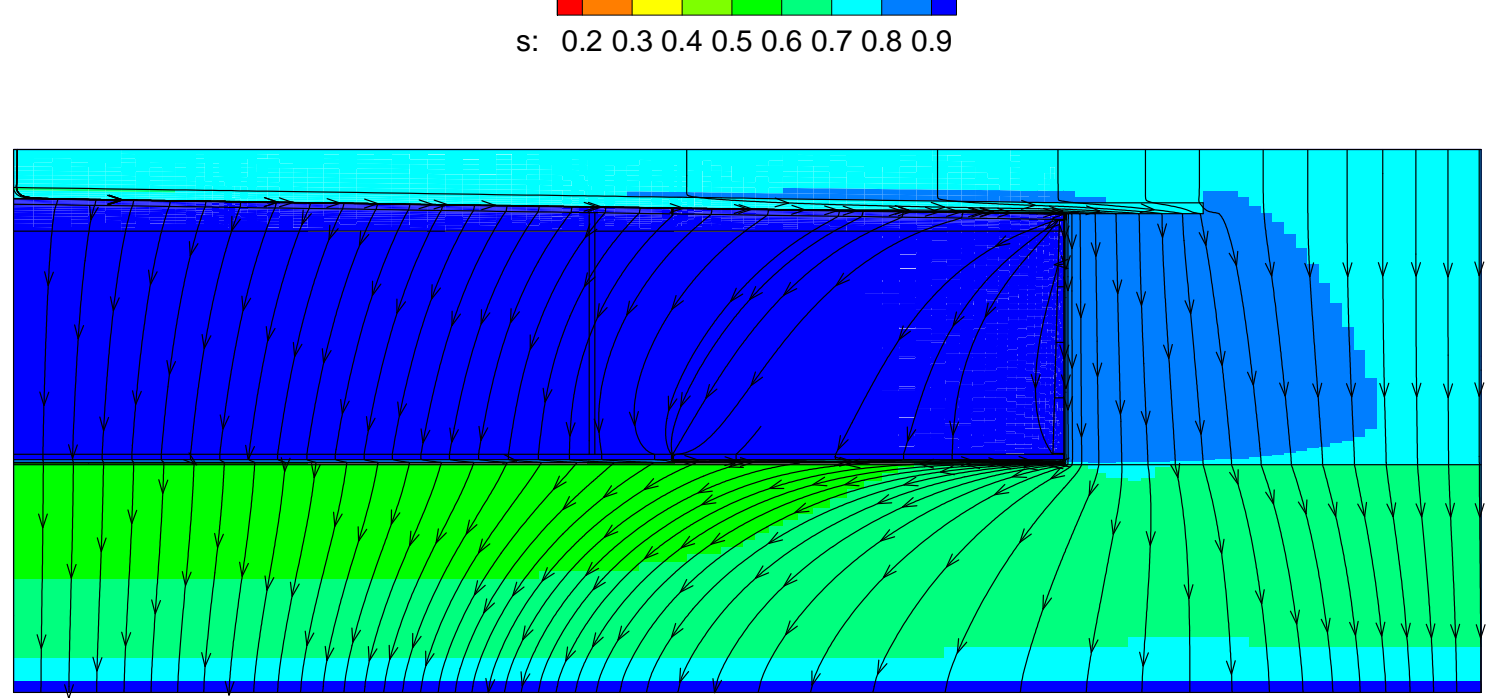

Figure 7. Flow streamlines and water saturation contours for SDU Final Design Case K in the time period $1000-1200$ years. 
s: $\quad 0.20 .30 .40 .50 .60 .70 .80 .9$

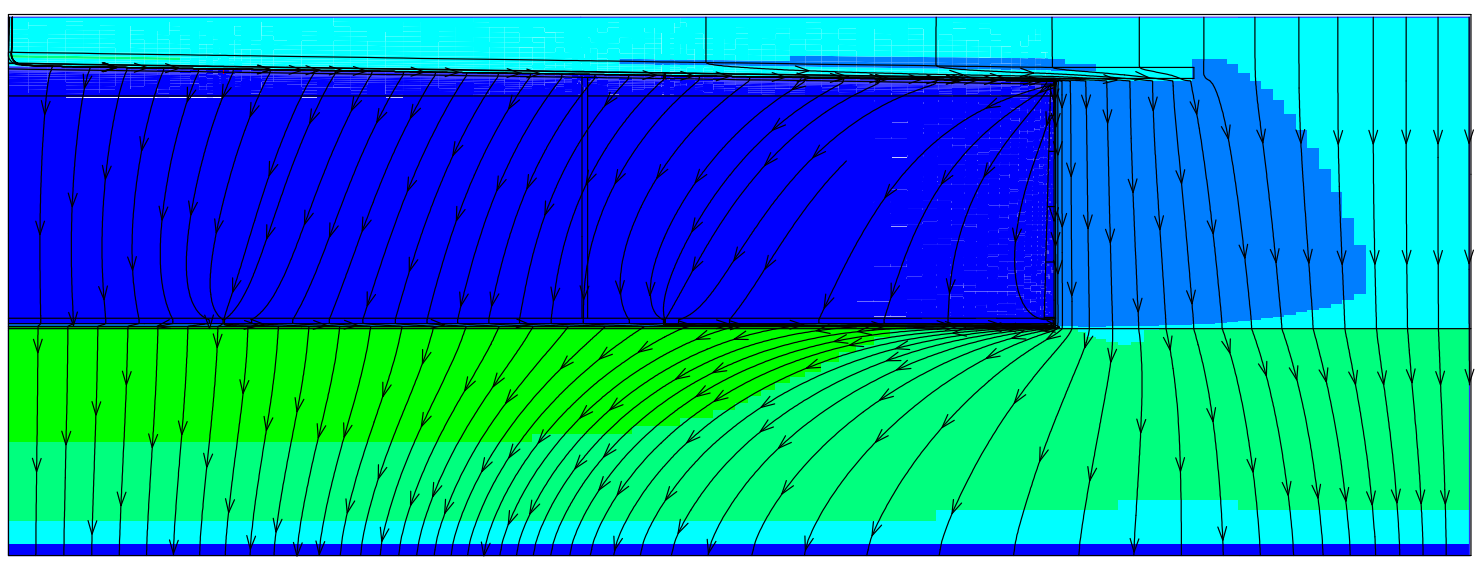

Figure 8. Flow streamlines and water saturation contours for SDU Final Design with Margin Case $\mathrm{K}$ in the time period $1000-1200$ years.

\subsection{Vadose Transport}

Seven of the cases analyzed required vadose zone transport calculations for the SDUs. The two cases simulating relocation of SDU 9 did not require additional vadose zone calculations. The vadose zone transport calculations were performed on the basis of having an inventory of $1.0 \times 10^{21} \mathrm{Ci}$ of each radionuclide in the SDU. Actual inventories for each disposal unit are introduced in the aquifer transport calculation. Selected results from the vadose transport calculations showing fluxes to the water table for the radionuclides Cs-135, I-129, Np-237, Tc-99, Pu-238 and U-238 are plotted in Figure 9 for the SDU Final Design case studies and in Figure 10 for the SDU Final Design with Margin simulations. Figure 9 includes results for the four cases run for the SDU Final Design and plots of the previously calculated fluxes from FDC Case A and Case K for comparison. Figure 10 includes results for the three cases run for the SDU Final Design with Margin and plots the previously calculated fluxes from FDC Case A and Case K and the SDU Final Design Case K results for comparison.

In general, the vadose transport results follow a pattern consistent with expected behavior of the cases and are consistent with the results obtained in a preliminary study examining variations in SDU design (8). As observed in the previous study (8), small releases of radionuclides from the SDU occur early in the transient. This early release results from modeling the joints between the concrete slabs used to form the SDU roof and floor as open areas which provide small leak paths for water to enter and exit the unit. The PORFLOW model used in this study also modeled a joint between the SDU wall and floor which may add to the leakage. As constructed, these joints will have seals and water stops but, for modeling purposes, the joints were assumed to be gaps between the concrete slabs. As modeled, the joints provide leak paths through the floor that allow water and contaminants to escape from the SDU. 
Examining the I-129 flux in Figure 9, because I-129 was a principal contributor to dose for the Case $\mathrm{K}$ analysis presented in the response to RAI PA-8, the SDU Case K flux is seen to be very similar to the FDC Case K flux. For both types of disposal unit, Case K I-129 releases occur early in the transient and give the highest fluxes peaking between 6,000 and 10,000 years. The SDU peak flux $\left(\sim 2 \times 10^{-4} \mathrm{Ci} / \mathrm{yr} / \mathrm{Ci}\right)$ is actually lower than the peak flux from the FDC $\left(\sim 3 \times 10^{-4} \mathrm{Ci} / \mathrm{yr} / \mathrm{Ci}\right)$; however, the SDU inventory is about 8.3 times that of a single FDC unit and occupies the ground space of approximately four FDC units. For the Case A scenarios, FDCs have a marked spike in flux at 15,000 years when the hydraulic conductivity of the wall significantly increases due to concrete degradation. SDU results assuming maximum concrete degradation prior to the start of the simulation (Case A Sensitivity) show a similar spike in flux at 12,000 years when the hydraulic properties of floor and the upper section of the wall in contact with the saltstone experience significant degradation. Peak fluxes for SDU Case A are relatively low throughout the transient because none of the concrete structures fully degrade within 20,000 years. Fluxes from SDU Case A using $\mathrm{K}_{\mathrm{d}}$ values updated to those used for Case $\mathrm{K}$ are slightly lower than fluxes from the nominal SDU Case A calculation.

For Np-237 and Tc-99, the SDU model predicts small but observable releases of material through the floor joints early in the transient, whereas the FDC Case A model used in the 2009 PA predicts essentially no releases until around 15,000 years when the disposal unit wall is fully degraded. Case $\mathrm{K}$ fluxes from the SDU for these two radionuclides are greater than those from a FDC for the first 5,000 to 10,000 years. However, peak fluxes over the 20,000 year period of assessment are higher from the FDC for Tc-99 and almost identical for Np-237. For U-238, fluxes to the water table from SDU Case K start about 2,000 years earlier than fluxes from the FDC design but both sets of fluxes converge around 14,000 years and remain similar thereafter.

Flux profiles for the SDU Final Design with Margin plotted in Figure 10 are not significantly different from the SDU Final Design fluxes plotted in Figure 9. In Figure 10, results for Case K from both SDU designs are plotted for comparison. For most radionuclides, the two Case $\mathrm{K}$ flux profiles are very similar. There is some divergence of the fluxes for Np-237 at 8,000 years. The I-129 peak flux is slightly higher for the SDU Final Design when compared to the SDU Final Design with Margin. The SDU Final Design with Margin has higher I-129 fluxes earlier in the transient which lead to a reduction in the peak flux. 
SRNL-STI-2012-00445, Rev. 0
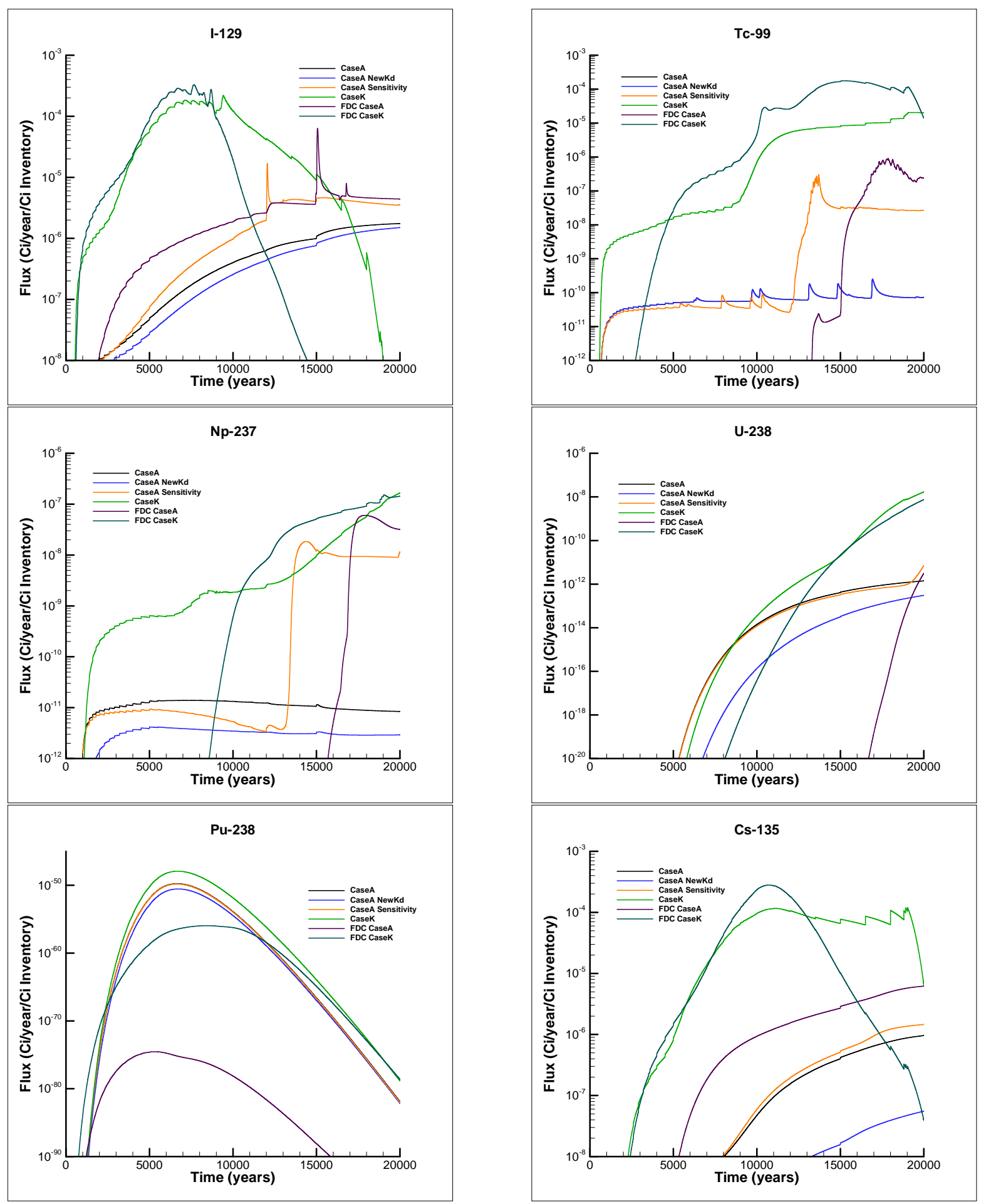

Figure 9. Fluxes to water table for six radionuclides for SDU Final Design case studies and FDC Case A and Case K. 
SRNL-STI-2012-00445, Rev. 0
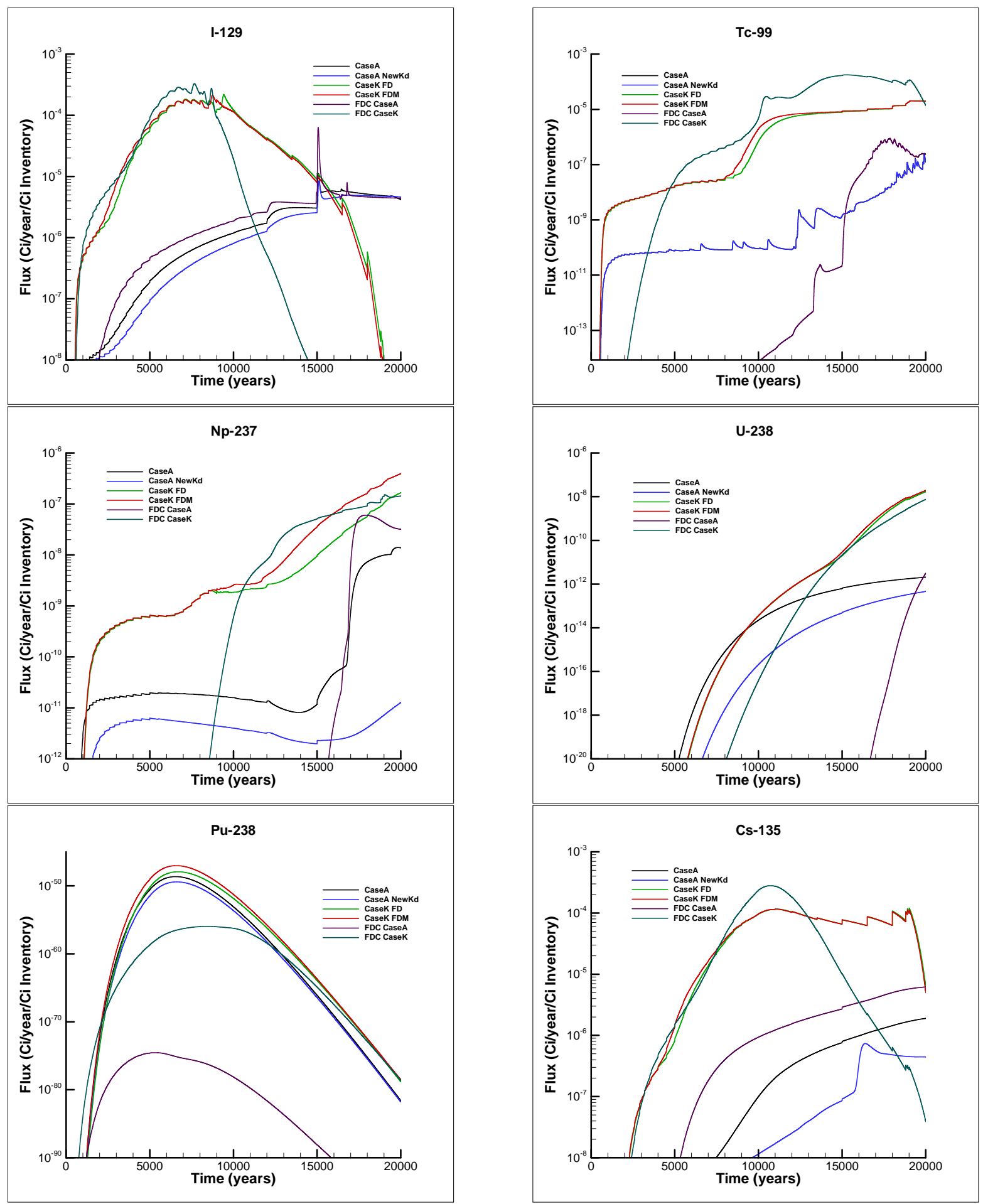

Figure 10. Fluxes to water table for six radionuclides for SDU Final Design with Margin case studies, SDU Final Design Case K, and FDC Case A and Case K. 


\subsection{Aquifer Transport}

PORFLOW aquifer calculations were made using the same computational mesh employed for the 2009 Saltstone PA calculations. The model domain for the Saltstone Disposal Facility (SDF) is shown in Figure 11 in relationship to the full General Separations Area (GSA) aquifer model. The SDF aquifer model is 74 nodes in the horizontal direction by 94 nodes in the vertical direction by 18 nodes deep. Resolution in the surface cells is 50 feet by 50 feet while depth resolution varies with local topography. The groundwater flow in the model is based on the average infiltration measured over the entire GSA.

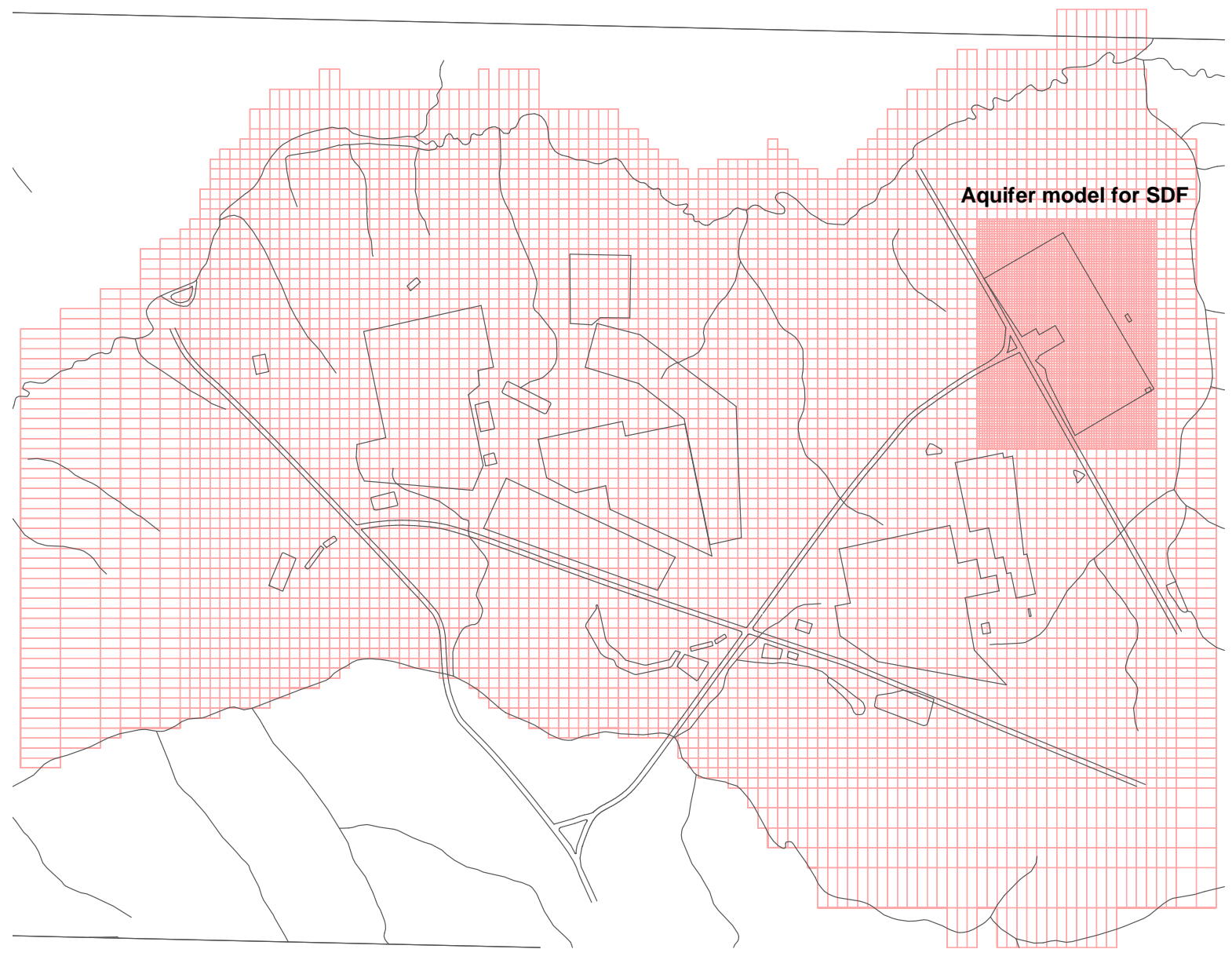

Figure 11. PORFLOW groundwater aquifer model for the GSA and the SDF submodel.

Figure 12 shows the SDF PORFLOW model with the initial proposed layout of SDUs along with existing disposal units, the $100 \mathrm{~m}$ boundary and boundary sectors. The existing disposal units are Vault 1, Vault 4, and FDCs 2A, 2B, 3A, 3B, 5A, and 5B. Seven SDUs, designated as SDU 6 through SDU 12, are included in the model. The $100 \mathrm{~m}$ boundary has been recalculated for the change from FDCs to SDUs. However, the angles used to define the sectors along the boundary are the same as those used in the PA. The sector distribution will likely be revised in the final PA calculation. 
SRNL-STI-2012-00445, Rev. 0

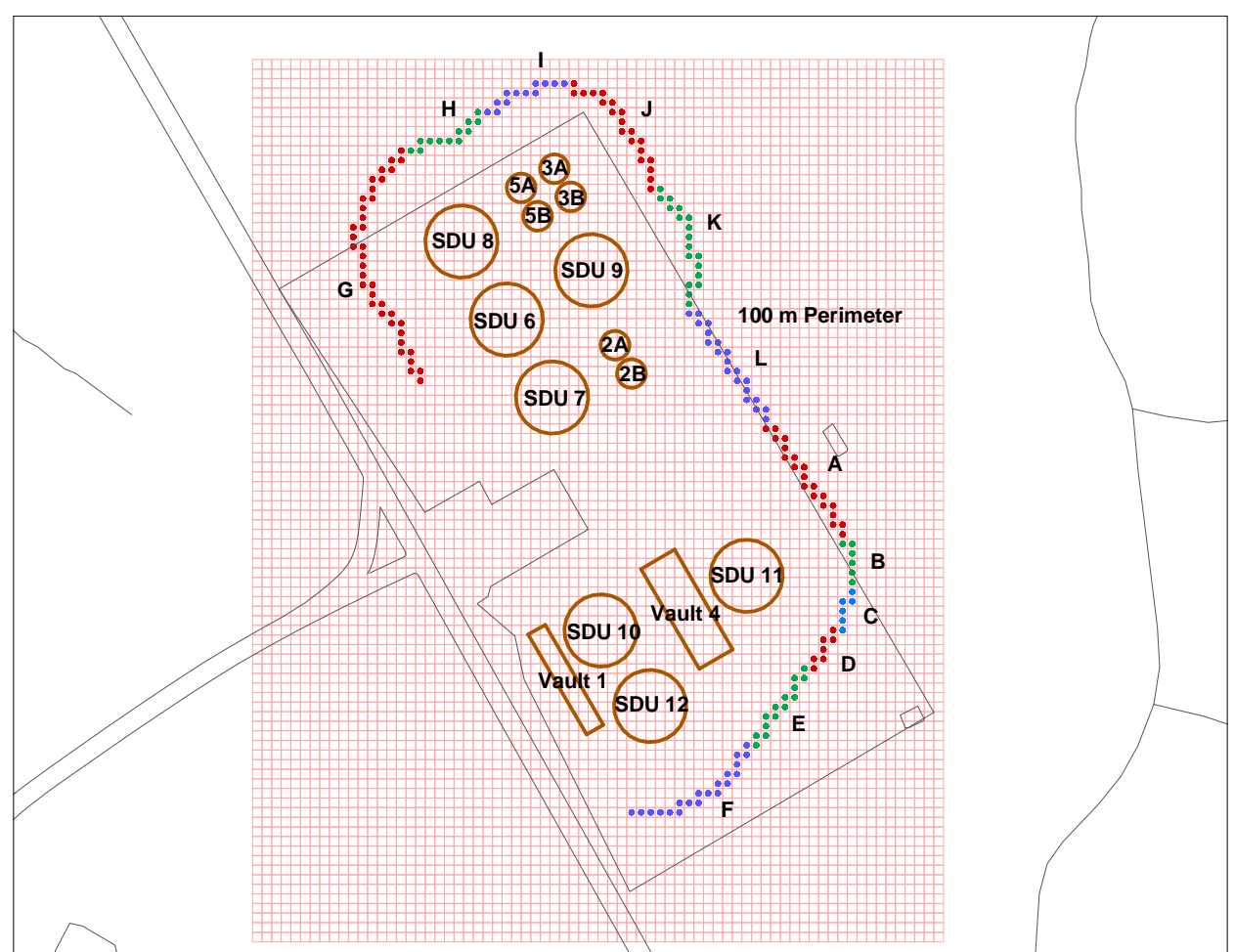

Figure 12. PORFLOW model for SDF showing initial proposed layout of SDUs, existing disposal units, the $100 \mathrm{~m}$ boundary and boundary sectors.

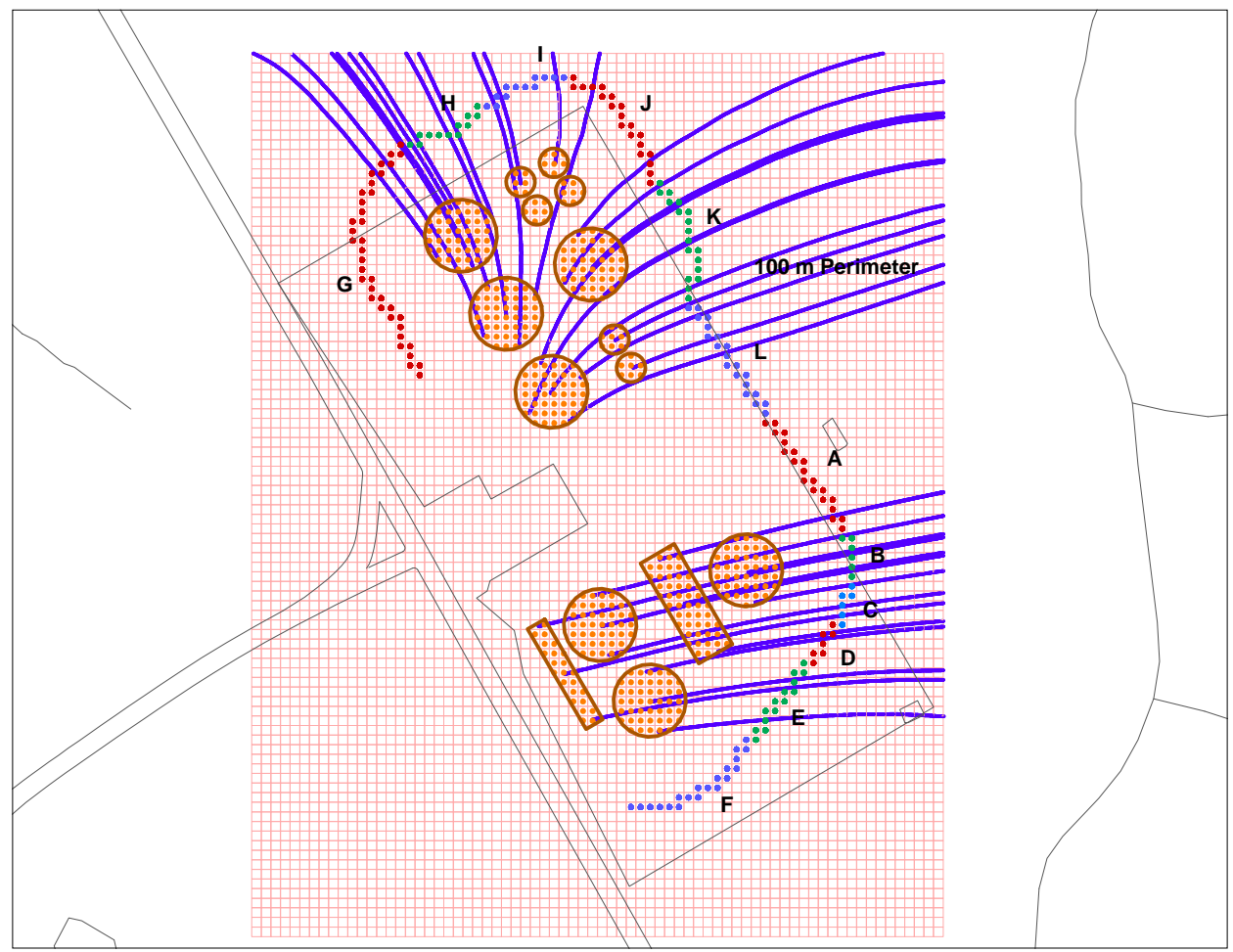

Figure 13. PORFLOW model for SDF showing aquifer flow streamlines. 
Figure 13, plots a few aquifer flow streamlines from each source to provide a sense of the direction of movement of radionuclides from the sources once they reach the groundwater.

Two sensitivity studies were performed to evaluate the relocation of SDU 9. Peak concentrations at the $100 \mathrm{~m}$ boundary obtained from the nominal configuration shown in Figure 12 occurred in the northern sectors. To reduce peak concentrations, SDU 9 was relocated to the extreme southwest corner of the SDF, where FDCs 18A-18D were originally intended to be located [5]; and, for the second sensitivity study, SDU 9 was positioned midway between the original SDU 9 location and SDU 11. The latter relocation position is not a realistic choice because it would interfere with the SDF closure cap placement which would be in two segments covering the northern disposal units and southern disposal units separately. However, this calculation is still useful because it provided information on the sensitivity of results to SDU location. The revised models with SDU 9 relocated and the $100 \mathrm{~m}$ boundaries recalculated for each case are shown in Figures 14 and 15.

As shown in Appendix A, 27 radionuclides appear in the analysis as either one of the 20 parent radionuclides specified for analysis or daughters. If individual daughter radionuclides are considered as separate species (e.g. Ra-226 from Pu-238 and Ra-226 from $\mathrm{U}-238$ ), the number of radionuclides in the analysis increases to 68 . However, it would seem to be more meaningful to consider the total concentration of each radionuclide. In any event, plotting results for 27 radionuclides and nine case studies would still require 243 plots. Therefore, it was decided to only plot concentration contours for 12 radionuclides for each case study to show representative results from the aquifer transport calculations. The 12 radionuclides selected for plotting were: Ac-227, Cm-245, Cs-135, I-129, Np-237, Pa231, Pb-210, Pu-238, Ra-226, Tc-99, Th-230 and U-238. Based on the SDF PA results and the results presented in the response to RAI PA-8, I-129 and Ra-226 are the principal contributors to the peak dose for Case A; and Cs-135, I-129 and Tc-99 are the principal contributors to dose for Case $\mathrm{K}$.

Concentration contour plots for the 12 radionuclides from each case study are presented in Appendix D. The plots show total concentrations in cases where there may be more than one parent for the radionuclide. Because a large number of plots were to be made, the plotting was automated by revising an existing Fortran program that created Tecplot input files. As part of this process, the code was modified to automatically choose nine contour levels spanning three orders of magnitude closest to the maximum concentration. The disadvantage of automation is that each plot can have a different set of contour values making comparison of results between cases more difficult. For reference, each plot shows the saltstone disposal unit layout and the $100 \mathrm{~m}$ boundary. The initial PORFLOW runs were made saving concentration histories at 100,1000, and 20,000 years. Subsequent dose calculations showed that peak doses occurred around 8,000 years. Therefore, the last two case studies saved concentration histories at 100, 1000 and 10,000 years. The contour plots for these two cases were made at 10,000 years which is close to the time of maximum peak concentration. Plots for the other seven cases are shown at 20,000 years. 
SRNL-STI-2012-00445, Rev. 0

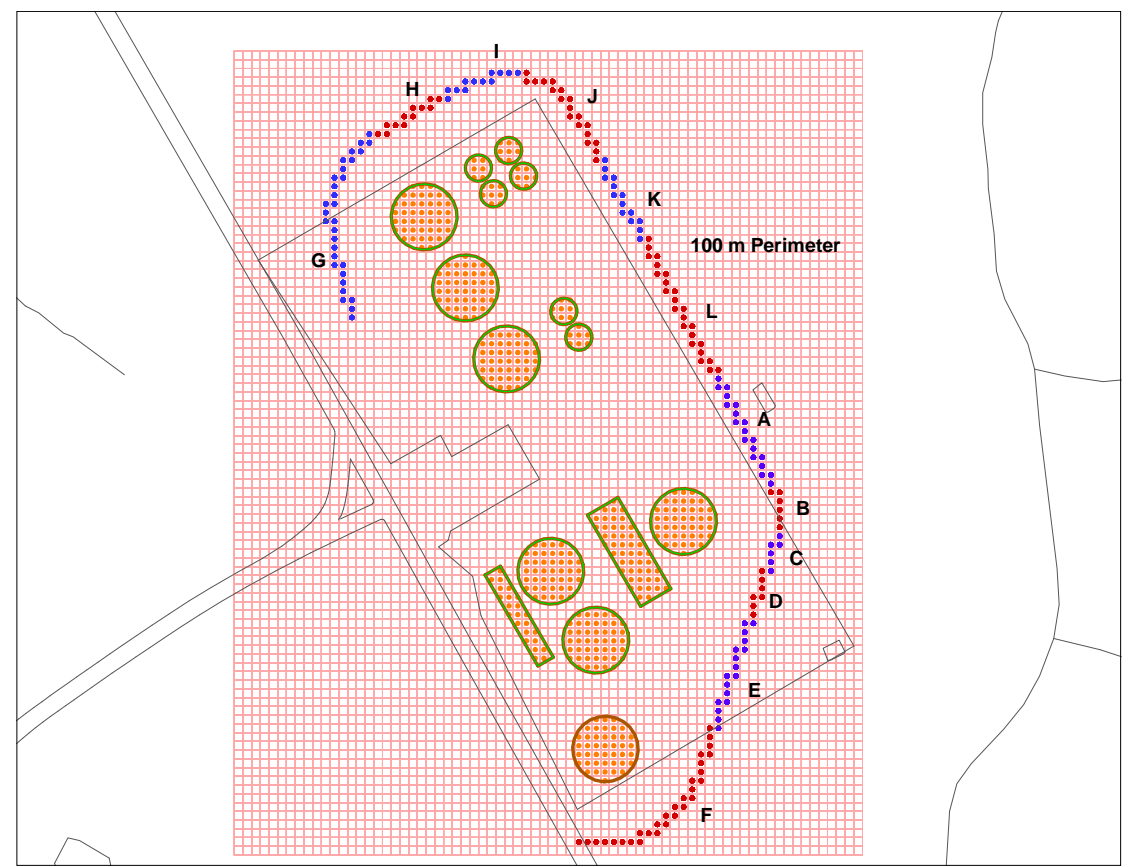

Figure 14. Source locations and $100 \mathrm{~m}$ boundary with SDU 9 relocated to southwest corner of SDF.

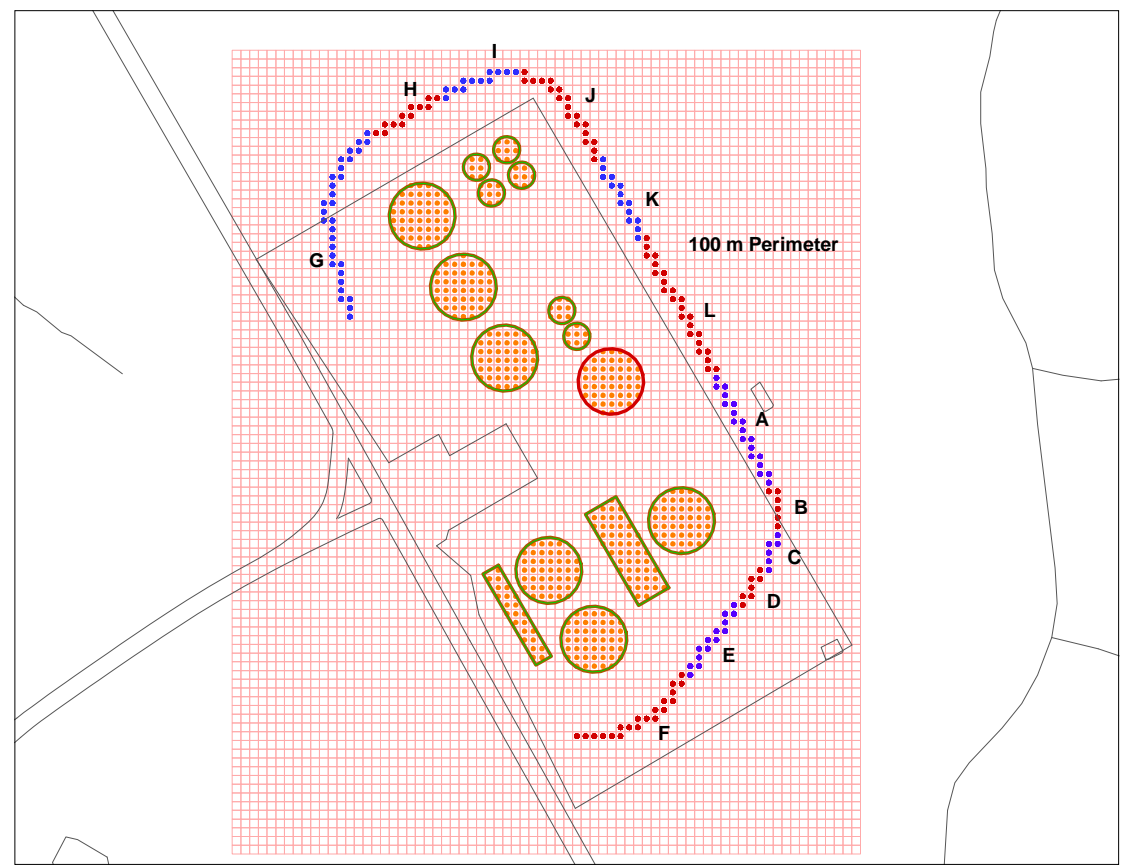

Figure 15. Source locations and $100 \mathrm{~m}$ boundary with SDU 9 relocated midway between original location and SDU 11. 
The following paragraphs give a brief description of the concentration results plotted in Appendix D. While the results appear to be qualitatively correct and consistent, a caution in viewing the plots is that, except for the two cases examining the impact from relocating SDU 9, the concentrations are plotted at 20,000 years which is well past the time at which peak concentrations were reached. Therefore, the plotted concentrations do not correspond to the values used for dose calculations. The PORFLOW calculations saved peak concentrations at each mesh point along the $100 \mathrm{~m}$ boundary at each time step but only saved a limited number of complete concentrations over the entire computational grid. Maximum concentrations at any vertical layer in the three-dimensional mesh are used to make the two-dimensional contour plots. Peak concentrations recorded at any time are used for dose calculations while the contour plots of concentration profiles are valuable in giving a snapshot of the contamination plume showing how the plume has developed and identifying the most significant sources.

Comparing concentration profiles for the SDU Final Design Case A in Appendix D.1 with those for the SDU Final Design Case K in Appendix D.2 shows that, in general, Case K produces higher concentrations along the $100 \mathrm{~m}$ boundary. In particular, the I-129 contour levels for Case $\mathrm{K}$ at 20,000 years are 100 times the values for Case A so a significant increase in concentration along the boundary is readily evident. Similarly, for Pa-231, the Case K contours are plotted at values 10 times those of the Case A contours. The similar appearance of contours from the southern group of disposal units indicates higher concentrations for Case $\mathrm{K}$ by approximately an order of magnitude. Tc-99 concentrations from the Case $\mathrm{K}$ simulation are also significantly higher than those from Case A.

Examining the results in Appendix D.3, when SDU 9 is relocated to the southwest corner of the SDF, a separate plume from the SDU 9 source is readily apparent for several of the radionuclides. This means that not only has the SDU 9 source been removed from the northern group, where contamination released from SDU 9 mixed with that from the other nearby sources, but the SDU 9 plume is not mixing significantly with the combined plume from the other disposal units in the southern group. Therefore, relocating an SDU to this location is likely to result in less potential dose while utilizing space within the SDF. Comparing the contour plots in Appendix D.4 with those in Appendix D.3 a distinct plume from SDU 9 is not evident when it is located in the middle of the SDF. Examining the I-129 results, placing SDU 9 in the middle has clearly increased concentrations in the region where Sectors L and A meet. However, it is not clear from the contour plots alone if peak concentrations in either sector have increased.

The results obtained using updated Case $\mathrm{K} \mathrm{K}_{\mathrm{d}}$ values in a Case A simulation plotted in Appendix D.5 do not appear to significantly increase concentrations along the $100 \mathrm{~m}$ boundary compared to concentrations shown in Appendix D.1. $K_{d}$ values for Tc-99 and Cm-245 did not change in soil or oxidizing concrete and the concentration profiles for these radionuclides are identical in both sets of plots. $K_{d}$ values for Ac-227 and Th-230 also did not change but these radionuclides are in decay chains so are influenced by the transport of parent radionuclides. $K_{d}$ values for all of the other radionuclides plotted changed to some degree and consequently show differences in the concentration profiles. While the $\mathrm{K}_{\mathrm{d}}$ 
values for I-129 in soil did change they are still small and the contours for both cases are very similar but not identical.

Comparing results obtained with the worst case concrete degradation scenario (i.e. the sensitivity case in Table 3) plotted in Appendix D.6 to the nominal Case A results in Appendix D.1 does not show a significant difference. In all cases, the radionuclide contour plots in Appendix D.6 are on the same scale as the corresponding plot in Appendix D.1 so a direct comparison between the two sets of plots is possible. The increased concrete degradation prior to closure is only applied to the SDUs. Therefore, releases that are primarily from Vault 1 and Vault 4 do not show any change. The biggest impact from the increased SDU concrete degradation is in the northern group of disposal units where the three SDUs dominate the overall releases. Increased release of Ac-227, Pa-231, I-129, Np237, $\mathrm{Pb}-210, \mathrm{Ra}-226$ and Tc-99 from all SDUs is apparent with concrete degradation. However, maximum concentrations along the $100 \mathrm{~m}$ boundary are generally in the same range for both cases.

Results obtained with the Case A scenario for the SDU Final Design with Margin are plotted in Appendix D.7. These results are very similar to those obtained with the worst case concrete degradation case presented in Appendix D.6. Again, this scenario only impacts releases from the SDUs so essentially no change from the nominal Case A results are expected for $\mathrm{Cm}-245, \mathrm{Cs}-135, \mathrm{U}-238, \mathrm{Pu}-238$ and $\mathrm{Th}-230$ where the releases are dominated by Vault 1 and Vault 4. Except for I-129 and Tc-99, it is difficult to tell any difference between the results from the SDU Final Design with Margin and the concrete degradation sensitivity case. For I-129 and Tc-99, the SDU Final Design with Margin appears to give slightly higher releases. As shown in Table 3, the concrete degradation scenario reduced the initial 12 inch floor thickness by 3.4 inches leaving 8.6 inches of concrete which is nearly the same as the 9 inch floor thickness in the SDU Final Design with Margin. The increased release of I-129 and Tc-99 from the SDU Final Design with Margin is likely the result of the increased floor joint length.

Comparing results obtained with the Case K scenario for the SDU Final Design with Margin plotted in Appendix D.8 to the nominal Case K results in Appendix D.2 shows similar behavior to that observed for the Case A results discussed in the preceding paragraph. In this case, some small differences between the two cases can be seen in the I-129, Np-239 and Tc-99 concentration contours. The two sets of plots are all on the same scale so can be compared directly. On the whole, there does not appear to be a significant difference in the results obtained with the two SDU design specifications.

Finally, the results show in Appendix D.9 for the SDU Final Design with Margin Case A using Case $\mathrm{K} \mathrm{K}_{\mathrm{d}}$ values are in most cases very similar to the corresponding results for the SDU Final Design plotted in Appendix D.5. A larger relative increase in the release of I129 and Tc-99 is observed for the SDU Final Design with Margin for this case than was observed for the other two design comparisons. 


\subsection{Conclusions}

PORFLOW modeling has been used to predict the performance of the proposed 32 million gallon SDU disposal unit design. The calculations first simulated infiltration flow and radionuclide transport through an SDU and the vadose zone below the disposal unit for the two sets of SDU design parameters shown in Table 2. Vadose zone simulations were run for Case A, which was the nominal 2009 PA case, and for Case K which was a case developed in response to the NRC RAI. Sensitivity studies were also performed to predict the change in performance resulting from increased concrete degradation and using updated $\mathrm{K}_{\mathrm{d}}$ values.

The vadose zone transport calculations provided radionuclide fluxes to the water table from an SDU. These were used as input to a PORFLOW model of aquifer transport along with fluxes calculated in previous work for existing saltstone Vaults 1 and 4, and FDC disposal units to calculate radionuclide concentrations in the groundwater. The aquifer model included releases from Vault 1, Vault 4, six existing FDC disposal cells, and seven proposed SDUs in the configuration shown in Figure 12 and calculated peak radionuclide concentrations within 12 sectors along a boundary located $100 \mathrm{~m}$ from the sources. Two additional aquifer transport calculations were performed to evaluate the impact from relocating SDU 9 to two alternative positions within the SDF. The $100 \mathrm{~m}$ boundary was repositioned for these two cases to account for the changes in disposal unit configuration.

Results from these calculations were stored on the SRNL high performance computing system and made available to SRR for dose calculations. A summary of the PORFLOW calculations is provided in this report. In particular, a set of concentration contours showing radionuclide release patterns for all of the nine scenarios investigated in this study is provided in Appendix D.

Key findings from the PORFLOW analysis are:

Significant reductions in peak radionuclide concentrations along the $100 \mathrm{~m}$ boundary were achieved by relocating SDU 9 from the northern group of disposal units to the extreme southwest corner of the SDF. The PORFLOW calculations indicated that locating a SDU in the southwest corner is particularly advantageous since it minimizes interaction between the disposal unit at this location and the other disposal units.

Peak radionuclide concentrations for the SDU Final Design and Final Design with Margin did not appear to be significantly different. 


\subsection{References}

1. Rosenberger, K. H., “30 Million Gallon Saltstone Disposal Unit Preliminary Design PORFLOW Modeling,” Task Technical Request, HLW-SSF-TTR-2012-0018, Rev. 0, March 29, 2012.

2. Clendenen, G. B., "SDU-6 Modeling Inputs for Preliminary PA Modeling," SRR-SDU2012-00021, Rev. 0, April 11, 2012.

3. Smith, F. G., "Task Technical and Quality Assurance Plan for SDU Preliminary Design PORFLOW Modeling," SRNL-RP-2012-00190, Rev. 0, April 23, 2012.

4. Smith, F. G., "Design Check Package Associated with PORFLOW Calculations for Saltstone Disposal Unit Design," SRNL-L4220-2012-00006, Rev. 0, June 28, 2012.

5. "Performance Assessment for the Saltstone Disposal Facility at the Savannah River Site," SRR-CWDA-2009-00017, Rev. 0, October, 2009.

6. Levitt, M. "Concrete Materials: Problems and Solutions," Taylor \& Francis e-Library. 2003.

7. Sappington, F. C., and M. A. Phifer. "Moisture Content and Porosity of Concrete Rubble Study,” WSRC-TR-2005-00054, Rev. 0, October 2005.

8. Smith, F. G., "SDU 6 Modeling Study to Support Design Development," SRNL-STI2012-00219, Rev. 0, May 2, 2012.

9. SRR-CWDA-2011-00044, Comment Response Matrix for Nuclear Regulatory Commission RAI-2009-02 Second Request for Additional Information (RAI) on the Saltstone Disposal Facility Performance Assessment (SRR-CWDA-2009-00017, Revision 0, dated October 29, 2009), Savannah River Site, Aiken, SC, Rev. 1, August $25,2011$. 


\section{Appendix A Radionuclides and Daughters Included in Analysis}

\begin{tabular}{|c|c|c|c|c|c|}
\hline \multirow{2}{*}{ Radionuclide } & \multicolumn{5}{|c|}{ Parents } \\
\hline & & & & & \\
\hline $\mathrm{Cm}-244$ & & & & & \\
\hline $\mathrm{Cm}-245$ & & & & & \\
\hline Cs-135 & & & & & \\
\hline I-129 & & & & & \\
\hline $\mathrm{Nb}-93 \mathrm{~m}$ & & & & & \\
\hline $\mathrm{Pu}-238$ & & & & & \\
\hline $\mathrm{Pu}-244$ & & & & & \\
\hline U-238 & & & & & \\
\hline Tc-99 & & & & & \\
\hline Ac- $227^{1}$ & Am-243 & $\mathrm{Pu}-239$ & U-235 & & \\
\hline Am-241 & $\mathrm{Cm}-245$ & $\mathrm{Pu}-241$ & & & \\
\hline $\mathrm{Np}-237$ & Am-241 & $\mathrm{Cm}-245$ & $\mathrm{Pu}-241$ & & \\
\hline $\mathrm{Pa}-231^{1}$ & Am-243 & $\mathrm{Pu}-239$ & U-235 & & \\
\hline $\mathrm{Pb}-210^{1}$ & $\mathrm{Pu}-238$ & U-234 & U-238 & Th-230 & \\
\hline $\mathrm{Pu}-239$ & Am-243 & & & & \\
\hline $\mathrm{Pu}-240$ & $\mathrm{Cm}-244$ & $\mathrm{Pu}-244$ & & & \\
\hline $\mathrm{Pu}-241$ & $\mathrm{Cm}-245$ & & & & \\
\hline $\mathrm{Ra}-226^{1}$ & $\mathrm{Pu}-238$ & U-234 & U-238 & Th-230 & \\
\hline $\mathrm{Ra}-228^{1}$ & $\mathrm{Cm}-244$ & $\mathrm{Pu}-240$ & $\mathrm{Pu}-244$ & & \\
\hline U-233 & Am-241 & $\mathrm{Cm}-245$ & $\mathrm{~Np}-237$ & $\mathrm{Pu}-241$ & \\
\hline U-234 & $\mathrm{Pu}-238$ & U-238 & & & \\
\hline U-235 & Am-243 & $\mathrm{Pu}-239$ & & & \\
\hline $\mathrm{U}-236^{1}$ & $\mathrm{Cm}-244$ & $\mathrm{Pu}-240$ & $\mathrm{Pu}-244$ & & \\
\hline Th-229 & Am-241 & $\mathrm{Cm}-245$ & $\mathrm{~Np}-237$ & $\mathrm{Pu}-241$ & U-233 \\
\hline Th-230 & $\mathrm{Pu}-238$ & U-234 & U-238 & & \\
\hline Th-232 1 & $\mathrm{Cm}-244$ & $\mathrm{Pu}-240$ & $\mathrm{Pu}-244$ & & \\
\hline
\end{tabular}

${ }^{1}$ Seven radionuclides that only occur as daughters 


\section{Appendix B Estimation of Initial Wall Degradation}

Degradation of the concrete wall and floor from sulfate attack immediately after exposure of the concrete to saltstone drain water can be approximately bounded by two scenarios defined by the rate of chemical reaction compared to capillary liquid transport. If dissolved sulfate reacts with concrete minerals much faster than the transport rate, then sulfate cannot advance past the reaction front until all of the local reaction capacity is consumed. Damage front penetration will be controlled by the amount of bleedwater (and sulfate) imbibed into the concrete and the reaction capacity of the concrete minerals. The penetration depth for this fast reaction scenario is calculated using the formula:

$$
x_{1}=\frac{\varphi \delta s L C}{R}
$$

where: $\quad x_{1} \ldots \ldots .$. degraded concrete length (same units as $L$ )

$\varphi$........concrete porosity $(0.11)$,

$\delta$ s.......change in concrete saturation from the assumed initial value of 0.75 to full saturation $(0.285)$,

$L$........ thickness of concrete (units of length),

C......... sulfate concentration $(0.15 \mathrm{~mol} / \mathrm{L})$, and

$R$........ reaction capacity of the concrete $(1.77 \mathrm{~mol} / \mathrm{L})$

The initial saturation value is typical of field exposure conditions (WSRC-TR-2005-00054, Rev. 0). The reaction capacity is derived from Equation (9) of SRNL-STI-2009-00115 Rev. 1. Values of the degraded concrete calculated using this equation proved to be very small, less than 0.05 inches.

On the other hand, if the reaction rate is slow, then sulfate will advance as far as the wetting front before reacting with solids and partially consuming the reaction capacity. An upper bound on the degradation from sulfate attack was estimated by assuming that all of the concrete exposed to imbibed bleedwater under this scenario will be damaged:

$$
x_{2}=\varphi \delta s L
$$

This slow reaction analysis produced damage penetration depths ranging from 2.4 to 5.3 inches depending on the thickness of the wall segment, roughly two orders of magnitude larger than the fast reaction scenario.

Considering this large difference in magnitude, representative blended values for sulfate attack degradation were then obtained by taking the geometric average of $x_{1}$ and $x_{2}$ :

$$
x_{\text {avg }}=\sqrt{x_{1} x_{2}}
$$

This intermediate estimate of the concrete degradation from sulfate attack was then about 0.2 to 0.5 inches and was the same order of magnitude as the assumed $1.0 \mathrm{~cm}(0.4 \mathrm{in})$ surface cracking. Adding the two values was used as an estimate of the total concrete degradation at the start of the analysis. 


\section{Appendix C Equivalent Gravel Flow Path for Roof and Floor Joints}

Joints in the roof and floor of SDU and the joint between the wall and floor are assumed to be $0.455 \mathrm{~mm}$ gaps between the concrete slabs. Watertight structures are designed to have cracks of less than $0.2 \mathrm{~mm}$ and the SDU joints will have water-stops installed. The assumption of a $0.455 \mathrm{~mm}$ gap, which, as shown below, is equivalent to 2.0 inches of gravel, appears to be reasonable and is made to obtain a convenient model dimension. If a better basis for the assumed gap size can be established, it will be applied in future analysis.

The saturated hydraulic conductivity for an aperture of width $x$ is given by:

$$
K_{s a t}=\frac{\rho g x^{2}}{12 \eta}
$$

where: $\quad x \ldots \ldots \ldots$......aperture width $(\mathrm{m})$

$g \quad$.......gravitational constant, $9.81\left(\mathrm{~m} / \mathrm{s}^{2}\right)$

$\rho$........density of water, $998\left(\mathrm{~kg} / \mathrm{m}^{3}\right)$

$\eta$........ viscosity of water, $0.001002(\mathrm{~kg} / \mathrm{m}-\mathrm{s})$

For a $0.455 \mathrm{~mm}$ aperture, this equation gives a saturated conductivity of $0.169 \mathrm{~m} / \mathrm{s}$.

Gravel has a saturated conductivity of $0.15 \mathrm{~cm} / \mathrm{s}$. Therefore, the equivalent gravel width for a $0.455 \mathrm{~mm}$ aperture would be:

$$
b(0.0015 \mathrm{~m} / \mathrm{s})=(0.455 \mathrm{~mm})(0.169 \mathrm{~m} / \mathrm{s})
$$

Which gives an equivalent gravel width of $51.3 \mathrm{~mm}$ or 2.0 inches. Obviously, the choice of a $0.455 \mathrm{~mm}$ gap was made to produce a convenient 2.0 inch equivalent gravel width. While the aperture width of approximately $0.5 \mathrm{~mm}$ does not seem unreasonable, as mentioned above, this assumption was made for convenience and is not based on any physical evidence. 


\section{Appendix D Contour Plots of Radionuclide Concentrations}

\section{D.1 Concentration Profiles for SDU Final Design Case A at 20,000 years}

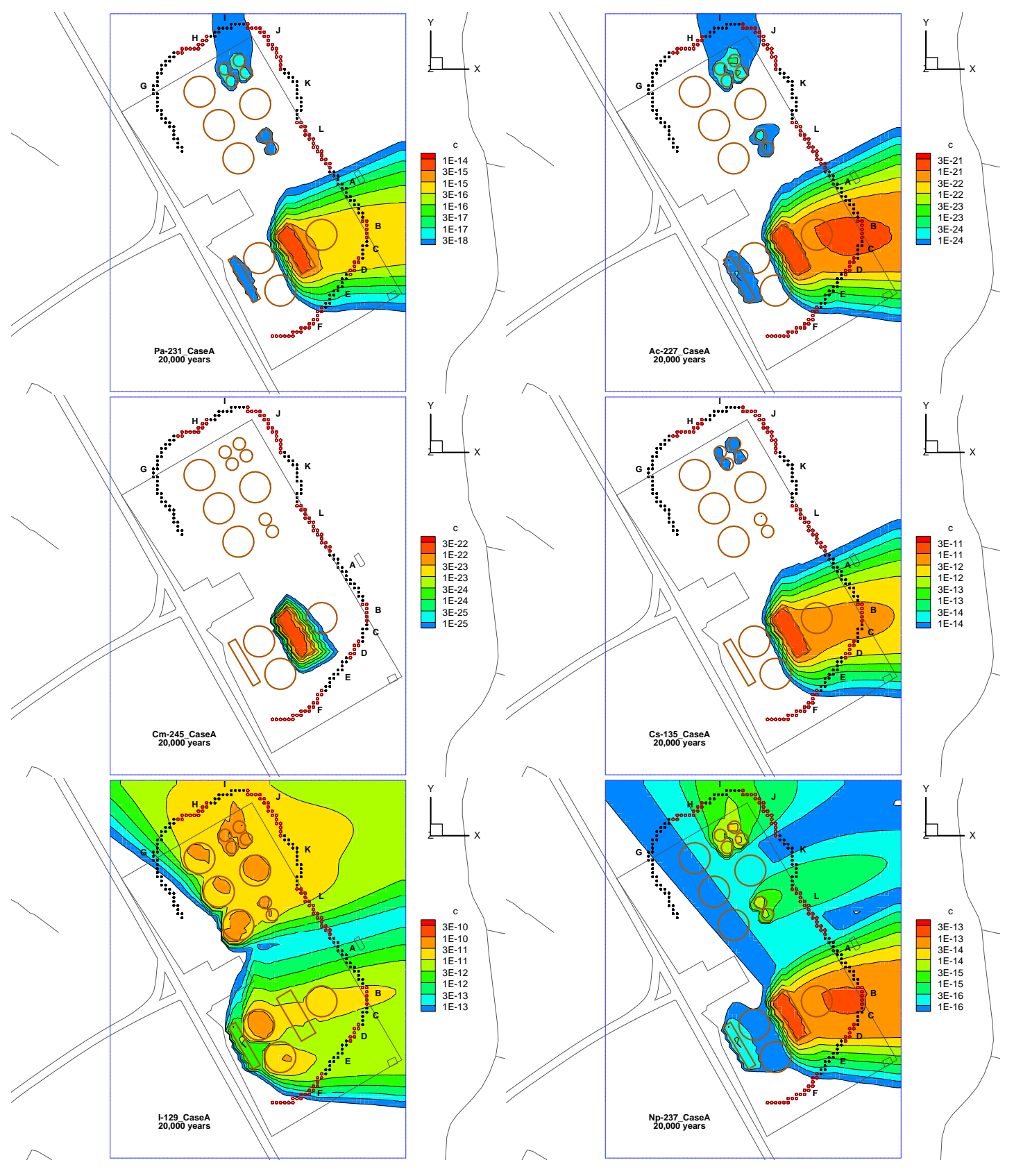




\section{D.1 Concentration Profiles for SDU Final Design Case A at 20,000 years (continued)}

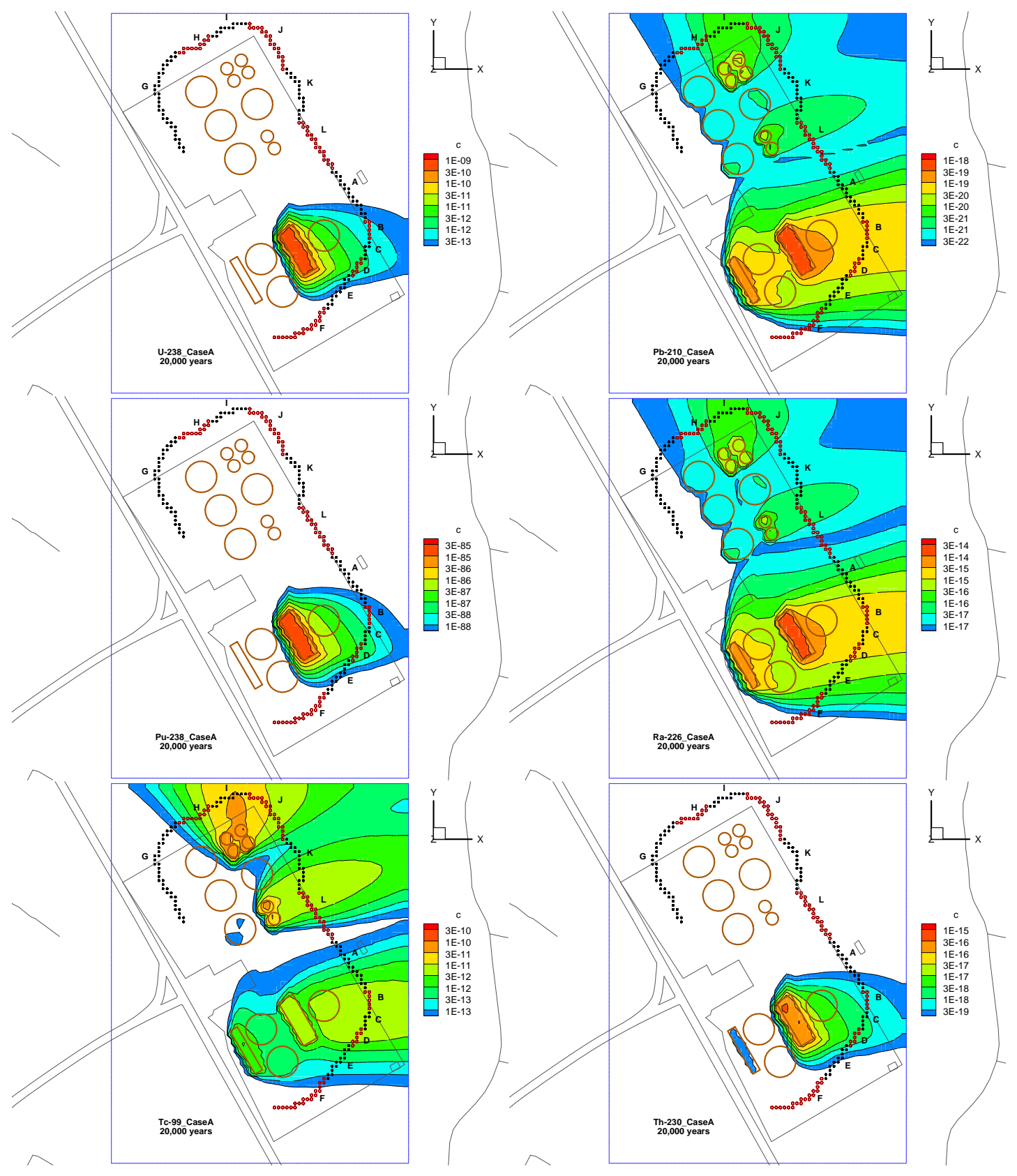




\section{D.2 Concentration Profiles for SDU Final Design Case $\mathrm{K}$ at 20,000 years}
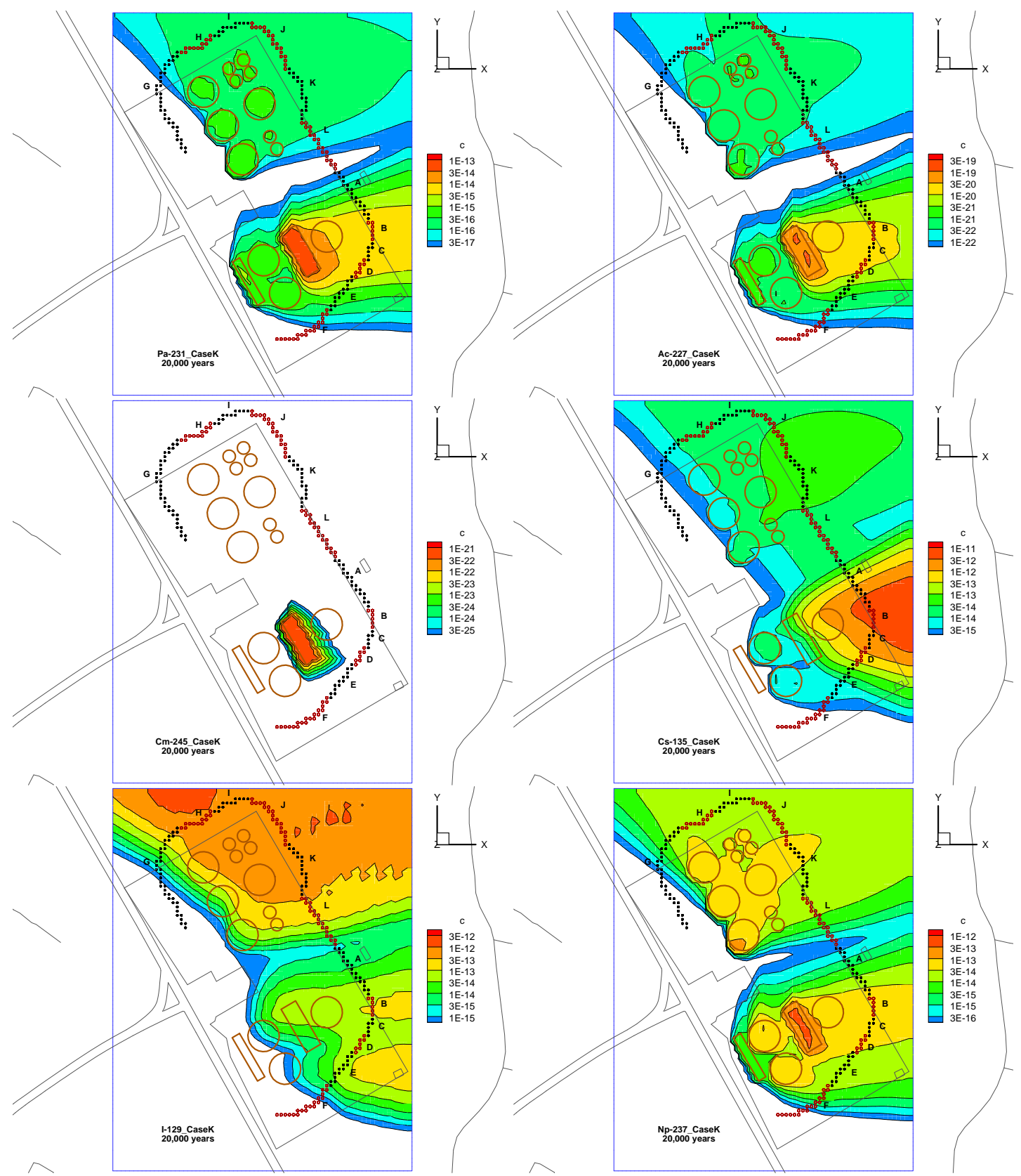


\section{D.2 Concentration Profiles for SDU Final Design Case $\mathrm{K}$ at 20,000 years (continued)}

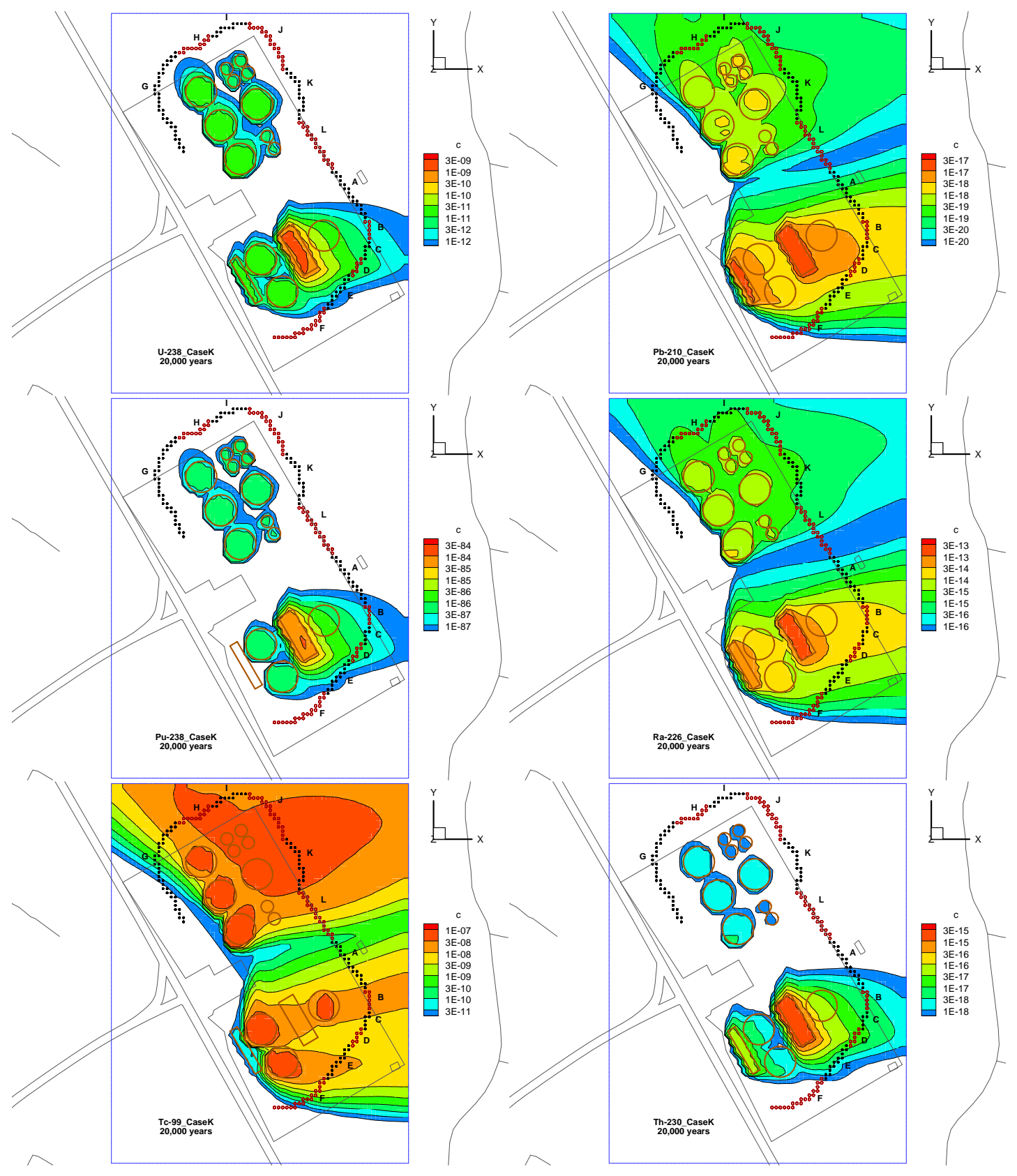




\section{D.3 Concentration Profiles for SDU Final Design Case K with SDU 9 Relocated to Southwest Corner of SDF at 10,000 years}

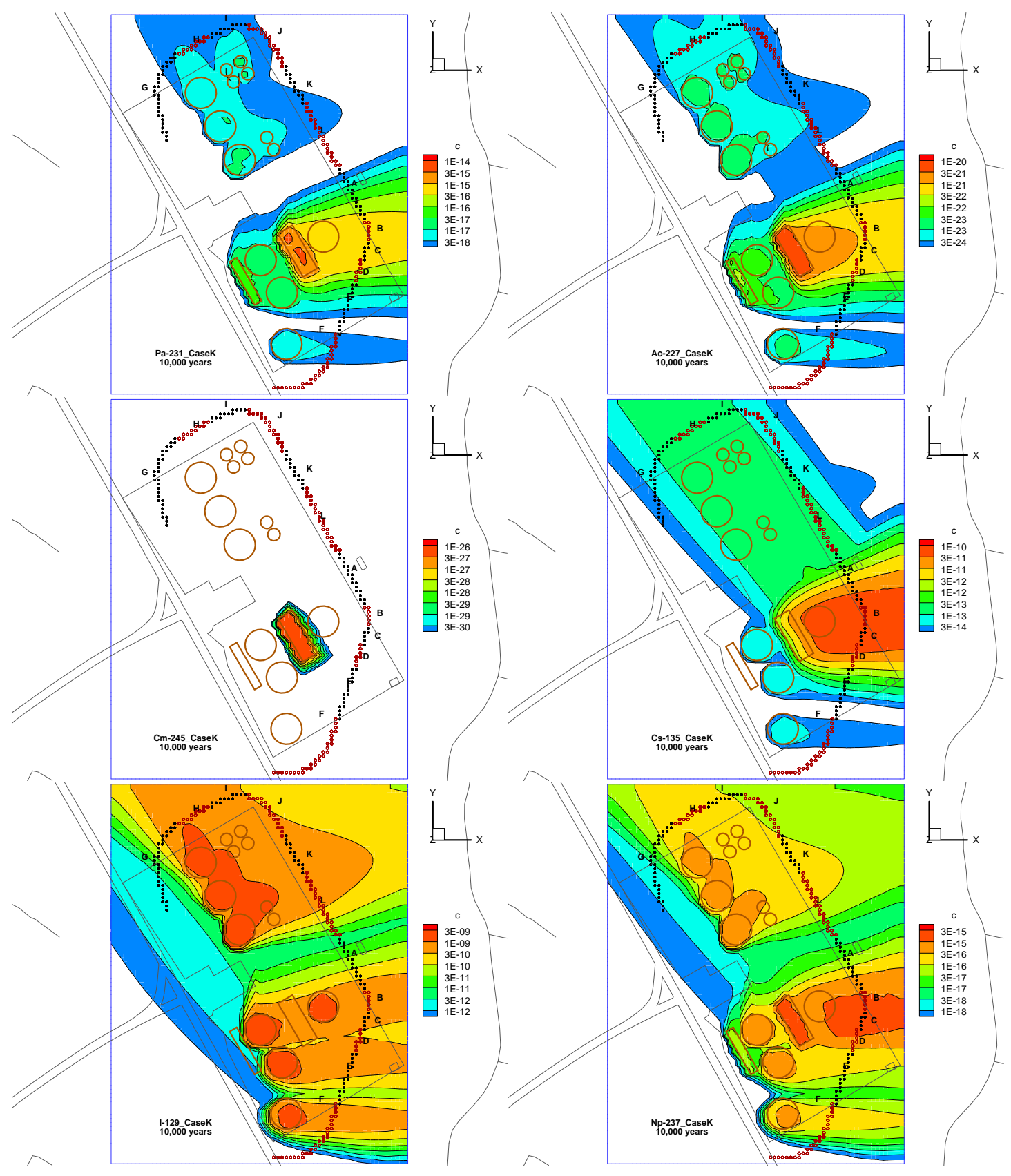




\section{D.3 Concentration Profiles for SDU Final Design Case K with SDU 9 Relocated to Southwest Corner of SDF at 10,000 years (continued)}

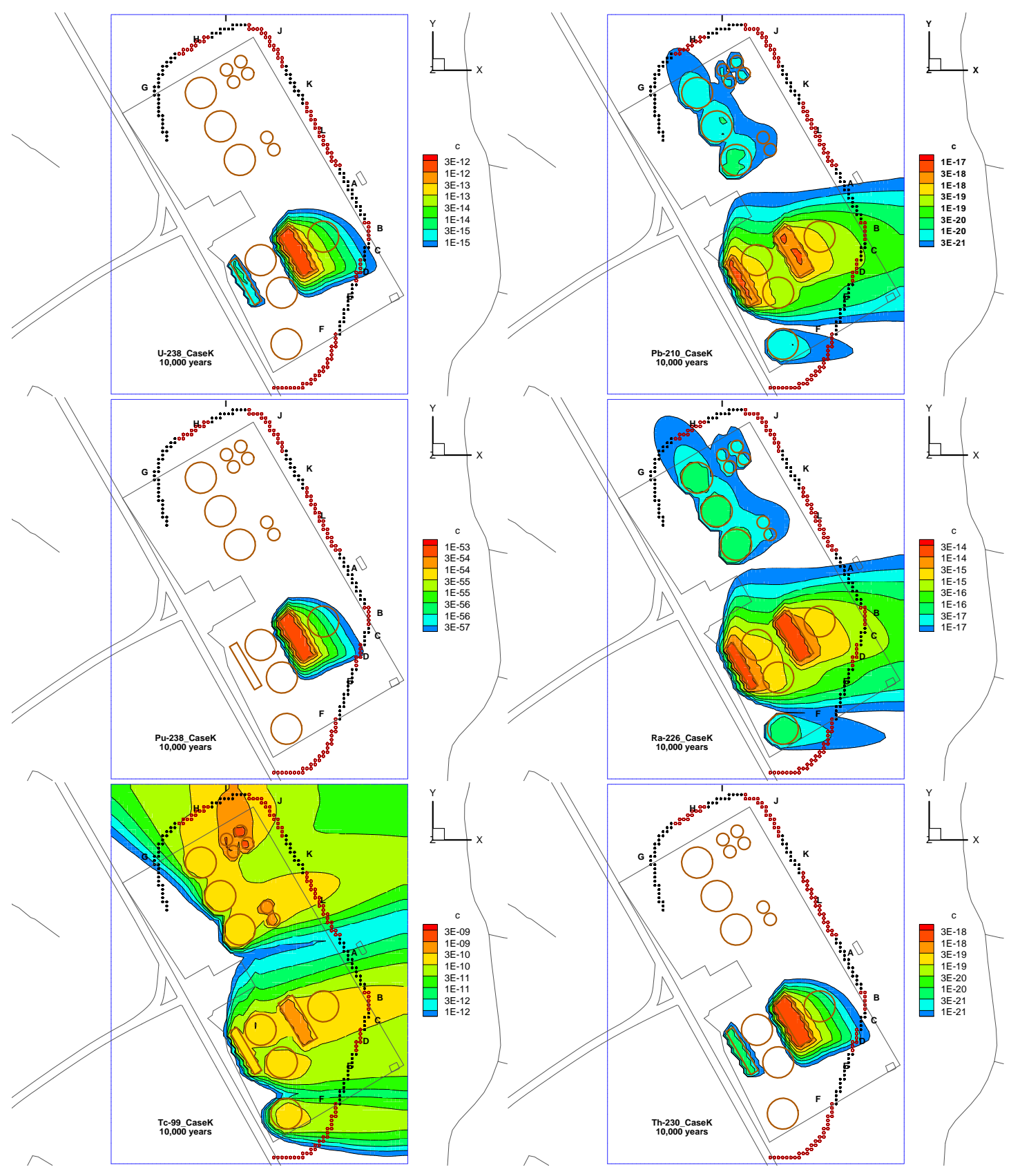




\section{D.4 Concentration Profiles for SDU Final Design Case K with SDU 9 Relocated Midway Between SDU 9 and SDU 11 at 10,000 years}

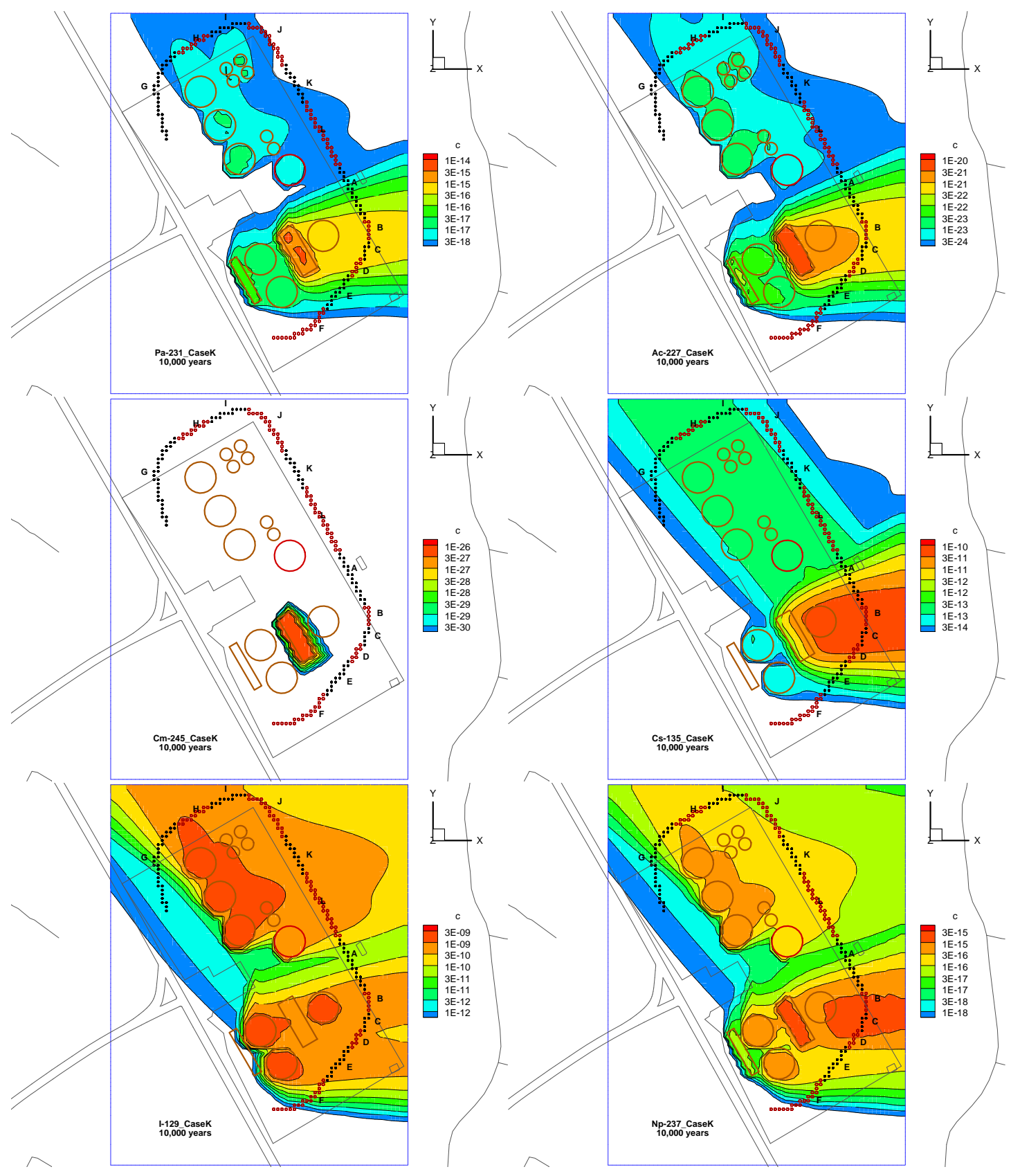




\section{D.4 Concentration Profiles for SDU Final Design Case K with SDU 9 Relocated Midway Between SDU 9 and SDU 11 at 10,000 years (continued)}

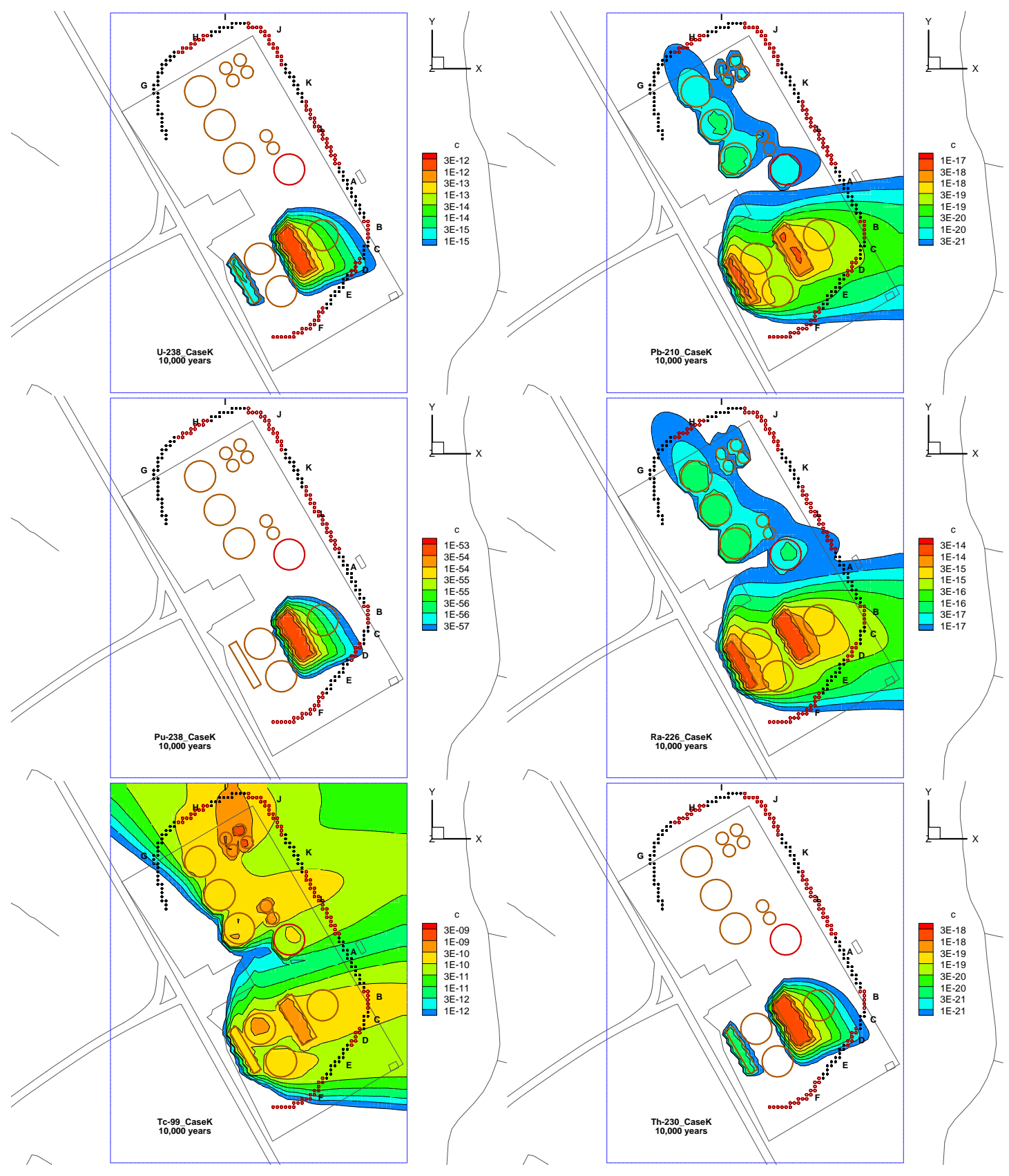


D.5 Concentration Profiles for SDU Final Design Case A with New $K_{d}$ Values at 20,000 years

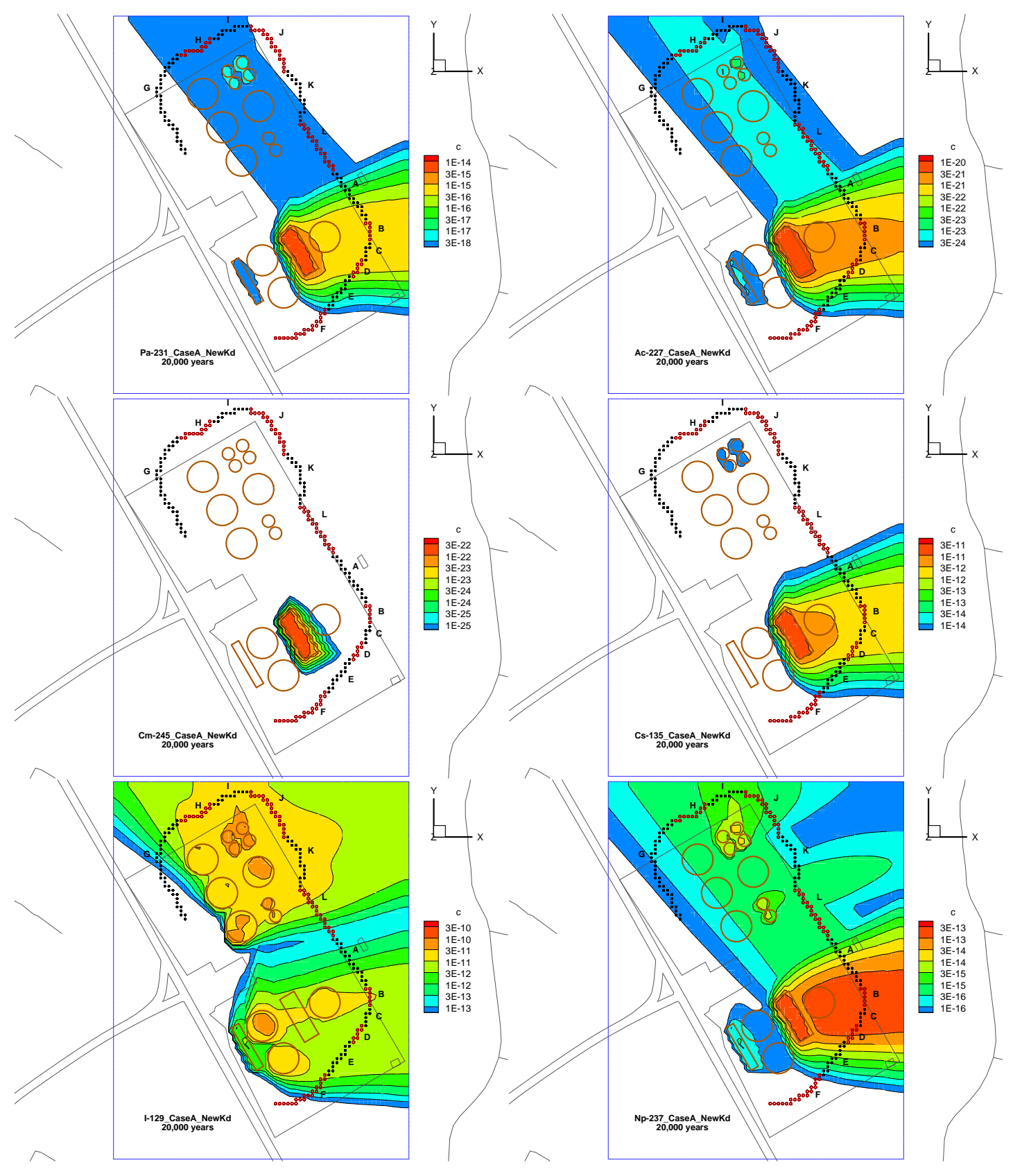


D.5 Concentration Profiles for SDU Final Design Case A with New $K_{d}$ Values at 20,000 years (continued)

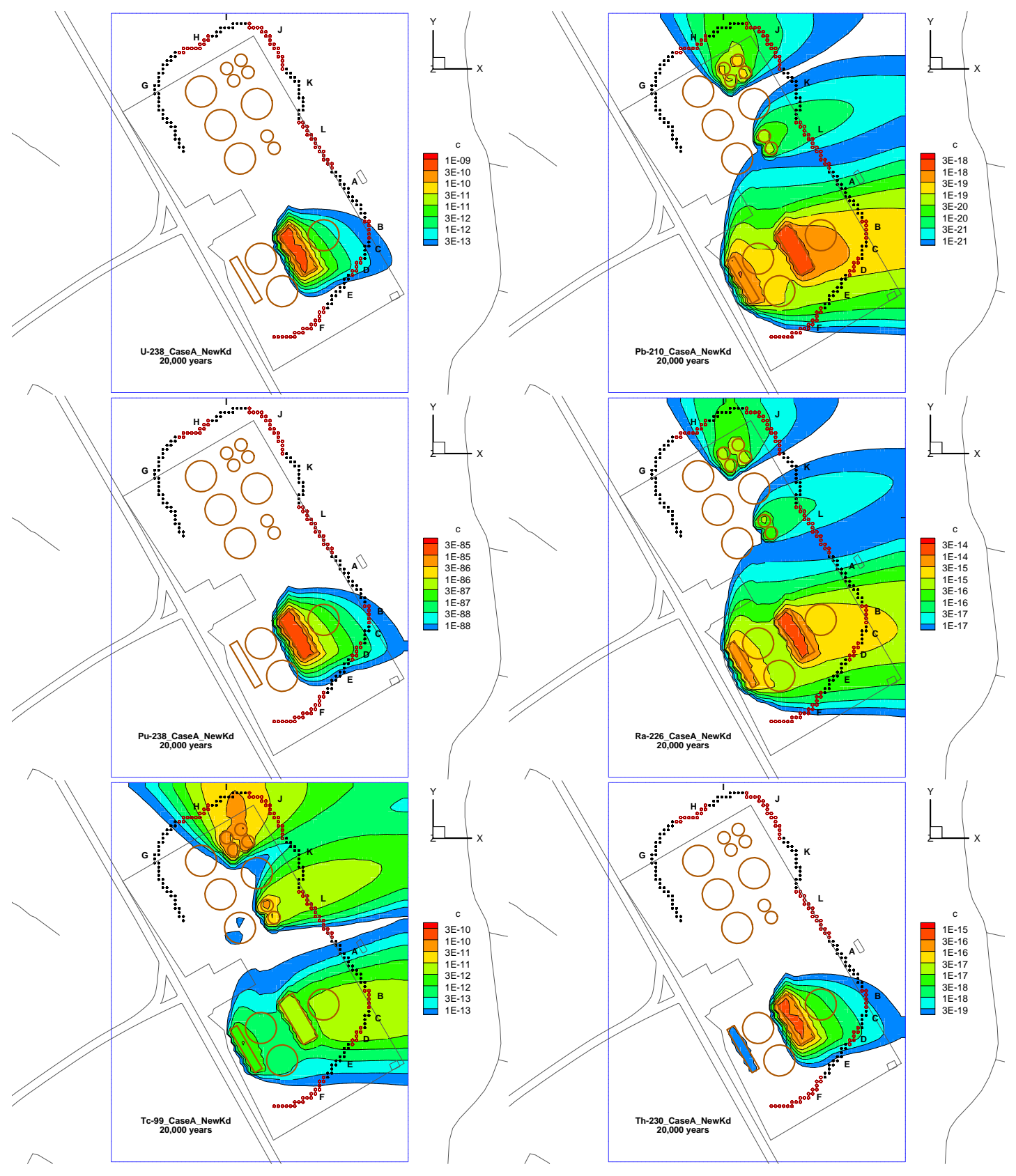




\section{D.6 Concentration Profiles for SDU Final Design Case A with Worst Case Concrete Degradation at 20,000 years}

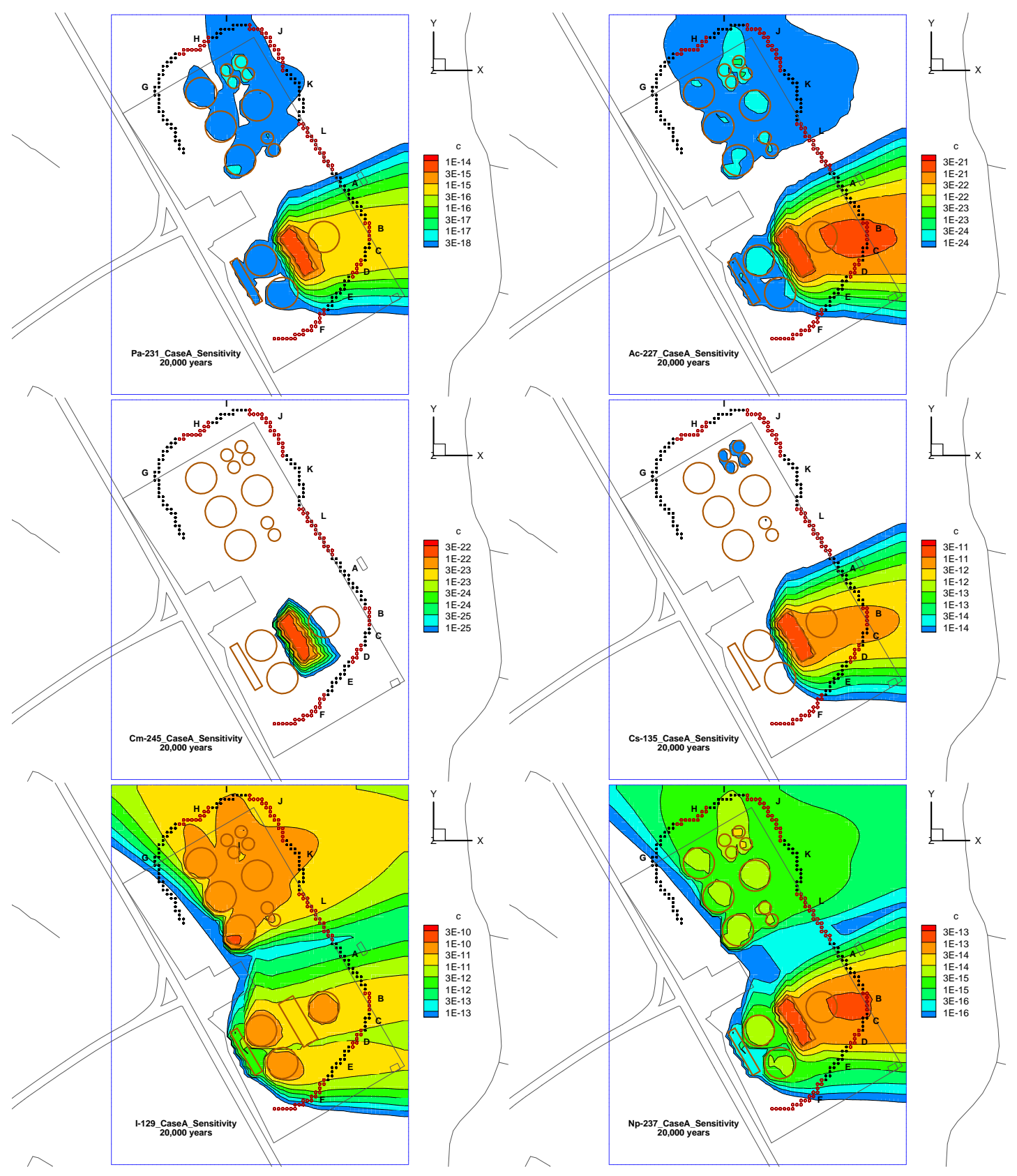




\section{D.6 Concentration Profiles for SDU Final Design Case A with Worst Case Concrete Degradation at 20,000 years (continued)}

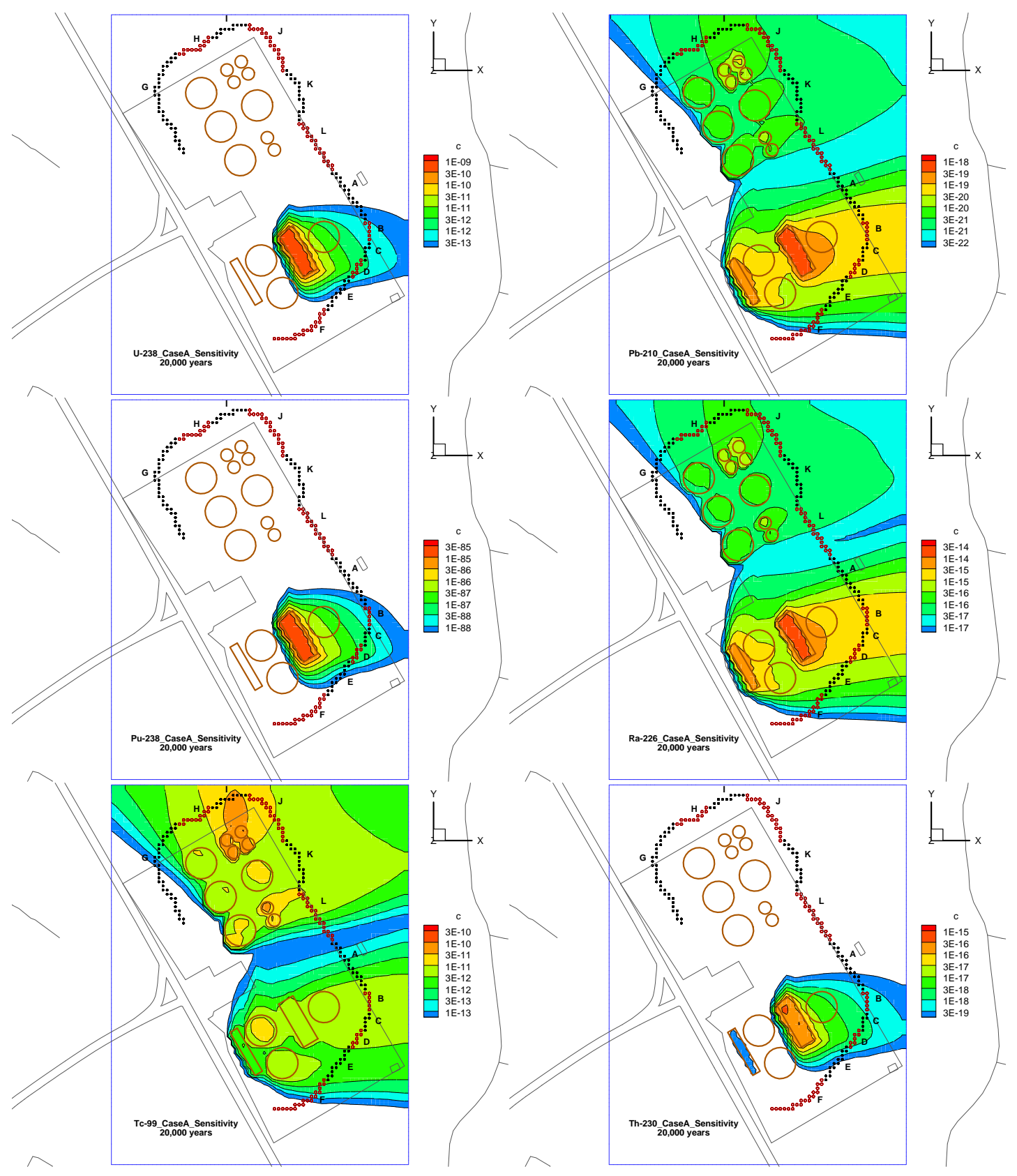




\section{D.7 Concentration Profiles for SDU Final Design with Margin Case A at 20,000 years}

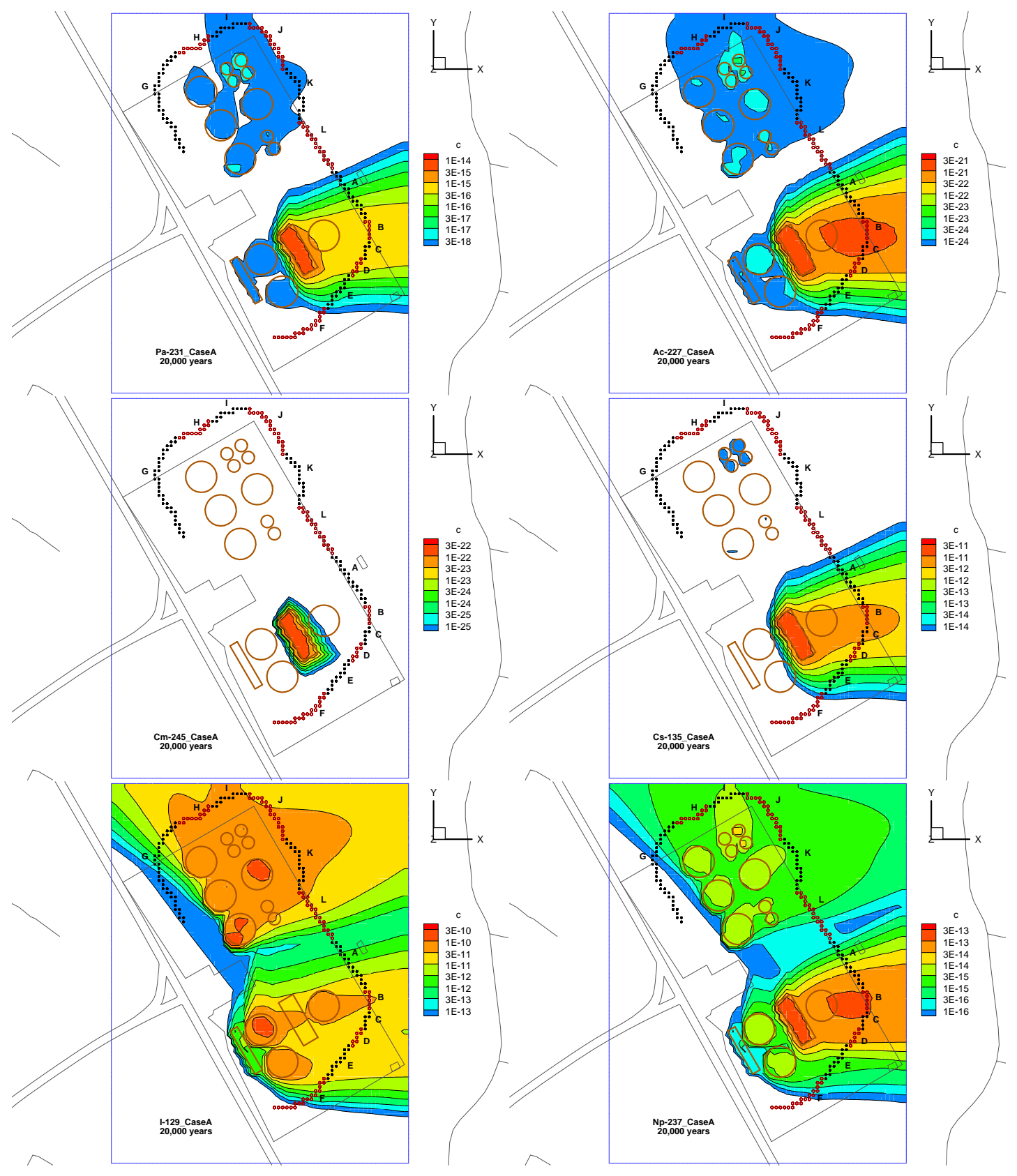




\section{D.7 Concentration Profiles for SDU Final Design with Margin Case A at 20,000 years (continued)}

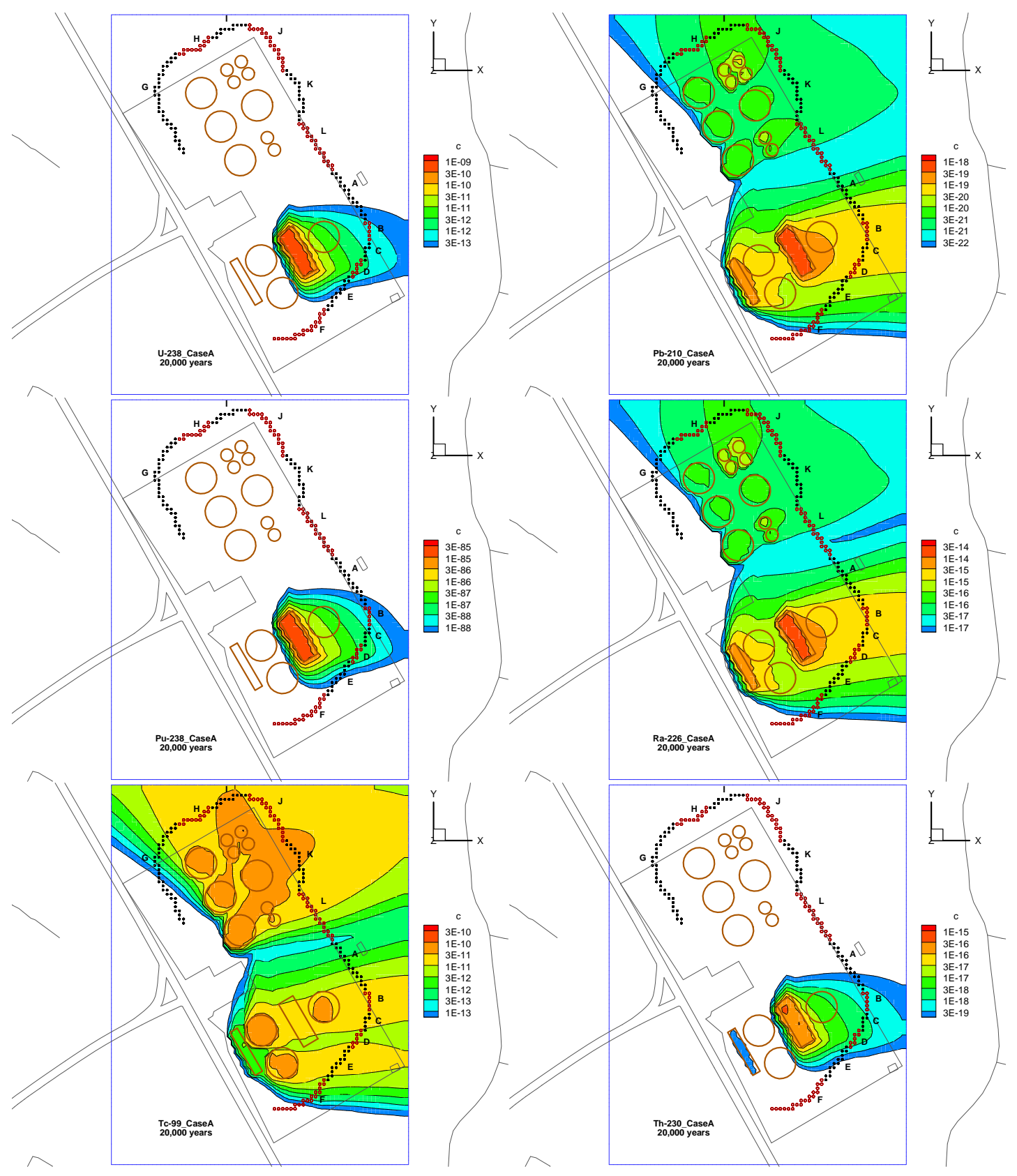




\section{D.8 Concentration Profiles for SDU Final Design with Margin Case K at 20,000 years}
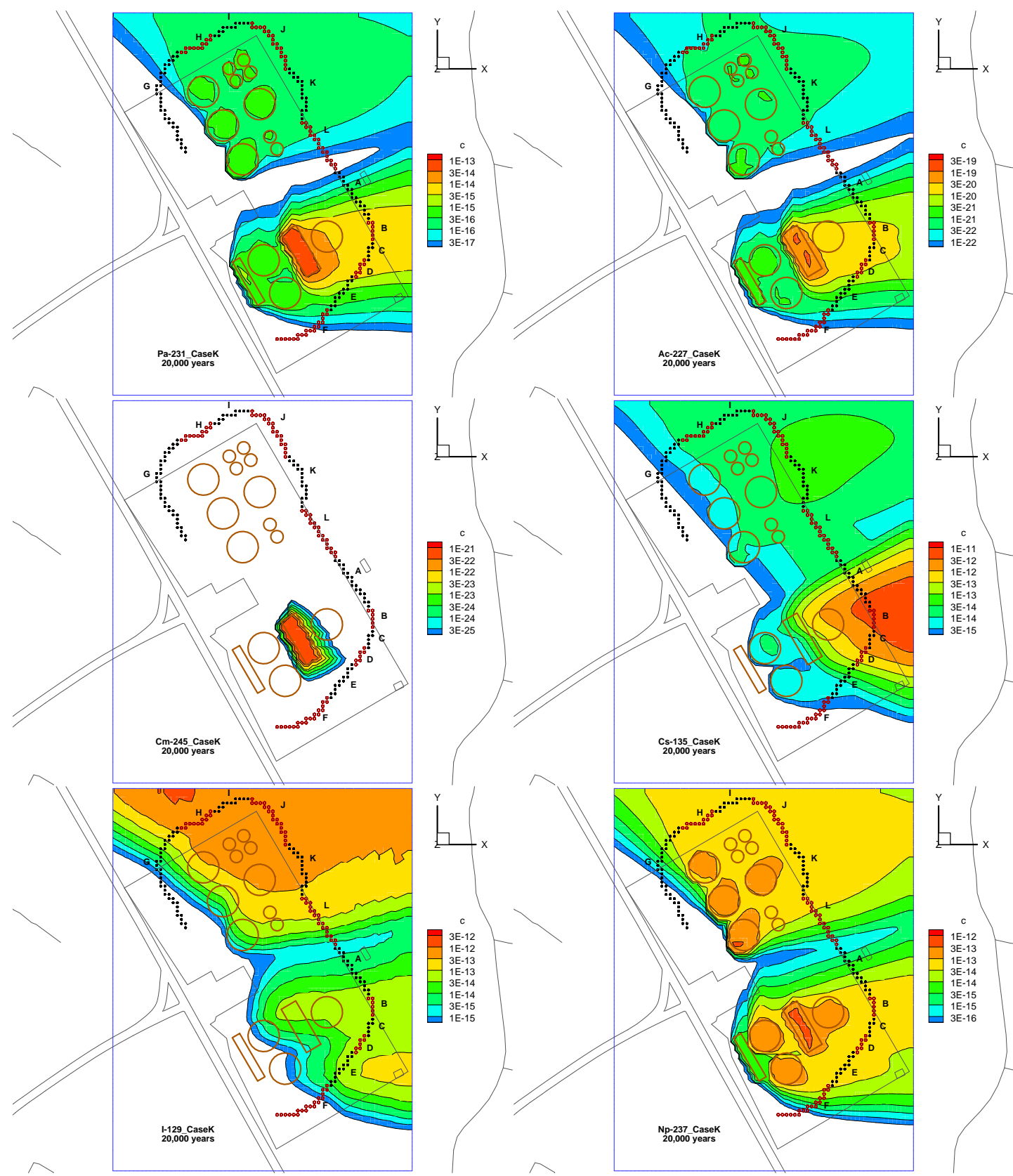


\section{D.8 Concentration Profiles for SDU Final Design with Margin Case K at 20,000 years (continued)}

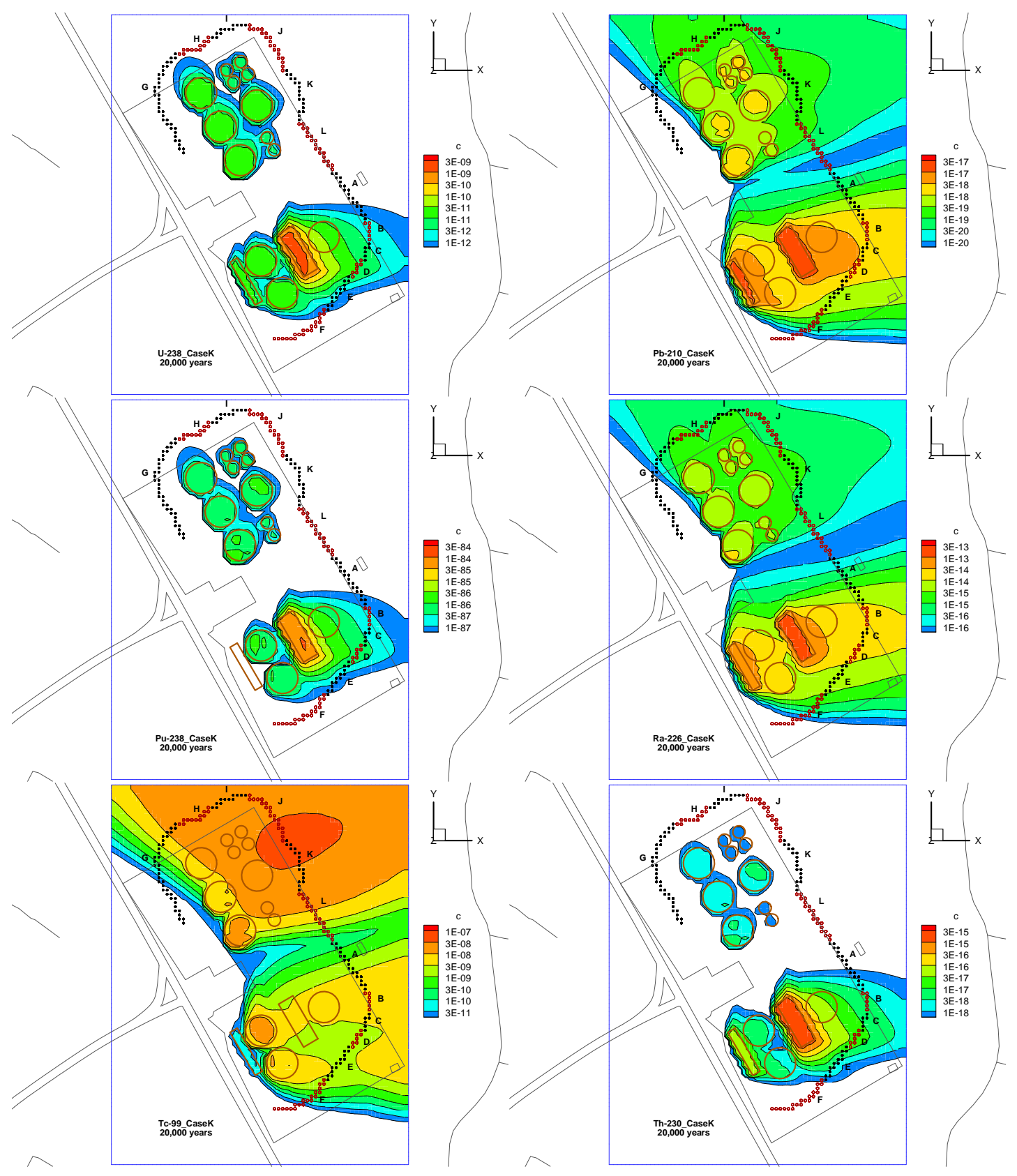


D.9 Concentration Profiles for SDU Final Design with Margin Case A with New $\mathbf{K}_{d}$ Values at 20,000 years

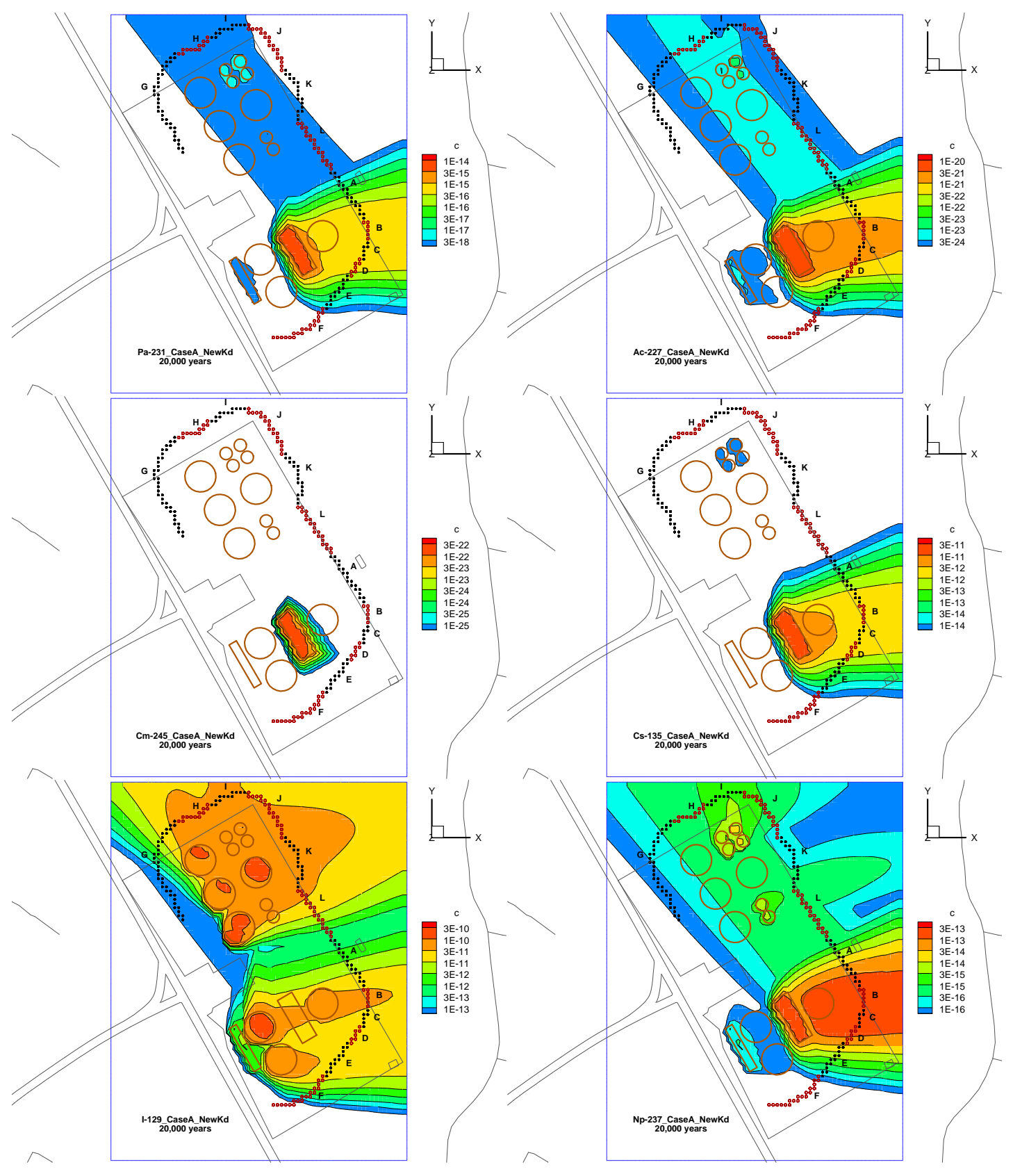




\section{D.9 Concentration Profiles for SDU Final Design with Margin Case A with New $\mathbf{K}_{\mathbf{d}}$ Values at 20,000 years (continued)}

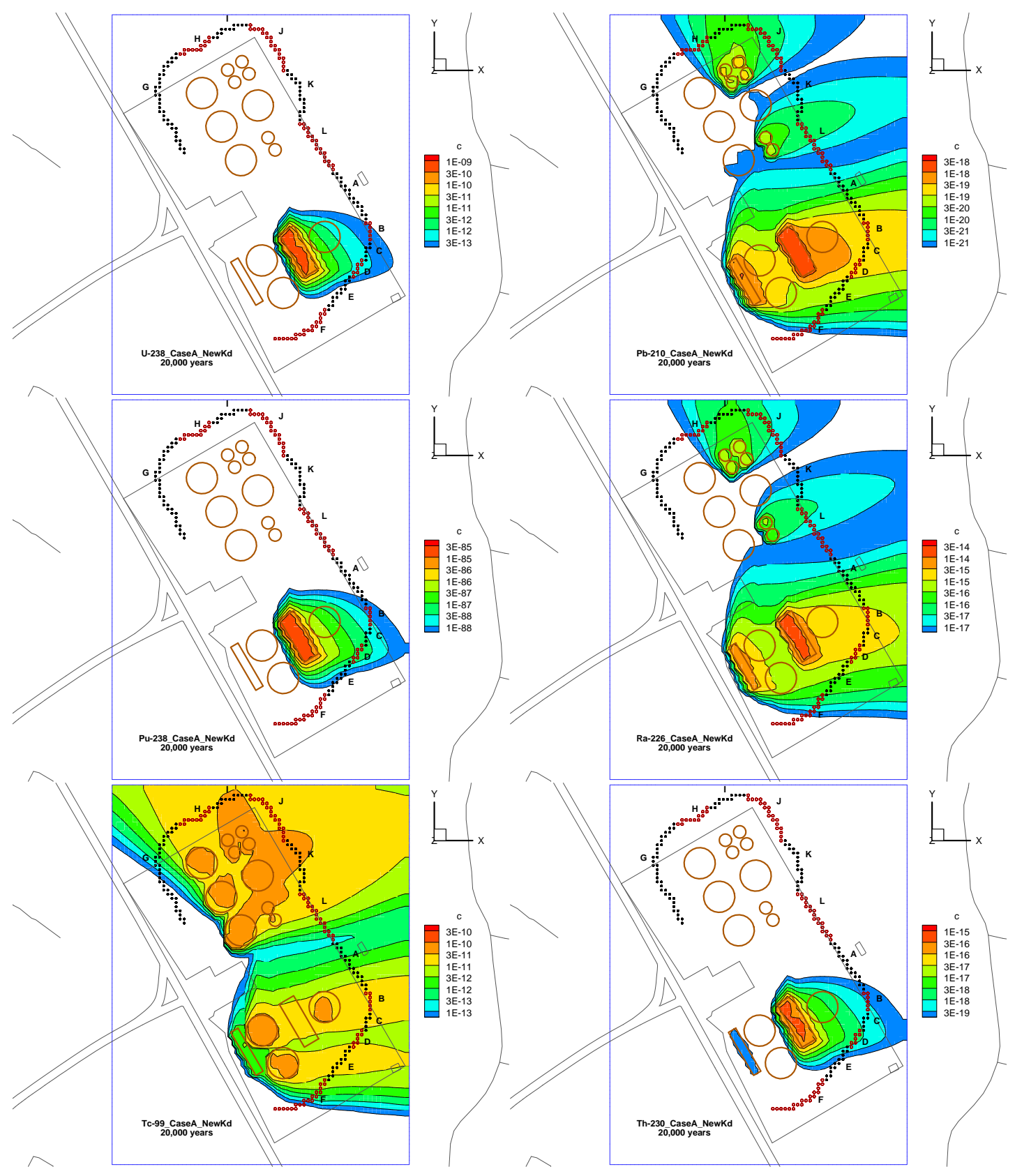




\section{Appendix E Design Check Documentation \\ (1) SRNL \\ INTER-OFHCE MEMORANDUM}

SRNL-L4220-2012-00006, Rev. 0

DATE: June 28, 2012

TO: $\quad$ D.A. Crowley, 773-43A

Manager, Radiological Performance Assessment

FROM: F.G. Smith, III, 703-41A ZramhAlmotill

CC: $\quad$ H.H. Burns, 773-43A

R.A. Hiergesell, $\quad 773-43 \mathrm{~A}$

F.M. Smith, 705-1C

K.H. Rosenberger, 705-1C

\section{DESIGN CHECK PACKAGE ASSOCIATED WITH PORFLOW CALCULATIONS FOR} SALTSTONE DISPOSAL UNIT DESIGN

At the request of Savannah River Remediation (SRR), an analysis was performed to evaluate the performance of 30 million gallon Saltstone Disposal Units (SDUs) proposed for use in Z-Area. The analysis included the following primary activities:

1. Creating a PORFLOW mesh appropriate for modeling the SDU design and the SDU design with margin.

2. Running PORFLOW calculations of infiltration flow through the SDU and the vadose zone using appropriate material properties.

3. Running PORFLOW calculations of radionuclide transport through the SDU and the vadose zone using appropriate $\mathrm{K}_{\mathrm{d}}$ values.

4. Running PORFLOW calculations of radionuclide transport through the aquifer beneath Z-Area modeling releases from the existing Vault 1, Vault 4, disposal cells $2 \mathrm{~A}, 2 \mathrm{~B}, 3 \mathrm{~A}, 3 \mathrm{~B}, 5 \mathrm{~A}$ and $5 \mathrm{~B}$, and seven proposed SDUs.

The design check consisted of reviews throughout the processing of the PORFLOW calculations. The independent design checker (R.A. Hiergesell) was familiar with the construction and execution of PORFLOW models for groundwater flow and contaminant transport. The design check was performed following the SRNL Technical Report Design Check Guidelines WSRC-IM-2002-IM00011, Rev.2.

The attachment includes design check instructions written by F.G. Smith, design check findings provided by R.A. Hiergesell (in blue), responses to the finding from F.G. Smith (in red) and finally a note of acceptance of the findings by R.A. Hiergesell.

Cc/Encl.: $\quad$ RPA Group File, $\quad$ 773-43A 


\section{Design Check Instructions: SDU 6 Phase 2 PORFLOW Calculations}

The objective of this work was to determine the performance of the proposed 32 million gallon Saltstone Disposal Unit (SDU) to support the decision to proceed with detailed design. To accomplish this it was decided to evaluate the SDU using the Case A scenario that was the base case for the 2009 Saltstone PA and the Case K scenario performed in response to NRC comments on the PA (see Attachment). Both cases were to be run with the SDU Final Design (FD) and a Final Design with Margin (FDM) which was considered to be a more conservative case with reduced wall, floor, and roof concrete thickness. In addition, it was decided to perform a sensitivity study on Case A assuming maximum concrete degradation prior to SDU closure and to run Case A with updated $\mathrm{K}_{\mathrm{d}}$ values. The analysis was limited to evaluating the transport of 20 radionuclides over a 20,000 year period after closure. In all, the analysis required running five sets of vadose flow calculations and seven sets of vadose transport and aquifer transport calculations. A total of 240 vadose flow runs, 140 vadose transport runs, and 140 aquifer transport runs were made using PORFLOW. Details of the SDU configuration and case runs requested by SRR are provided in Ref. (1).

The analysis methodology used the python scripting system created on the linux cluster to preprocess a set of spreadsheets and files to create the PORFLOW run.dat files, make the PORFLOW runs and post-process the output. This design check is not intended to verify or validate the python scripting system. Rather the various files created to provide input to the system will be checked and the resulting PORFLOW 'run.dat' files spot checked. In addition, output from the PORFLOW calculations will be checked to ensure that the results are reasonable.

All files are located in subdirectories within base directory:

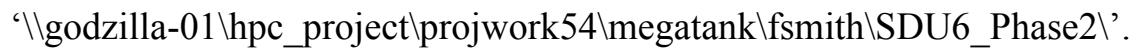

\section{Geometry}

The PORFLOW mesh geometry is calculated in workbook:

'Geometry $\backslash$ Analysis $\backslash$ Mesh_Geometry.xlsx'. There are four spreadsheets that calculate radial and axial meshing for the SDU final design and for the SDU Final Design with Margin as defined in SRR-SDU-2012-00021, Rev. 0, April 11, 2012. For PORFLOW meshing and material assignment, the two designs have different SDU roof, floor and wall thicknesses and different specifications for total linear feet of joints in the roof and floor concrete slabs. Joints in the roof and floor are modeled as two inch wide annular segments filled with gravel. Similar two inch joints between the wall and floor and wall and roof are also included in the model.

\section{Geometry Design Check}

1. Check that the calculations in workbook 'Geometry\Analysis \Mesh_Geometry.xlsx' are correct and conform to the specified geometry.

Coordinates in the spreadsheets "Final Design radial" and "Final Design+Margin radial" were checked and found to accurately reflect the specifications in SRR-SDU-2012-00021, Rev. 0. The axial coordinates accurately reflect the differences in the concrete roof and floor thicknesses for both the Final Design and the Final Design with Margin; however SRRSDU-2012-00021 indicates the "Tank Height" is $43 \mathrm{ft}$ and I can't determine if this is accurately incorporated into the model grid. The Mesh_Geometry.xlsx file Final Design and Final Design + Margin worksheets show the sum of the 4 Saltstone element layer 
thicknesses and the Clean grout layer thickness to total up to 45.83 feet. Is this correct? $[\mathrm{BH}]$

The $43 \mathrm{ft}$ height refers to the vault height at the wall and the tank roof has a slope of 1.5 percent over the $189 \mathrm{ft}$ radius. The height at the centerline is then $45.83 \mathrm{ft}$ and is calculated in the spreadsheet. [FGS]

2. Check that the 'xmesh.dat', 'ymesh.dat', and 'mtypMesh.dat' files in subdirectories

'VadoseSDU_FD/Flow' and 'VadoseSDU_FDM/Flow' are correct.

It appears these files are correct. The xmesh.dat and ymesh.dat files had actually been copied into the Excel spreadsheet file Mesh_Geometry.xlsx earlier to make a comparison with the calculations performed in those spreadsheets (Final Design radial; Final Design axial; Final Design +Margin radial; and Final Design +Margin axial). [BH] OK [FGS]

3. Examine plots of the mesh and material zones using the Mesh2d.lay Tecplot files to further verify that the geometry is correct. Checking of these files indicates the gridding is correct and the material types have been properly assigned. [BH] OK [FGS]

\section{Properties}

Calculations of cementatious material degradation are in workbook:

'Geometry $\backslash$ Analysis $\backslash$ CemintitiousMaterialDegradation.xlsm'. These workbooks were provided by Greg Flach and I am following the same method used in the 2009 Saltstone PA. For the SDU calculation, it is assumed that the upper section of the wall and the roof do not experience any degradation prior to the start of the analysis since concrete in these part of the vault would not be wetted during saltstone pouring.

Three cases are considered:

1. SDU Final Design - Nominal wall, floor and roof thicknesses where the loss of concrete from sulfate attack prior to starting the analysis is estimated as the geometric mean of the depth of penetration resulting from sulfate reaction and the depth of penetration assuming saturation of the concrete with water containing sulfate.

a. Calculated factors for diffusion coefficient and hydraulic conductivity are in spreadsheets: 'Wall Section 1', 'Wall Section 2', 'Wall Section 3', 'Wall Section 4', 'Wall Section 5', 'Floor', and 'Roof'.

2. SDU Final Design with Margin - Reduced wall, floor and roof thicknesses where the loss of concrete from sulfate attack prior to starting the analysis is estimated using the same method used for the SDU Final Design.

a. Calculated factors for diffusion coefficient and hydraulic conductivity are in spreadsheets: 'Wall Section 1 Margin', 'Wall Section 2 Margin', 'Wall Section 3 Margin', 'Wall Section 4 Margin', 'Wall Section 5 Margin', 'Floor Margin', and 'Roof Margin'.

3. SDU Final Design Sensitivity - Nominal wall, floor and roof thickness where the loss of concrete from sulfate attack prior to starting the analysis is estimated as the depth of penetration assuming saturation of the concrete with water containing sulfate. 
a. Calculated factors on diffusion coefficient and hydraulic conductivity are in spreadsheets: 'Wall Section 1 Sensitivity', 'Wall Section 1 Sensitivity', 'Wall Section 2 Sensitivity', 'Wall Section 3 Sensitivity' and 'Floor Sensitivity'.

\section{Properties Design Check}

1. Check that the calculations in workbook 'CemintitiousMaterialDegradation.xlsm' are correct.

In the "Design" workbook: Average thicknesses of wall sections correctly calculated in all scenarios. Initial and degraded thicknesses appear correctly calculated.

Harmonic mean definition: the reciprocal of the arithmetic mean of the reciprocals of a set of specified numbers. When I apply this formula for the Di and Dd values the answer is different. $\quad \mathrm{Da}=1 /([(1 / 5 \mathrm{E}-08)+(1 / 5 \mathrm{E}-06)] / 2)=9.9 \mathrm{E}-08 \ldots .$. vs $5.22 \mathrm{E}-08$ in the spreadsheet.

Make sure the formula utilized to calculate the values of $\mathrm{Da}$ and $\mathrm{Ka}$, under the heading "Harmonic Averaged Values" (columns O and P), is what was intended. It is not the same as the classic definition of "harmonic mean". [BH]

In calculating what I called the "Harmonic Averaged Values" for $\mathrm{Da}$ and $\mathrm{Ka}$, the intact and degraded values were weighted by the respective wall thicknesses. For example:

$\mathrm{Da}=(\mathrm{ti}+\mathrm{td}) /(\mathrm{ti} / \mathrm{Di}+\mathrm{td} / \mathrm{Dd})$ where ti is the thickness of intact wall and td is the thickness of the degraded part of the wall. The total wall thickness is $t i+t d$. If one or the other wall segment is not present, this calculation reduces to the correct value so I think this weighted average is correct. [FGS]

2. Five sets of flow calculations were performed. These cases and the subdirectory where property data is specified for each case are:

a. Final Design Case A - 'VadoseSDU_FD/Common/CaseA'

b. Final Design Case A Sensitivity - 'VadoseSDU_FD/Common/CaseA_Sensitivity'

c. Final Design Case K - 'VadoseSDU_FD/Common/CaseK'

d. Final Design with Margin Case A - 'VadoseSDU_FDM/Common/CaseA'

e. Final Design with Margin Case K - 'VadoseSDU_FDM/Common/CaseK'

Check that the 'MaterialPalette.xls', MaterialZones.xls', 'MaterialFactor1.xls', and 'MaterialFactor2.xls' workbooks and the 'config' file are correct for each case.

The 'MaterialPalette.xls' 'Palette' spreadsheet gives a list of materials that can be used in the PORFLOW calculation and their basic properties. This file should be the same for all cases.

In the VadoseSDU_FD scenario, the MaterialPalette.xls files are identical for CaseA, CaseA_Sensitivity and CaseK, except for: CaseK has higher $\mathrm{Kh}$ and $\mathrm{Kv}$ values entered, and CaseK utilizes different characteristic curves for the vault walls, roof and floor (e.g. "fractured_walls", "fractured_floor"). Is this what was intended? The VadoseSDU_FDM MaterialPalette.xls files are identical to the CaseA and CaseK MaterialPalette.xls files used in the VadoseSDU_FD scenario. [BH] 
This is the intended 'MaterialPalette' file structure. The same material properties apply for the CaseA calculations but are different for CaseK. [FGS]

Spreadsheets in 'MaterialZones.xls' for each material zone named in the PORFLOW calculation specify the material name from the palette used for that material's properties. The 'cement_type' should be specified as either saltstone or cement for cementitious materials and NA for other materials. OK, this was confirmed for all Cases that were evaluated. CleanGrout is listed as "saltstone" in all cases; is that what was intended? [BH]

Yes, it was intended to model clean grout with saltstone properties. [FGS]

The 'MaterialFactor1.xls' workbook should have the factors calculated in the 'CementitiousMaterialDegradation.xlsm' spreadsheet for each cementitious material. These values were copied and pasted by hand so need to be checked carefully.

For /VadoseSDU_FDM/Common/CaseA (item "d" listed above), it appears the sdu_roof_m spreadsheet in the MaterialFactor1.xls file does not have the $\mathrm{Kv}$ values from the CementitiousMaterialDegradation.xlsm file transcribed properly. You should examine the PORFLOW input files to determine if the correct $\mathrm{Kv}$ values were incorporated or not. If not, the steady-state flow fields for the VadoseSDU_FDM Case A time periods may have to be re-simulated. Other than this, the values for cementitious materials appear to have been transcribed accurately for all of the other materials in all of the cases. [BH]

The Kv values were corrected and vadose zone calculations redone for the affected cases. [FGS]

The 'MaterialFactor2.xls' workbook should be identical to that used in the Saltstone PA wih all entries being 1 except for two values for the liner $\mathrm{Kv}$ and De which are 3.333.

The MaterialFactor2.xls files are exactly as you describe they should be. Those files were examined for VadoseSDU_FD: CaseA; CaseA_Sensitivity; and CaseK as well as for VadoseSDU_FDM: CaseA and CaseK.[BH] OK [FGS]

3. Check that property specifications in the 'config' and 'LOCA.dat' files in subdirectories 'VadoseSDU_FD/Flow/Common' and 'VadoseSDU_FDM/Flow/Common' and the 'config' file in the top level 'Common' subdirectory are correct. Most of this input was extracted directly from the Saltstone PA files and is probably best checked by comparing against them.

The property zones identified in the LOCA.dat files are consistent with those found in the "config" files found in the same Common directories. It appears that all of these files are in order and likely produced the proper PORFLOW input. [BH] OK [FGS]

\section{Vadose Flow Calculations}

If everything up to this point checks out correctly, the 'run.dat' files for PORFLOW vadose flow runs should have been created correctly using the python scripts and the flow runs should run correctly. No checking of the python scripts is required. 


\section{Vadose Flow Design Check}

1. Check that specifications in the 'config' files in subdirectories

'VadoseSDU_FD/Flow/Common' and 'VadoseSDU_FDM/Flow/Common' and that the 'config' file in the top level 'Common' subdirectory are correct. These files were examined, as per the instructions in item "3", just prior to "III Vadose Flow Calculations". [BH]

OK [FGS]

2. Spot checking of some of the run.dat files and graphical checking of some of the flow results should be sufficient to double check that vadose flow runs were performed correctly. The 'run.dat' and output files for completed flow runs can be found for each time interval in subdirectories:

'VadoseSDU_FD/Flow/CaseA',

'VadoseSDU_FD/Flow/CaseA_Sensitivity',

'VadoseSDU_FD/Flow/CaseK',

'VadoseSDU_FDM/Flow/CaseA', and

'VadoseSDU_FDM/Flow/CaseK'.

For Case A, 42 time intervals were used while Case K used 57 time intervals.

The flow simulations obviously ran. I spot checked the run.dat files and don't see anything that might produce erroneous results. The number of time intervals for each case is confirmed. [BH]

OK $[\mathrm{FGS}]$

3. Graphical spot checking of selected 'fcnet.tec' files in each time folder and flowbudget files in the Flow folders can be done to verify the flow calculations.

In the few fenet.lay files that were created it appears that an efficient algorithm has been applied to reach fully-converged steady-state solutions in each of the time periods. The color flooding in tecplot for the different cases were entirely clustered around 0 for the fcnet value. This is strong evidence that the simulations are running properly. It was, however, difficult to evaluate this in most time-step folders (in all of the Cases) except where you had a "fcnet.lay" file already created. I don't have write privileges in your workspace to save files there and couldn't copy the tecplot layer file to other folders. [BH]

OK, I think this limited checking was enough. CaseA flow runs made for the different sub cases were all very similar. CaseK was different and, of course, flow changed over time. [FGS]

\section{Vadose Transport Calculations}

Again, if everything has checked out up to this point, using the python scripts to setup and run the PORFLOW vadose transport calculations was relatively simple and should have processed correctly. The five vadose flow cases were used to run seven vadose transport cases for the 20 radionuclides specified in Ref. (1). The unique transport cases are:

1. CaseA from the saltstone PA which using the "shrinking core" model of Tc oxidation in the saltstone and $\mathrm{K}_{\mathrm{d}}$ values used in the PA, 
2. CaseA_NewKd which is the same as CaseA but uses the latest $K_{d}$ values as specified in Ref. (1),

3. CaseA_Sensitivity which used the worst case estimate of concrete degradation during SDU filling to reduct concrete thicknesses at the start of the simulation

4. CaseK which is the "worst case" scenario devised to address NRC comments on the PA (see Attachment).

These four cases were run for the SDU Final Design (FC) and cases 1, 2 and 4 run for Final Design with Margin (FDM) for a total of seven vadose transport cases for 20 radionuclides equaling 140 PORFLOW runs.

\section{$\underline{\text { Vadose Transport Design Check }}$}

1. Check that specifications in the 'config' and '.dat' files in subdirectories 'VadoseSDU_FD/Transport/Common' and 'VadoseSDU_FDM/Transport/Common' are correct. The 'config' file was modified from one used for saltstone PA calculations and was the only step needed to make the transport runs using the python scripts. The config and all of the *.dat files in the Common directories of the "FD" and "FDM" folders appear to be correct. The .dat files were all checked using FreeDiff and are identical except for those that pertain to the differences in the FD and FDM design features. [BH] OK, good check. [FGS]

2. Check that Kd values in the 'Chemistry.xls' files for each case in 'VadoseSDU_FD/Common' and in 'VadoseSDU_FDM/Common' are correct. These files look to be identical in each of the cases. As to specific values of $\mathrm{Kd}$ in each, it is not clear if you intended me to check them and if so, what resource is to be used to verify that the correct values are entered. [BH]

The intent was to verify that the Kd differences specified in the reference were correctly implemented. The remarks below show that this was done. [FGS]

3. Spot checking of some of the run.dat files (in Phase 1, an error in a 'MaterialZones.xls' file caused $\mathrm{Kd}$ values of zero to be set in the vault floor) and graphical checking of some of the vadose transport results should be sufficient to double check that the transport runs were performed correctly. The 'run.dat' and output files for completed vadose transport runs can be found for each of the 20 parent radionuclides in subdirectories:

'VadoseSDU_FD/Transport/CaseA', Ac, Am

'VadoseSDU_FD/Transport/CaseA_NewKd', Cm, Cs

'VadoseSDU_FD/Transport/CaseA_Sensitivity', I, Np

'VadoseSDU_FD/Transport/CaseK', $\mathrm{Pa}, \mathrm{Pb}$ (500 used vs 5000 for Red. Cement)

'VadoseSDU_FDM/Transport/CaseA', Pu, Ra

'VadoseSDU_FDM/Transport/CaseA_NewKd', Tc, Th

'VadoseSDU_FDM/Transport/CaseK' ${ }^{-}$. U

Check at least one 'run.dat' file for each case and for each radionuclide. 
I checked the Chemistry.xls files in the Common directories for each of the cases evaluated under the VadoseSDU_FD and VadoseSDU_FDM scenarios. I extracted the Kd information for each of the elements that were considered in this investigation and compared those values to those which are presented in the Table "Kd values modified for Case K" table on page 3 of the document SRR-SDU-2012-00021. This document provided the SDU6 Modeling Inputs for Preliminary PA Modeling. The table in SRR-SDU-2012-00021 lists two columns for each of 3 material types. Each of those columns corresponds to PA Kd and RAI Kd values and a number is provided for each of the listed 13 elements that are either a parent or progeny radionuclide in this investigation. It has been pointed out that the PA Kd values are associated with CaseA and CaseA Sensitivity cases while the RAI Kd values are associated with the CaseK and CaseA_NewKd cases. [BH] OK, the checking procedure is what was intended. [FGS]

The PORFLOW input files were created for the Vadose Zone transport simulations by running a Python script that obtains the appropriate $\mathrm{Kd}$ for each material in the Chemistry.xls file located in the "Common" subfolder of each CaseA, CaseA_Sensitivity, CaseA_NewKd and CaseK subfolders for the two scenarios that were evaluated. These Chemistry.xls files were examined carefully to determine if the corresponded accurately to the table of Kd values presented in SRR-SDU-2012-00021. In doing this check it was discovered that the RAI Kd values for $\mathrm{Pb}-210$ associated with Reducing Cements are not consistent with the table in SRR-SDU-2012-00021. There appears to be a question as to whether $500 \mathrm{~mL} / \mathrm{g}$ or $5000 \mathrm{~mL} / \mathrm{g}$ is the correct value to use for Case K and CaseA_NewKd based on the files that were used to generate input $\mathrm{Kd}$ 's for CaseK in the past and the guidance supplied in SRR-SDU-2012-00021. [BH]

Yes, there is some confusion here. The RAI Kd value for $\mathrm{Pb}$ should be 5,000 $\mathrm{ml} / \mathrm{g}$ which should be used for the CaseK and CaseA_NewKd calculations. However, from an examination of the previous saltstone calculations it appeared that a $\mathrm{Kd}$ value of $500 \mathrm{ml} / \mathrm{g}$ was used in the CaseK calculations. Therefore, to be consistent with the previous saltstone calculations, this value was not changed. [FGS] OK, as long as you have considered this question and agree that the $500 \mathrm{ml} / \mathrm{g}$ value is the intended one for these cases, then my comment is addressed adequately. [BH]

The use of a $500 \mathrm{~mL} / \mathrm{g} \mathrm{Kd}$ value is "conservative" compared to a value of $5000 \mathrm{~mL} / \mathrm{g}$, as described in your email to Greg Flach dated 5/31/2012. As you point out there, it is conservative in that $\mathrm{Pb}$ releases faster when the $500 \mathrm{~mL} / \mathrm{g}$ value is used. I assume that since there has been no further discussion of this issue, and since the use of the $500 \mathrm{~mL} / \mathrm{g}$ value for $\mathrm{Pb}-210$ in reducing cement is most likely a bounding analysis, that the decision to retain that value is acceptable and therefore will not require any re-simulation of the Vadose zone models. [BH]

$\mathrm{OK}$, as noted above, $500 \mathrm{ml} / \mathrm{g}$ was intentionally used as the $\mathrm{Kd}$ value for $\mathrm{Pb}$ to be consistent with previous saltstone modeling. [FGS]

While the Chemistry.xls files were carefully examined, the spot checks you requested above were also conducted. The following Materials and $\mathrm{Kd}$ associations are embedded in the run.dat files and must be understood to make the determination of whether the appropriate $\mathrm{Kd}$ is assigned:

Native_Soil is Sandy

Backfill is Clayey 
Lower_Mud_Mat is Sandy

Upper_Mud_Mat is Sandy

Concrete Roof, Floor, Walls and Columns are all Reducing Cement

Saltstone is Reducing Cement

HDPE_GCL and Joints have no retardation, $\mathrm{Kd}=0$

Spot checking of Kd's was conducted, as requested above. Except for the issue with $\mathrm{Pb}-210$ using $500 \mathrm{~mL} / \mathrm{g}$ in reducing cement, all other Kd assignments are as specified in SRR-SDU2012-00021. [BH] OK [FGS]

\section{Aquifer Transport Calculations}

To perform aquifer transport calculations and obtain concentrations at the $100 \mathrm{~m}$ boundary, it was first necessary to establish the Z-Area source locations and $100 \mathrm{~m}$ boundary geometry. This was done in folder "GSA_PORFLOW $\backslash$ GSA_PORFLOW_Z $\backslash$ TransportLLOCAte" and subdirectory "SourceFiles". To calculate groundwater concentrations in Z-Area, the contributions from existing saltstone in Vault 1, Vault 2 and the six Vault 2 units (2A, 2B, 3A, $3 \mathrm{~B}, 5 \mathrm{~A}$ and $5 \mathrm{~B})$ must be considered in addition to that from the seven proposed SDU units $(6$ 12). The proposed Z-Area vault geometry is shown in Attachment A of the reference. With SRR concurrence, the $100 \mathrm{~m}$ boundary was divided into sectors $\mathrm{A}-\mathrm{L}$ using the same angular divisions used in the PA. The geometry was created in subdirectories "LOCAte" and "LOCAtelSourceFiles" using the respective "Makefile" scripts. These subdirectories were cleaned up so that only the files used in the current calculation appear.

PORFLOW runs for aquifer transport are contained in the two folders AquiferSDU_FD and AquiferSDU_FDM. To perform the aquifer transport calculations it was necessary to also include fluxes to the water table from vadose zone transport calculations performed previously for Vault 1, Vault 4, and FDC Vault 2. No new vadose transport calculations were performed for these saltstone units. Case A files were provided by Jeff Jordan. For Case K, the following files were copied from the saltstone directory:

'VadoseVault1_rev1/Transport/CaseK_rev2/Vault1' (all rads except Tc-99),

'VadoseVault1_rev1/Transport/CaseK_rev2_spacing/Vault1 (Tc-99)',

'VadoseVault2_rev1/Transport/CaseK_rev2/Vault2 (all rads except Tc-99)',

'VadoseVault2_rev1/Transport/CaseK_rev2_spacing/Vault2 (Tc-99)',

'VadoseVault4_rev1/Transport/CaseK_rev2/Vault4 (all rads except Tc-99)', and

'VadoseVault4_rev1/Transport/CaseK_rev2_spacing/Vault4 (Tc-99)'.

The same cases and radionuclides run for vadose transport were run for aquifer transport giving a total of seven aquifer transport cases for 20 radionuclides equaling 140 PORFLOW runs.

\section{Aquifer Transport Design Check}

1. Using Tecplot, examine the "LOCAteWide_for Report.lay" file in the "LOCAte" directory. This file shows the location of the Z-Area sources, the $100 \mathrm{~m}$ boundary, and the boundary Sectors. There are various ways in which a $100 \mathrm{~m}$ boundary can be defined so, for the purposes of this preliminary calculation, the check simply needs to verify that the boundary shown is sufficient to establish a reasonable estimate of the maximum concentration. Also graphically check the Z-Area source geometry and locations for accuracy. Since the 
Makefiles should have contained the same data that was used in the PA, this graphical check should be sufficient.

The Tecplot representation of the plan view of the SDU vaults, source cells and the $100-\mathrm{m}$ perimeter cells indicate that the appropriate locations have been identified and applied for this modeling exercise. I sketched the water table contours onto a printout of this representation and am convinced that the perimeter cells will intercept any contaminants that are released to the subsurface from any of the vaults. $[\mathrm{BH}] \mathrm{OK}$, nice verification. [FGS]

2. Check that specifications in the 'config' and '.dat' files in subdirectories 'AquiferDU_FD/Transport/Common' and 'VadoseSDU_FDM/Transport/Common' are correct. These 'config' files were modified from ones used for saltstone PA calculations and, once the source geometry was set up, this was the only step needed to make the transport runs using the python scripts.

The run.dat files are evidently produced by running the Python script in the config.sys file. While I have no experience with Python, it appears that the run.dat files are generally produced correctly. [BH]

OK, Jeff Jordan has reviewed the 'config' files as well in helping me set up the aquifer runs. [FGS]

3. Spot checking of some of the run.dat files and graphical checking of some of the aquifer transport results (C.plt files) should be sufficient to double check that the transport runs were performed correctly. The 'run.dat' and output files for completed aquifer transport runs can be found for each of the 20 radionuclides in subdirectories:

'AquiferSDU_FD/Transport/CaseA/All', 'AquiferSDU_FD/Transport/CaseA_NewKd/All', 'AquiferSDU_FD/Transport/CaseA_Sensitivity/All', 'AquiferSDU_FD/Transport/CaseK/ All', 'AquiferSDU_FDM/Transport/CaseA/ All', 'AquiferSDU_FDM/Transport/CaseA_NewKd/ All', and 'AquiferSDU_FDM/Transport/CaseK/All'.

Check at least one 'run.dat' file for each case and one for each radionuclide.

I have been checking the Aquifer transport run.dat files (on 6/13/2012) and discovered that for CaseA_NewKd and CaseK, the Kd values assigned in Sandy and Clayey materials, the only materials in the Aquifer domain, are assigned the CaseA Kd values for Sandy and Clayey materials. I assume you want to be consistent from the Vadose zone to the Aquifer for each of these cases. [BH]

$\mathrm{Kd}$ values were corrected and the aquifer transport runs redone. [FGS] OK [BH]

All of the responses you have provided to my individual comments are sufficient and I regard all issues as being resolved. [BH - 6/26/2012]

\section{References}

Clendenen, G. B., "SDU-6 Modeling Inputs for Preliminary PA Modeling”, SRR-SDU-2012-00021, Rev. 0, April 11, 2012. 


\section{Attachment: Saltstone NRC Response Simulation (Case K_rev2)}

Case $\mathrm{K}$ simulations are to be based on Case A and incorporate the following modifications.

\section{Vadose zone flow}

a) Change saturated conductivity for intact saltstone grout to $1 . \mathrm{e}-8 \mathrm{~cm} / \mathrm{s}$ (no changes to concrete).

b) For physical degradation (hydraulic property changes) of cementitious materials, assume the saturated conductivity varies through time following a log-linear (semi-log) relationship:

$$
\log 10\left(K_{\text {sat }}\right)=\left\{\begin{array}{cc}
\log 10\left(K_{\text {sat }, 0 \%}\right) & t \leq t_{0 \%} \\
\frac{\log 10\left(K_{\text {sat }, 100 \%}\right)-\log 10\left(K_{\text {sat }, 0 \%}\right)}{t_{100 \%}-t_{0 \%}\left(t-t_{0 \%}\right)+\log 10\left(K_{\text {sat }, 0 \%}\right)} & t_{0 \%}<t<t_{100 \%} \\
\log 10\left(K_{\text {sat }, 100 \%}\right) & t \geq t_{100 \%}
\end{array}\right.
$$

Material zone specifications for time of initial degradation $\left(t_{0 \%}\right)$ :

\begin{tabular}{|c|c|c|c|}
\hline Initial degradation (years) & V1 & V4 & FDC \\
\hline Saltstone grout & 10 & 10 & 10 \\
\hline Concrete roof & 10 & 10 & 10 \\
\hline Concrete wall & -1 & -1 & 10 \\
\hline Concrete floor, upper and lower mudmats & 10 & 10 & 10 \\
\hline
\end{tabular}

Material zone specifications for time of complete degradation $\left(t_{100 \%}\right)$ :

\begin{tabular}{|c|c|c|c|}
\hline Complete degradation (years) & V1 & V4 & FDC \\
\hline Saltstone grout & 10,000 & 10,000 & 10,000 \\
\hline Concrete roof & 10,000 & 3500 & 10,000 \\
\hline Concrete wall & 0 & 0 & 10,000 \\
\hline Concrete floor, upper and lower mudmats & 10,000 & 10,000 & 10,000 \\
\hline
\end{tabular}

Set the fully degraded saturated conductivity $\left(K_{\text {sat }, 100 \%}\right)$ to $1 . e-6 \mathrm{~cm} / \mathrm{s}$ for all cementitious materials.

c) Assume $100 \%$ saturation and relative permeability equal to 1 for all suctions $\left(S=k_{r}=1\right)$.

d) Increase the number of flow periods (same as Cases $\mathrm{N}_{-} *$ )

\section{Vadose zone transport}

a) Abandon explicit shrinking core model in PORFLOW Tc-99 simulation for more efficient and flexible external model described in SRNL-L4321-2011-00004 (except use log-linear fracture growth model as noted below).

b) Assume fracture spacing $(B)$ varies through time in a semi-log manner defined by 
SRNL-STI-2012-00445, Rev. 0

$$
\log 10(B)=\left\{\begin{array}{cc}
\infty & t \leq t_{0 \%} \\
\frac{\log 10\left(B_{100 \%}\right)-\log 10\left(B_{0 \%}\right)}{t_{100 \%}-t_{0 \%}\left(t-t_{0 \%}\right)+\log 10\left(B_{0 \%}\right)} & t_{0 \%}<t<t_{100 \%} \\
\log 10\left(B_{100 \%}\right) & t \geq t_{100 \%}
\end{array}\right.
$$

The start and end times for degradation are specified under vadose zone flow.

Materials zone specifications for initial fracture spacing:

\begin{tabular}{|c|c|c|c|}
\hline Initial degradation $(\mathrm{m})$ & V1 & V4 & FDC \\
\hline Saltstone grout & $=\mathrm{W}$ & $=\mathrm{W}$ & $=\mathrm{W}$ \\
\hline Concrete roof & 10 & 10 & $=\mathrm{W}$ \\
\hline Concrete wall & $10^{*}$ & $10^{*}$ & $=\mathrm{W}$ \\
\hline Concrete floor, upper and lower mudmats & 10 & 10 & $=\mathrm{W}$ \\
\hline
\end{tabular}

* immaterial because the wall fails at time zero

Material zone specifications for fracture spacing at complete degradation:

\begin{tabular}{|c|c|c|c|}
\hline Complete degradation $(\mathrm{m})$ & V1 & V4 & FDC \\
\hline Saltstone grout & 0.1 & 0.1 & 0.1 \\
\hline Concrete roof & 0.1 & 0.1 & 0.1 \\
\hline Concrete wall & 0.1 & 0.1 & 0.1 \\
\hline Concrete floor, upper and lower mudmats & 0.1 & 0.1 & 0.1 \\
\hline
\end{tabular}

Note: 0.1 meters is approximately 4 inches.

Set the minimum number of fracture faces to 2 for all materials: left (bottom) and right (top) boundaries are exposed.

c) Continue to use Eh shrinking core model only with Tc-99.

d) Use current/latest published $\mathrm{Kd}$ values for all elements and materials (e.g., $1000 \mathrm{~mL} / \mathrm{g}$ for Tc-99 in reducing cementitious materials instead of $5000 \mathrm{~mL} / \mathrm{g}$ ), except as noted below.

e) Use $30 \mathrm{~mL} / \mathrm{g}$ for Se-79 in oxidized aged/old cementitious materials (instead of $150 \mathrm{~mL} / \mathrm{g}$ ).

f) Degrade diffusion coefficient using a log-linear relationship to $5 . e-6 \mathrm{~cm}^{2} / \mathrm{s}$ using the semi-log relationship

$$
\log 10\left(D_{e}\right)=\left\{\begin{array}{cc}
\log 10\left(D_{e, 0 \%}\right) & t \leq t_{0 \%} \\
\frac{\log 10\left(D_{e, 100 \%}\right)-\log 10\left(D_{e, 0}\right)}{t_{100 \%}-t_{0 \%}}\left(t-t_{0 \%}\right)+\log 10\left(D_{e, 0 \%}\right) & t_{0 \%}<t<t_{100 \%} \\
\log 10\left(D_{e, 100 \%}\right) & t \geq t_{100 \%}
\end{array}\right.
$$

The start and end times for degradation are specified under vadose zone flow. 


\section{Aquifer transport}

a) Use the new PORFLOW "STRAtified" hydrodynamic dispersion model with dispersivities of $\alpha \mathrm{LH}=10 \% \mathrm{~L}, \alpha \mathrm{TH}=1 \% \mathrm{~L}, \alpha \mathrm{LV}=1 \% \mathrm{~L}$, and $\alpha \mathrm{TV}=0.1 \% \mathrm{~L}$ where $\mathrm{L}=100$ meters $=328 \mathrm{ft}$ (same as HTF PA).

b) Include new STATistics commands to capture groundwater concentrations directly beneath sources by using the existing aquifer source cell zones, lumped by V1, V2, and V4 sources: 


\section{DISTRIBUTION:}

\section{SRNS}

R. S. Aylward, 773-42A

H. H. Burns, 773-41A

A. D. Cozzi, 999-W

D. A. Crowley, 774-43A

G. P. Flach, 773-42A

K. M. Fox, 999-W

S. J. Hensel, 703-41A

R. A. Hiergesell, 773-43A

J. M. Jordan, 703-41A

S. L. Marra, 773-A

M. G. Serrato, 773-42A

F. G. Smith, III, 703-41A

C. Wilson (1 file copy \& 1 electronic copy), 773-43A - Rm. 213

$\underline{\text { SRR }}$

T. C. Baughman, 707-14E

S. D. Burke, 766-H

G. B. Clendenen, 707-14E

T. W. Coffield, 705-1C

R. D. Freeman, 705-1C

K. A. Hauer, 705-1C

T. H. Huff, 707-14E

K. M. Lancaster, 766-H

K. H. Rosenberger, 705-1C

R. E. Sheppard, 705-1C

F. M. Smith, 705-1C

K. H. Subramanian, 766-H

DOE

P. R. Jackson, 703-46A 